University of Louisville

ThinkIR: The University of Louisville's Institutional Repository

Electronic Theses and Dissertations

8-2018

\title{
An examination of box office relationship quality and relationship selling in Division I college athletics.
}

James F. Weiner

University of Louisville

Follow this and additional works at: https://ir.library.louisville.edu/etd

Part of the Sports Management Commons

\section{Recommended Citation}

Weiner, James F., "An examination of box office relationship quality and relationship selling in Division I college athletics." (2018). Electronic Theses and Dissertations. Paper 3030.

https://doi.org/10.18297/etd/3030

This Doctoral Dissertation is brought to you for free and open access by ThinkIR: The University of Louisville's Institutional Repository. It has been accepted for inclusion in Electronic Theses and Dissertations by an authorized administrator of ThinkIR: The University of Louisville's Institutional Repository. This title appears here courtesy of the author, who has retained all other copyrights. For more information, please contact thinkir@louisville.edu. 


\title{
AN EXAMINATION OF BOX OFFICE RELATIONSHIP QUALITY AND REALTIONSHIP SELLING IN DIVISION I COLLEGE ATHLETICS
}

\author{
By
}

James F. Weiner

B.S. James Madison University, 2011

M.Ed. Virginia Commonwealth University, 2015

\author{
A Dissertation \\ Submitted to the Faculty of the \\ College of Education and Human Development \\ in Partial Fulfillment of the Requirements \\ for the degree of
}

Doctor of Philosophy in Educational Leadership and Organizational Development

Department of Leadership, Foundations, and Human Resource Education University of Louisville

Louisville Kentucky

August 2018 
Copyright 2018 by James F. Weiner

All rights reserved 



\title{
AN EXAMINATION OF BOX OFFICE RELATIONSHIP QUALITY AND REALTIONSHIP SELLING IN DIVISION I COLLEGE ATHLETICS
}

By

\author{
James F. Weiner \\ B.S., James Madison University, 2011 \\ M.Ed., Virginia Commonwealth University, 2015
}

A Dissertation Approved on

July 25,2018

By the following Dissertation Committee:

T. Christopher Greenwell, Chair

Megan B. Shreffler

Evan L. Frederick

Jason C. Immekus 


\title{
DEDICATION
}

This dissertation is dedicated to my parents:

\author{
Buddy and Betty Weiner
}

who, together, supported me in every sense imaginable. This accomplishement would not have been possible without both of you in my corner 


\section{ACKNOWLEDGEMENTS}

To thank everyone who was significant to my doctocal studies would warrant a dissertation in itself. While many names may not appear on this page, there are countless individuals who helped me along the way. I hope you all know who you are and how much your support has meant to me over the past three years.

I would start with a sincere thank you to my chair, Dr. Chris Greenwell. Your prompt and thorough feedback was the only way I could have finished this dissertaion on time. To the other members of the committee, Dr. Megan Shreffler, Dr. Evan Frederick, and Dr. Jason Immekus, thank you for your availability, feedback and guidance. Additionally, thank you to all of the faculty in the University of Lousiville Sport Administration Program, with a special thank you to our department chair, Dr. Meg Hancock, who has been a mentor and career coach during my time as a student. Of course, the camraderie and friendship of the other Lousiville doctoral students kept this process fun, even during difficult times. A special shoutout to Dr. Sam Schmidt, who quite literally never said "no" when I asked for help regarding anything; dissertation or otherwise.

Last and most importantly, thank you to my family who molded me into the man I am today. To my father, Buddy, who still maintains a tireless work ethic I have always admired and strived to match. To my mother, Betty, who tackles every challenge in life with a positive spirit and happy heart. Your can-do attitude is contagious. To my brother, 
David, who has always relentlessly pursued his dreams, and isn't afraid to create his own path along the way. To Stephanie, for your unconditional love and support in all my decisions, even when they were difficult (or wrong). I couldn't have done this without you. Finally to my late grandmother, Doris, who showed us all grit and perserverence in life. Thank you all from the bottom of my heart. 
ABSTRACT

AN EXAMINATION OF BOX OFFICE RELATIONSHIP QUALITY AND

REALTIONSHIP SELLING IN DIVISION I COLLEGE ATHLETICS

James Weiner

July 25,2018

College athletics departments have experienced unprecedented growth. However, expenses have risen even faster (Fulks, 2016), and university athletics departments have relied on increased subsidies from host institutions and donations to make ends meet (Fulks, 2016). The root cause behind much of the revenue increases have been credited to large multimedia and broadcast contracts, which guarantee substantial income for decade-long terms (Sherman, 2016). Such agreements leave little room for individual growth, leaving ticket sales as one of the few controllable revenues to which a school could manipulate their own bottom line and increase profitability.

Further investigation into box office sales trends are concerning. Attendance has flatlined or decreased in many Division I conferences (Kahn, 2018), and literature has highlighted inefficient box office operations as a possible cause (Bouchet et al., 2011). Research has suggested improving relationship quality between the customer and the box office may yield positive outcomes (Smith \& Roy, 2011). However, the degree to which relationship quality effects purchase behaviors is still unknown. Furthermore, business literature has highlighted the importance of relationship selling behaviors in services industries (Crosby et al., 1990; Avila \& Inks, 2017) however relationship selling 
effectiveness has not yet been examined in a sport context. Thus, the purpose of this study was to measure relationship quality and relational selling from the university box office and determine the impact of relationship quality and relationship selling techniques on consumer behavior in Division I college football.

The current study utilized a sample of 520 participants representing over 90 Division I FBS schools. Data were collected using Amazon Mechanical Turk and analyzed using a series of hierarchical linear regressions. Relationship quality was measured using the Sport Consumer Team Relationship Quality Scale developed by Kim et al., (2011) while relationship selling was measures using a modified version of Crosby et al.'s (1990) instrument, adapted to fit the sport context. Purchase behaviors of renewal sales, add-on sales, upselling and cross-selling were regressed against the variables. Results showed commitment and customer disclosure as the most predictive variables for football related behavior, while cross selling (to another sport) was predicted by trust, reciprocity, agent disclosure, and cooperative intentions.

The findings suggest commitment resembles team identification in its ability to predict consumer behavior, and customer disclosure as an important variable in sales exchanges. Sales training should emphasize the fan's commitment to increase the likelihood of "new" sales (add-on, upsell), and sales representatives should take care to find out as much about the customer as possible. Additionally, the findings suggest crosssell pitches should vary from football-specific sales, as the consumers behave differently to different aspects of relationship-based sales pitches in these situations. By leveraging findings regarding increasing relationship quality and relationship selling, athletics departments may be able to increase ticket sales and become more self-sufficient. 
TABLE OF CONTENTS

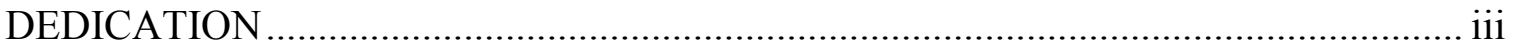

ACKNOWLEDGEMENTS …………………………........................................... iv

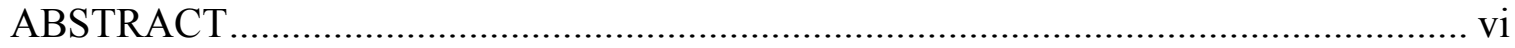

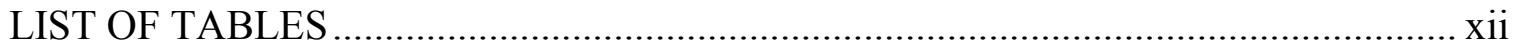

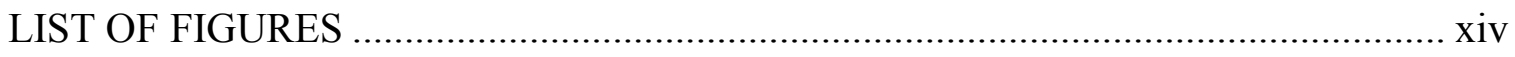

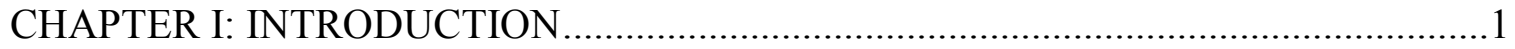

College Athletics Revenue Sources ....................................................................... 1

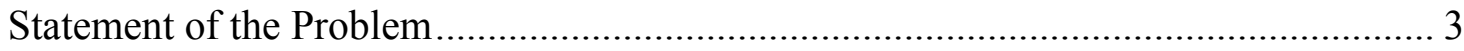

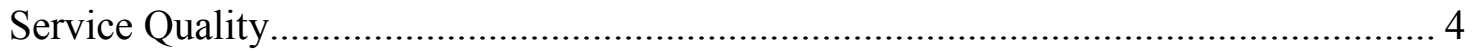

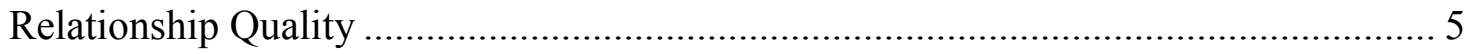

Relationship Selling ......................................................................................... 7

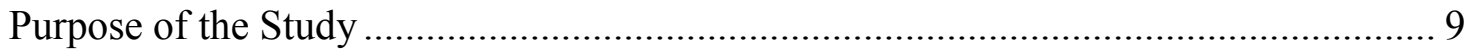

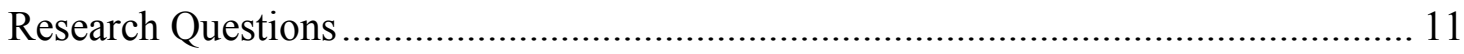

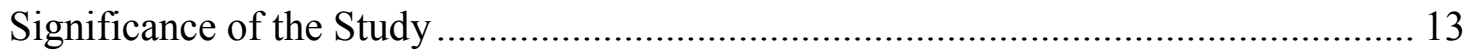

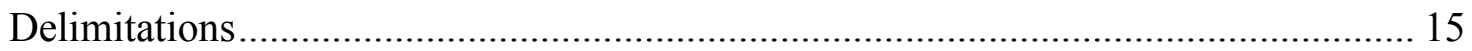

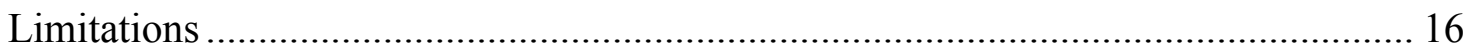

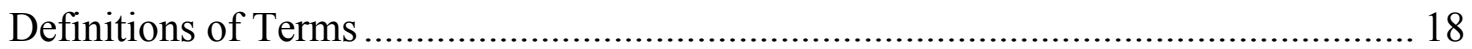

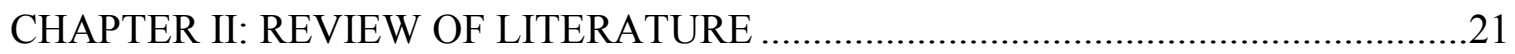

Service Quality, Value, and Satisfaction ………………........................................... 22

Theoretical Frameworks and Fundamentals of Service Quality ................................ 22

Service Quality in Sport................................................................................ 24

Summary of Service Quality, Value, and Satisfaction Literature............................. 35

Relationship Marketing and Relationship Quality...................................................... 38

Relationship Marketing: The Process, Purpose, and Parties..................................... 39

Relationship Marketing Mediators and Outcomes ................................................ 40

Relationship Marketing in Sport ...................................................................... 41 


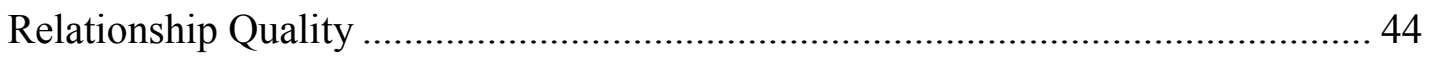

Relationship Marketing and Relationship Quality Summary of Literature .............. 48

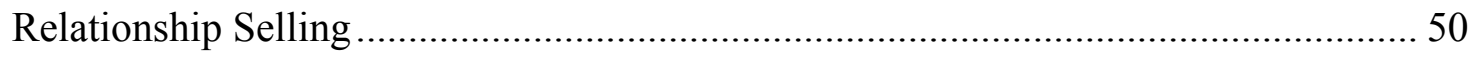

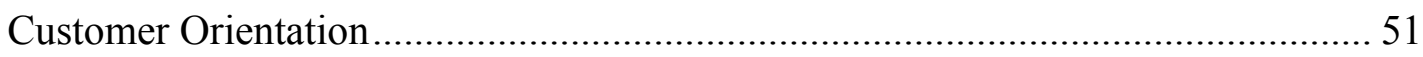

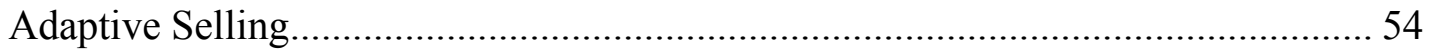

Relationship Building and Customer Perspectives ............................................... 58

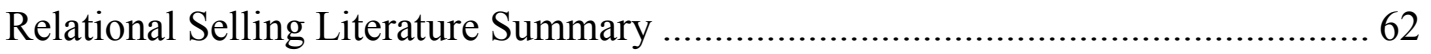

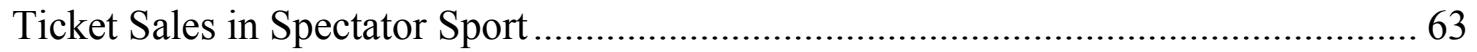

Box Office Influence on Consumer Behavior ........................................................ 64

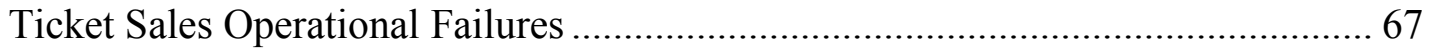

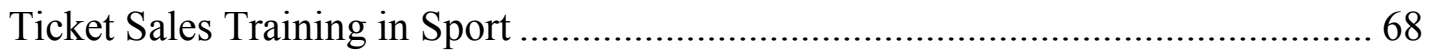

Ticket Sales in Spectator Sport Literature Summary ............................................... 70

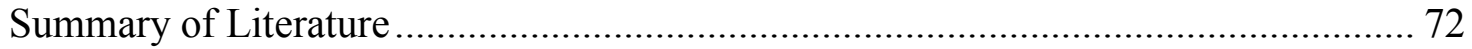

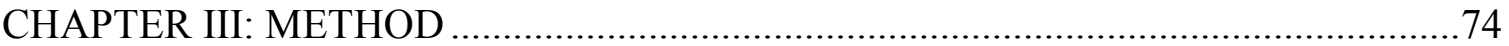

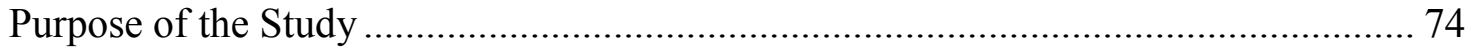

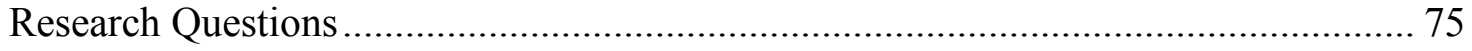

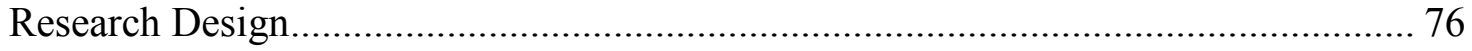

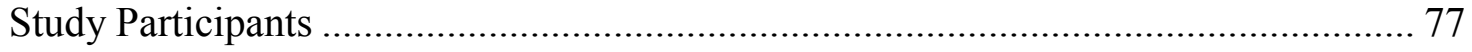

Sampling and Data Collection Procedure ……….................................................. 78

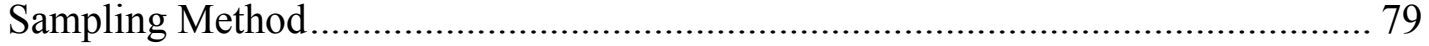

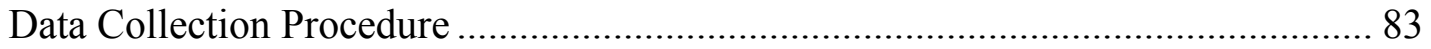

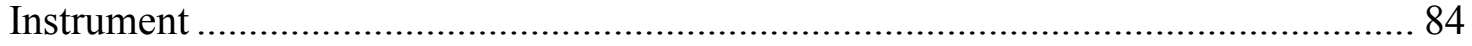

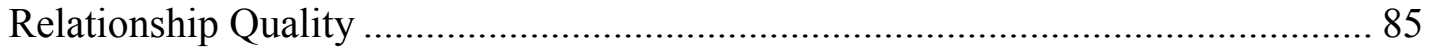

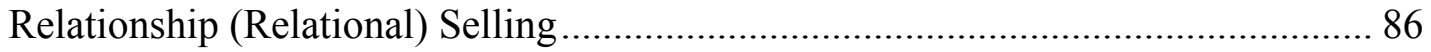

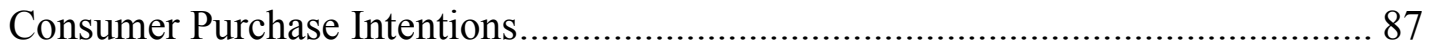

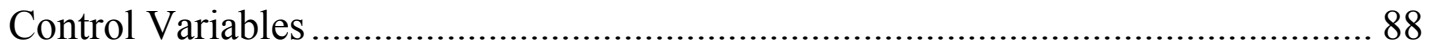

Demographic and Ticket Information............................................................... 90

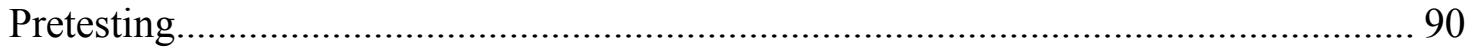

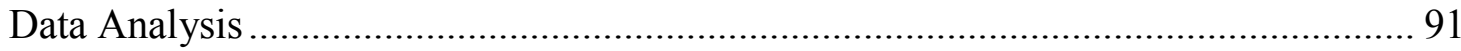

Confirmatory Factor Analysis........................................................................... 92

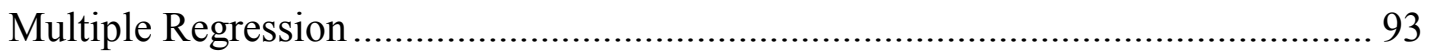

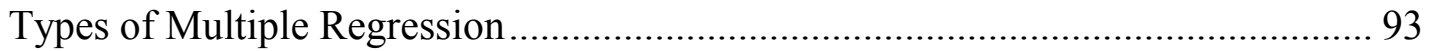

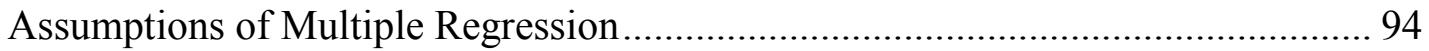




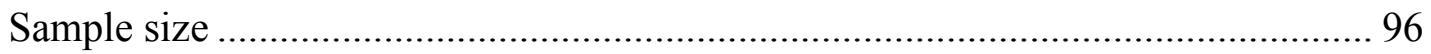

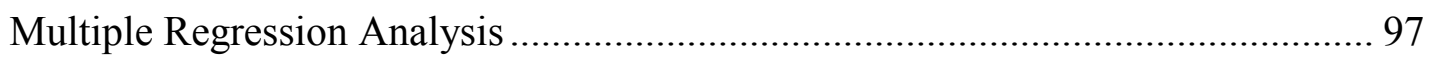

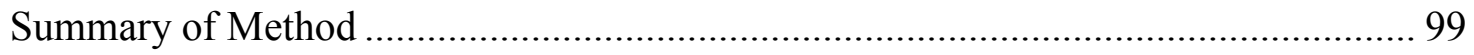

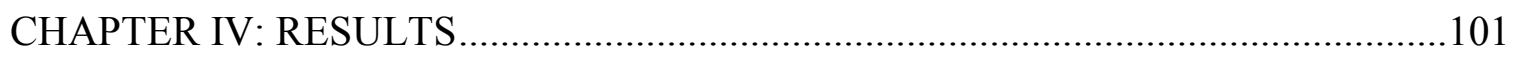

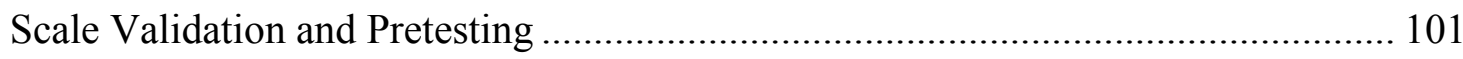

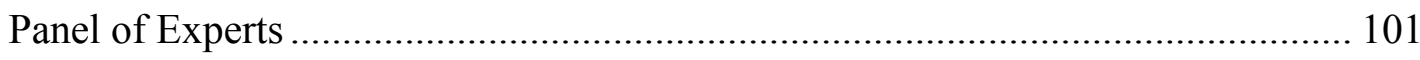

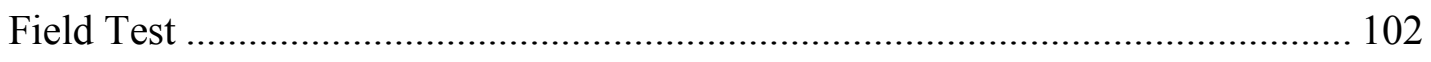

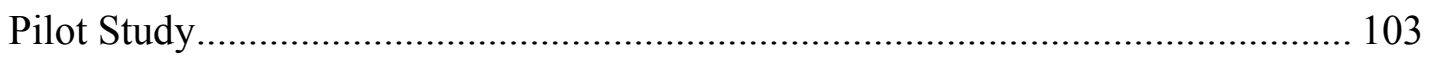

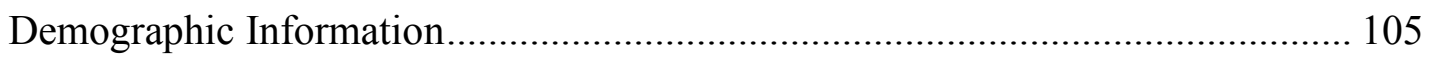

College Football Demographic Information......................................................... 107

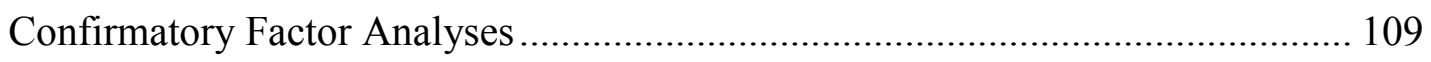

Summary of Pretesting Scale Validation, and Sample Statistics ................................ 117

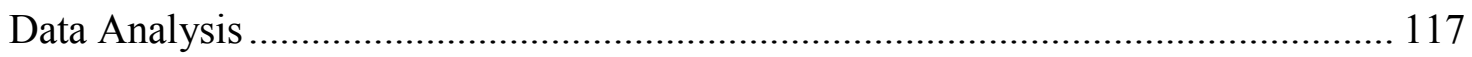

Assumptions of Multiple Regression .............................................................. 118

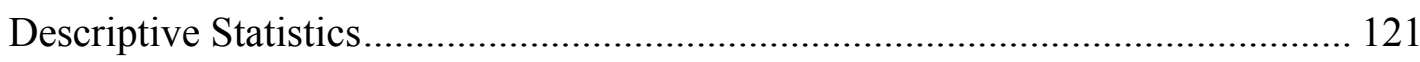

Results and Analysis of Research Question 1.................................................... 122

Results and Analysis of Research Question 2.................................................. 130

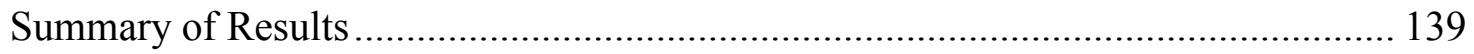

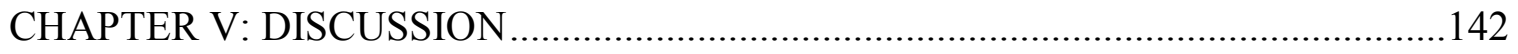

Interpretation of the Results.............................................................................. 143

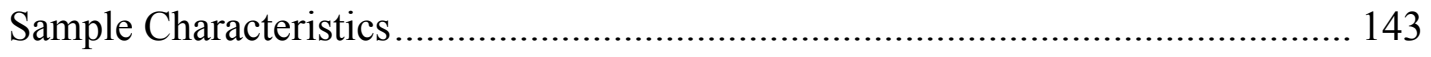

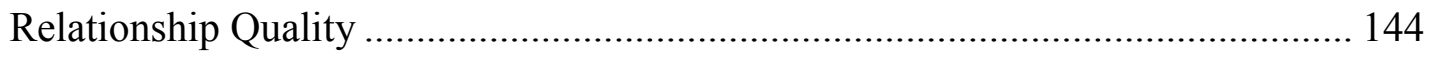

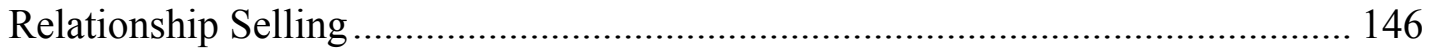

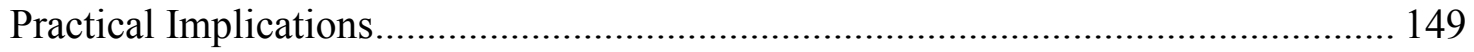

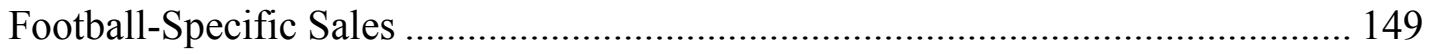

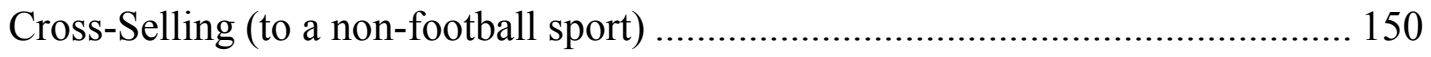

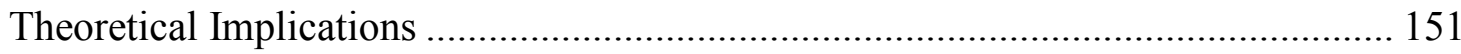

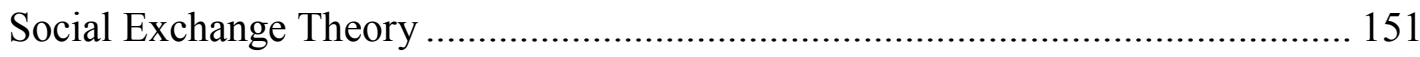

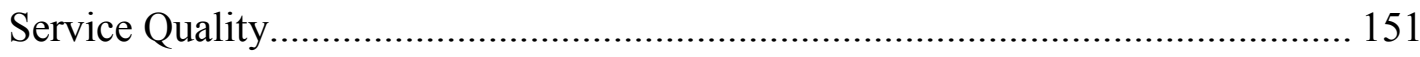

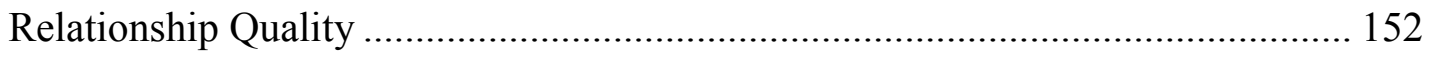

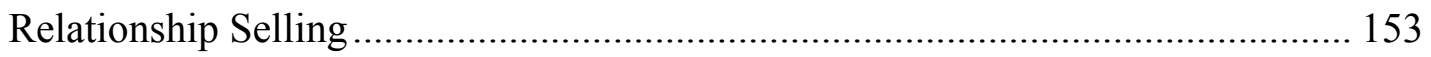

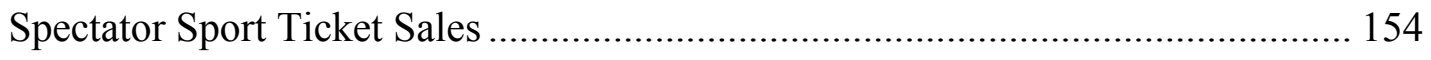

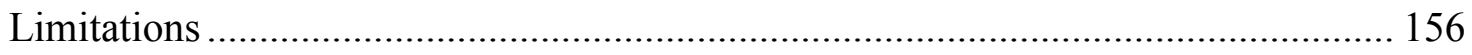




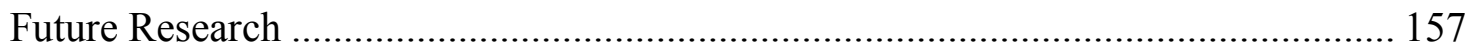

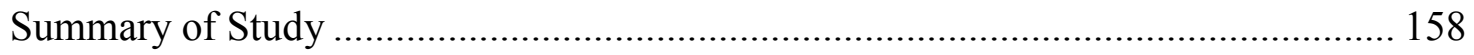

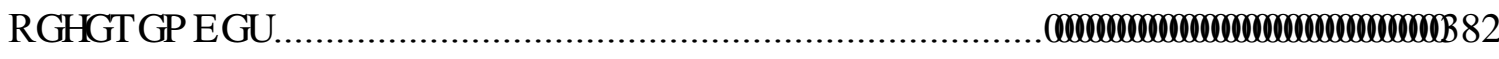

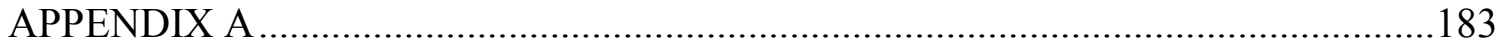

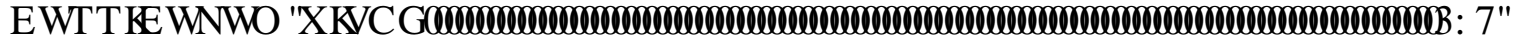
$\square$ 


\section{LIST OF TABLES}

\section{TABLE}

1. Sources of Revenues and Percentage of Ticket Sales as a Revenue Stream 77

2. Demographic Comparisons Between College Football Fans and MTurk Workers ... 81

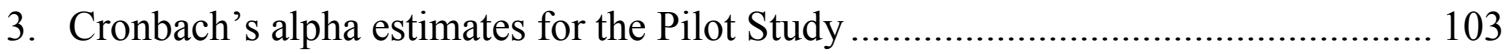

4. Frequency of Distributions for Demographic Variables...................................... 105

5. Demographic Comparisons of MTurk Workers, College Football Fans, and The

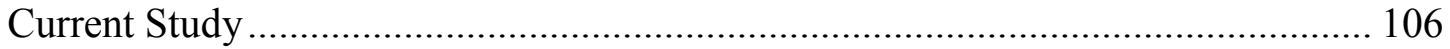

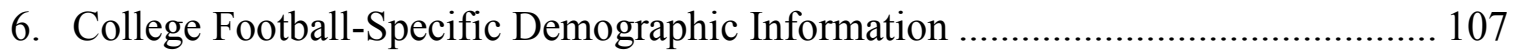

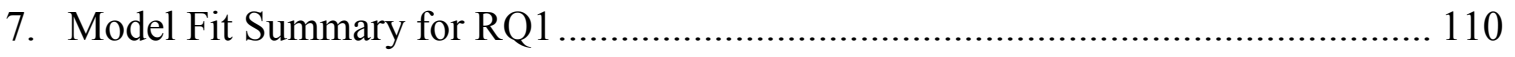

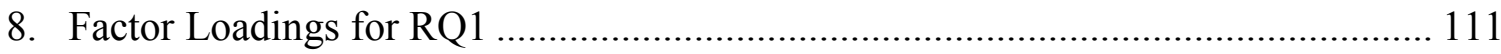

9. Correlation Estimates Between Variables ....................................................... 112

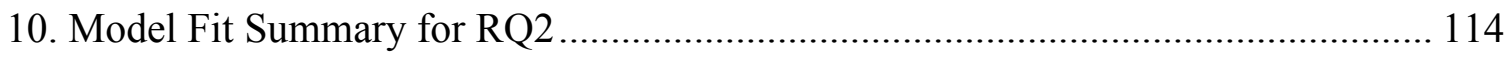

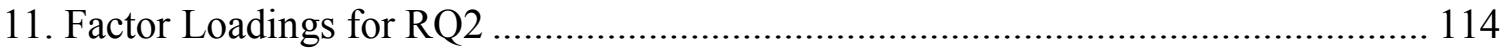

12. Correlation Estimates Between Variables ............................................................ 115

13. Descriptive Statistics of Independent and Dependent Variables ........................... 121

14. Pearson's Correlation Between Independent Variables (RQ1) .............................. 123

15. Results of Hierarchical Linear Regression Analysis for RQ1a ............................ 124

16. Results of Hierarchical Linear Regression Analysis for RQ1b ............................. 126

17. Results of Hierarchical Linear Regression Analysis for RQ1c ............................. 128 
18. Results of Hierarchical Linear Regression Analysis for RQ1d

19. Pearson's Correlation Between Independent Variables (RQ2) ............................. 131

20. Results of Hierarchical Linear Regression Analysis for RQ2a ............................. 132

21. Results of Hierarchical Linear Regression Analysis for RQ2b ............................. 134

22. Results of Hierarchical Linear Regression Analysis for RQ2c ............................. 136

23. Results of Hierarchical Linear Regression Analysis for RQ2d ............................. 138

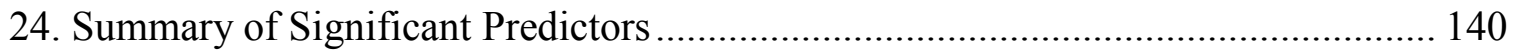




\section{LIST OF FIGURES}

\section{FIGURE}

1. The American Customer Satisfaction Index (ACSI) Model..................................... 34

2. Relationship Marketing Implementation in the Sport Industry .............................. 42

3. Proposed conceptual framework for relationship quality in sport .......................... 46

4. Proposed Model for Salesperson Information Overload ...................................... 56

5. Confirmatory Factor Analysis of Relationship Quality Instrument (RQ1) ............. 113

6. Confirmatory Factor Analysis of Relationship Selling Instrument (RQ2) .............. 117

7. Frequency Histograms of RQ1 Dependent Variables........................................ 118

8. Frequency Histograms of RQ2 Dependent Variables......................................... 119

9. P-Plot of Regression Standardized Residuals (RQ1) .......................................... 119

10. P-Plot of Regression Standardized Residuals (RQ2) ......................................... 120 


\section{CHAPTER I}

\section{INTRODUCTION}

Between 2004 and 2015, NCAA Division I athletics departments increased their generated revenues by over $\$ 24$ million (Fulks, 2016). However, during this same time, expenses rose by nearly $\$ 37$ million (Fulks, 2016). To cover the increased costs, athletics departments have begun to rely more heavily on "unallocated" revenues, which include school subsidies and student fees among other funds, to cover their cost (Fulks, 2016). Specifically, school subsidies granted by host institutions increased by nearly $\$ 200$ million between 2011 and 2012 (Berkowitz, 2012). Critics are highlighting issues including concerning athletics borrowing habits (Novy-Williams, 2017), the use of institutional funds for athletics buildings (Burnsed, 2015), and the trend of implementing student fees for athletics funding (Honson \& Rich, 2015); of which many students are unaware they are funding (Denhart \& Ridpath, 2011; Ridpath, 2014). Thus, as college athletic departments become a bigger business, they are also becoming more financially dependent on their host institutions; a potentially dangerous trend for higher education.

\section{College Athletics Revenue Sources}

When trying to find a solution for the financial dilemmas in college athletics, there are many revenue streams to consider. One of the largest revenue contributors; conference and NCAA distributions, has recently increased dramatically due to a boom in broadcast rights for both the NCAA Division I Men's Basketball Tournament (NCAA 
distribution revenue stream) as well as the respective conferences (Staples, 2016). However, a closer look at these broadcast agreements shows little room for further significant growth anytime soon. The March Madness tournament accounts for the largest revenue driver of the NCAA itself, and largely dictates NCAA payouts (Division I Revenue Distributions, 2017). However, the broadcast agreement for the tournament was recently extended until the year 2032 (Sherman, 2016), so NCAA payouts are not expected to have another dramatic increase in the near future. Conference agreements (and subsequently, conference payouts) have seen a similar trend. The ACC broadcast agreement was recently extended through the year 2035-36 (Baysinger, 2016), the Big East through 2025 ("New Big East," 2013), the SEC through 2034 (Fowler, 2013), the Big 10 through 2022-23 (Dodd, 2013), and the Pac 12 through 2023 (Rittenberg, 2017). Taken together, this means the "broadcast boom" which jumped athletics departments" revenue figures are unlikely to happen again for quite a while, and schools who wish to continue growing their business need to look elsewhere.

Second to broadcast and NCAA revenues, the largest increase in revenues has come from donations and ticket sales (Fulks, 2016). Often, donation revenue is tied to ticket sales, together suggesting this revenue stream would provide one of the largest areas of opportunity for athletics departments to improve profitability. Despite being a promising revenue stream, college football attendance has declined for four straight years. In fact, 2017 marked the largest drop in college football attendance since 1984 (Khan, 2018). Furthermore, college athletics ticket sales revenues remained flat on the most recent Revenues and Expenses report (Fulks, 2016). Reasons behind the lackluster attendance figures are uncertain, though popular press has pointed to higher ticket prices, 
less engaging games, and additional platforms for viewership as possible culprits (Tuttle, 2014).

\section{Statement of the Problem}

There is clearly a large gap between the operating expenses and revenues in college athletics, and athletics departments have relied heavily on subsidies and student fees to make ends meet. Much of the recent revenue growth has been due in large part to broadcast and multimedia contract renewals, of which many will span over the next decade and provide little room for additional growth. Athletics departments will need to look elsewhere to improve the bottom line. Ticket sales (and subsequently, donations) appear to be a promising area for improvement since each athletics department has more control over their own ticket operations than the broadcast agreement for the entire conference.

Ticket sales in college athletics typically stem from the college or university's box office operations. Season ticketholders contact the box office through the website, phone sales, or direct mail to renew existing season tickets or purchase new ones. Furthermore, many college athletics departments require donations in addition to their season ticket purchases, which are also handled by the box office (Novoy-Williams, 2018). Thus, the box office is identified as the primary point of contact between fans and athletics departments in regard to ticket sales. The majority of Division I college athletics departments box office operations offer not only season football tickets, but offerings for other sports teams as well (basketball, baseball, etc.) which uniquely position the box office to use a single affiliation to sell multiple sports. 
However, box office operations have been criticized for being undertrained and understaffed in college athletics, further compounding the problem. For instance, despite literature recommending at least two weeks of training prior to beginning live calls (Irwin, Sutton, \& McCarthy, 2008), one study found over 78 percent of athletics departments with outbound sales teams spent fewer than 20 hours per year on training their employees. Furthermore, 32 percent of such schools reported no formal training whatsoever (Popp \& McEvoy, 2012).

In sum, ticket sales are one of the only major revenue streams under the complete control of the university which can immediately result in increased profitability. However, despite the importance of ticket sales as an area for year-to-year growth, actual sales numbers have declined, and literature suggests proper staffing and training may be neglected. If college athletics departments desire financial independence from their host institutions, ticket sales must become more of a priority, and the best practices of ticket sales in college athletics should be investigated.

\section{Service Quality}

In order to examine the degree to which improved box office operations may benefit ticket sales, it is first important to examine the degree to which the box office (and all other personnel) have an influence on the customer's experience. Service quality refers to a "bundle of benefits" provided to the customer by the experience created by the firm or organization. This bundle of benefits adds perceived value for the customer and makes them more likely to engage in post-purchase behaviors including repeat purchase intentions as well as word of mouth marketing (Bateson, 1992). The original model of service quality proposed by Parasuraman, Zeithaml, and Berry (1994) includes five 
dimensions of service quality: reliability, assurance, tangibles, empathy, and

responsiveness. However, since this seminal work, it was suggested models of service quality should be content-specific and adapted to relate to the particular industry of which they are being examined (Parasuraman et al., 1988).

Service quality specific to sport has been examined from many different angles. Some researchers have found a three-factor model of service quality specific to sport which includes environmental factors (stadium), personal factors (employees), and product factors which include peripheral products such as concessions (Greenwell, Fink, \& Pastore, 2002; Ko \& Pastore, 2005; Koo, Hardin, \& Dittmore, 2015). However, the majority of service quality models are quite comprehensive, including the entirety of the customer's experience. Such encompassing models of service quality are effective when investigating the customer's experience as a whole, however only one element of these models relates to the interaction between personnel and customer. Considering this study aims to investigate the problem of box office revenues directly, it is less concerned with additional elements such as the environment or peripheral products. Thus, while providing the foundation for understanding the impact of the customer experience on their behavior, a more specific focus is necessary in order to examine the more detailed aspects of the interaction between box office personnel and the customer.

\section{Relationship Quality}

Stemming from the relationship marketing literature, relationship quality refers to the strength of the relationship between the customer and the organization (Palmatier, 2006) and allows the ability to address a more detailed and specific 
between customers and personnel. Relationship quality, generally studied from the viewpoint of the customer, has been studied in business realms and shown positive correlations with purchase intentions and customer satisfaction (Hennig-Thurau \& Klee, 1997; De Canniere \& Pelsmacker, 2010). Additionally, relationship quality is suggested as a useful tool in evaluating relationship marketing efforts (De Wulf, OderkerkenSchroder, \& Iacobucci, 2001) and in diagnosing discord between a customer and an organization (Roberts, Varki, \& Brodie, 2003).

Relationship quality in sport has been examined using a five-factor model proposed by Kim et al., (2011) consisting of trust, commitment, intimacy, selfconnection, and reciprocity. Trust refers to the degree in which the consumer believes the other person in a relationship is reliable, has high integrity, and unlikely to engage in devious behavior (Morgan \& Hunt, 1994). Commitment refers to "believing that an ongoing relationship with another is so important that it warrants maximum efforts in maintaining it" (Morgan \& Hunt, 1994, p. 23). Self-connection is a concept similar to fan identification which leads to consumers developing loyalty towards the product due to feelings of uniqueness or dependency (Drigotas \& Rusbult, 1992). Intimacy is similar to self-connection; however, it refers to a connection between the individual and the organization, rather than the overlap between the two (Kim \& Trail, 2011). The last factor of relationship quality is reciprocity, or the social norm of obligated behavior based on past behavior (Gouldner, 1960). In the relationship quality context, reciprocity refers to the perception that the customer believes they will be rewarded for their support and patronage (Kim \& Trail, 2011) 
Relationship quality provides a clearer picture of the strength of the relationship between the customer and the organization. Kim and Trail (2011) proposed the fivefactor structure and posited relationship quality would have correlations with word of mouth marketing, media consumption, the purchase of licensed merchandise, and attendance. Kim and Trail's (2011) proposal would suggest by strengthening the relationship between the customer and the sport organization, the customer is more likely to engage in repeat purchase behavior. Furthermore, it was suggested relationship quality could be utilized as a tool to evaluate the effectiveness of relationship marketing and selling efforts, offering feedback to box office operations on how to best serve their customers.

\section{Relationship Selling}

While relationship quality may address potential problems between the customer and the organization, it is designed to examine the entirety of the sport organization. In order to examine the box office operations specifically and their practices, one must be even more specific. Relationship selling practices refer to the practice of engaging in exchanges with the customer which promote long-term relationship building (Jolston, 1997). By implementing relationship selling behaviors, salespeople can develop lasting relationships which add value to the exchange between the customer and the sales representative, making them more likely to engage in purchase behavior. Relationship selling is characterized by the practices of assuming a customer-based orientation, the use of adaptive selling practices, and the emphasis on relationship building between the customer and the sales representative. Customer orientation refers to the degree the salesperson places the priority on the customer's needs (Saxe \& Weitz, 1982). 
Furthermore, adaptive selling occurs when the salesperson is actively listening and empathizing with the customer, while also adapting their sales efforts according to the information they receive (Spiro \& Weitz, 1990). Lastly, relationship building practices closely resemble customer orientation in their goal of relationship development, however differ in that they are measured from the perspective of the customer, rather than the salesperson (Crosby, Evans, \& Cowles, 1990).

Relationship selling practices are often measured using constructs developed by Crosby et al. (1990) and modified for the particular industry. Crosby et al. (1990) measured relationship selling practices using a three-construct model of interaction intensity, mutual disclosure, and cooperative intentions. Interaction intensity refers to the frequency in which the sales representative contacts the customer (Williamson, 1983). These constructs often include various forms of communication and interaction (email, phone, gifts, etc.) and reflect a commitment to the sales relationship (Williamson, 1983). Mutual disclosure is a construct which includes two sub-factors: agent disclosure and customer disclosure. Customer disclosure refers to the degree in which the customer has willingly shared information, both personal and business-related, with the agent (Darlega et al., 1987). Agent disclosure is similar, though it refers to information regarding the sales representative themselves. Lastly, cooperative intentions refer to the degree of trust the customer has regarding the sales representative's willingness to do what is best for the customer (Crosby et al., 1990).

Relationship selling practices have been shown to increase purchase and repurchase likelihood (Han et al., 2014) as well as customer satisfaction (Foster \& Cadogan, 2000; Stock \& Hoyer, 2005). Additionally, relationship selling practices have 
led to increased sales performance (Kiellor, Parker, \& Pettijohn, 1999; Han et al., 2014)

and customer loyalty (Homburg, Muller, \& Klarmann, 2011). Nonetheless, the effectiveness of relational selling practices in sport is still largely unknown and offers potential benefits to sport managers looking to build both relationships with their fans and revenues for the department.

\section{Purpose of the Study}

Research regarding the ineffectiveness of collegiate ticket sales is scarce. Some researchers have highlighted the lack of training received by ticket sales employees (Irwin, Sutton, \& McCarthy, 2008; Irwin \& Sutton, 2011; McEvoy \& Popp, 2012; Popp, Simmons, \& McEvoy, 2017). Additional questions have been raised regarding the experience and lines of communication from sales managers (Bouchet, Ballouli, \& Bennett, 2011), and the commitment of the athletics department to invest in the necessary resources (human and financial) for an effective sales operation (Popp, 2014). Despite concerns over the capacity, willingness, and resources of athletics departments to better train sales employees, there is little agreement to which aspects of sales prove the most effective in increasing purchase intentions. That is to say, while literature is in agreement regarding inadequate training, there is a dearth of empirical literature in sport confirming whether or not additional training would actually result in enough of an improvement to trigger increased consumer behavior.

One suggestion appearing in the research stems from Smith and Roy's (2011) Framework for Developing Customer Orientation in Ticket Sales Organizations, which posits ticket sales operations should emphasize long-term relationships and building customer loyalty through relationship building and a customer-first approach. Such an 
approach is discussed in terms of relationship quality and relationship selling practices within business literature, though the impact of such topics in sport consumer behavior is still unknown.

Research has suggested improved relationship quality between a ticket sales organization and the customer may result in increased customer retention and purchase intentions (Smith \& Roy, 2011). However, it is still unknown whether relationship quality has a distinct relationship with consumer behavior in Division I college football, which represents the largest revenue generator for collegiate sport. Additionally, despite the call for increased emphasis on relationship-building practices in ticket sales training and practices, the degree to which such practices are being implemented as well as their effectiveness in increasing sales likelihood are also unknown.

College athletics consumers are also unique as they involve a high identification with not only a singular team, but also with a hosting university. This poses a significant opportunity for cross-selling and upselling. These consumer behaviors may prove important, yet little research has been done further investigating cross-selling behavior in sport. Considering the relationship between the consumer and the institution are posited as a link for cross-selling, it would be logical to investigate relationship quality and relationship selling techniques in this context as well.

Despite the unique identification and passion of college sports fans, the degree to which college athletics departments are able to leverage this passion into ticket sales is still unknown. Accordingly, it is important to understand the degree to which box office operations are currently developing relationship quality with their customers and the effects which relationship quality may have on customer purchase intentions. Regardless 
of these needs, no study has examined the effects of box office relationship quality on consumers in sport, and considering the importance placed on ticket sales revenues, and the independent control of each athletics department over their own ticket sales operation, this lack of understanding is important. Furthermore, this study offers an opportunity to extend the scope of sport relationship quality literature. Since the box office typically offers the first opportunity of interaction with the customer, it is also the first opportunity to develop a relationship with such customers. Thus, the purpose of this study is to measure relationship quality and relational selling from the university box office and to investigate the impact of relationship quality and relationship selling techniques on consumer behavior in Division I college football.

\section{Research Questions}

In order to investigate the impact of box office relationship quality and relationship selling practices on Division I college football consumer behavior, several research questions were developed.

RQ1- Which aspects of relationship quality (trust, commitment, intimacy, selfconnection, and reciprocity) predict sport consumer purchase intentions in Division I college football?

RQ1a- Which aspects of relationship quality (trust, commitment, intimacy, self-connection, and reciprocity) predict season ticket renewal intentions for the following season?

RQ1b- Which aspects of relationship quality (trust, commitment, intimacy, self- connection, and reciprocity) predict willingness to purchase additional football season tickets for the following season? 
RQ1c- Which aspects of relationship quality (trust, commitment, intimacy, self-connection, and reciprocity) predict willingness to purchase more expensive football season tickets for the following season?

RQ1d- Which aspects of relationship quality (trust, commitment, intimacy, self-connection, and reciprocity) predict willingness to purchase new tickets of any kind to a different sport of the same college or university?

This study aims to examine box office operations, and while it is important to measure and evaluate the strength of the relationship with the entire organization, it is also important to examine the relationship with the customer and the box office specifically. Measuring relationship selling practices allows the researcher to specifically target a single sales operation within an organization and offers the ability to examine the individual practices of relationship selling which may prove effective in increasing the likelihood of repurchase intentions. Accordingly, the second research question is as follows:

RQ2- Which aspects of relationship selling practices (interaction intensity, customer disclosure, agent disclosure, cooperative intentions) predict sport consumer purchase intentions in Division I college football? RQ2a- Which aspects of relationship selling practices (interaction intensity, customer disclosure, agent disclosure, cooperative intentions) predict season ticket renewal intentions for the following season? RQ2b- Which aspects of relationship selling practices (interaction intensity, customer disclosure, agent disclosure, cooperative intentions) 
predict willingness to purchase additional football season tickets for the following season?

RQ2c- Which aspects of relationship selling practices (interaction intensity, customer disclosure, agent disclosure, cooperative intentions) predict willingness to purchase more expensive football season tickets for the following season?

RQ2d- Which aspects of relationship selling practices (interaction intensity, customer disclosure, agent disclosure, cooperative intentions) predict willingness to purchase new tickets of any kind to a different sport of the same college or university?

\section{Significance of the Study}

This study is significant in its potential contributions to both the practical and theoretical realms of sport consumer behavior. As previously mentioned, college athletics departments are spending far more money than they generate and have been relying on host institutions to supplement their incomes in order to make ends meet. Additionally, college athletics has benefitted from a "broadcast boom," leading to increasing revenues from both the NCAA as well as many conference membership revenues. Such contracts are often negotiated in terms of 20 years or more, and many were recently renewed. Additionally, individual schools may have little control over the negotiation of revenues for the entire conference. Thus, athletics departments have little control or ability to enhance revenues from broadcast agreements year-to-year.

While the broadcast and multimedia contracts may be outside of the control of each individual athletics department, most athletics departments have far more control 
over the operations of their box offices, which represent a revenue stream independent to each school. By better understanding which aspects of relationship quality predict increased likelihood of purchase intentions, athletics departments will be better able to tailor their marketing efforts towards the areas of relationship building which are most important to the customer, as well as their own finances. Furthermore, understanding the aspects of relationship selling predicting purchase intentions will allow the athletics departments to better train their employees on how to build lasting relationships with the customers.

This study also poses a significant contribution to the body of research involving service quality and consumer behavior prior to the day of the game. The majority of sport service quality research measures the experience of the fans on the day of the game (Howat \& Murray, 1999; Murray \& Howat, 2002; Ko \& Pastore, 2005; Yoshida \& James, 2010; Ko et al., 2011; Shonk \& Chelladuai, 2016). However, it is certainly possible perceptions of service quality, product quality, and relationship quality could all be significantly impact prior to the consumer arriving at the facility. It is important to capture the entire experience of the consumer, from their first interaction. In many sport businesses, the first interaction with the consumer occurs in their interactions with the box office. Thus, research regarding box office service quality extends the scope of service quality and relationship quality research by broadening the lens in which we view the customer experience. Rather than the experience beginning in the parking lot and ending after the game, the experience begins when first contacted (or contacting) the box office, and ends following the conclusion of the event or season. 
Lastly, this research will contribute to sport management education research. Sport management sales training literature has shown the ability to communicate, listen, adapt, and develop relationships with customers as essential ingredients for successful ticket sales operations (Boles, Brashear, Bellenger, \& Barksdale, 2000; Drollinger \& Comer, 2013). Such practices are often referred to as relationship selling practices. While relationship selling practices have been highlighted as essential in sport management education training literature, and criticized as absent in college box office operations, little research has been done to bridge the gap between these training principles and actual consumer behavior within the sport context. In essence, sales training literature suggests it is important to teach relationship selling to future sales representatives, yet there is little empirical evidence to support the link between these practices and revenue generation in the context of sport ticket sales.

\section{Delimitations}

This is a study of college athletics departments, and data will only be collected at the collegiate level. While the results of this study may be generalizable to professional sport, it is not intended to draw direct correlations to the professional sport realm. This decision was made due to the nature of the problem of this study. College athletics departments find themselves in dire financial situations as the growth of broadcast revenues is generally controlled by long-term contracts and ticket revenues have remained stagnant. Additionally, the literature has specifically highlighted the need for improved training and resources to the collegiate segment of sport business, and there has not been such a need illuminated on the professional side (yet). Thus, it was decided this study would focus exclusively on college sport. 
Additionally, this study was designed to focus specifically on Division I college football. One outcome variable of the study will include consumer behaviors involving cross-selling activities with other sports, however the independent variable will remain consistent. That is to say, this study will examine the impact of football's ability to crosssell other sports, and not vice versa. Furthermore, the decision was made to focus only on FBS Division I programs. This is not to say the results will be useless to other divisions. In fact, the authors hope other divisions will be able to benefit from these results. However, the decision was made to focus on Division I due to the fact many other divisions may not have dedicated box office operations or full-time staff members who are most likely to engage in long-term relationships. Additionally, the purpose of this study is to aid in increasing ticket sales revenues. According to Fulks (2016), ticket sales at the Division II and Division III levels contribute significantly less to the institution's bottom line, and thus make less of an impact on the financial stability of the program.

\section{Limitations}

The current study is dependent on an adaptation of Crosby et al.'s (1990) measurement regarding relational selling activities from the perspective of the consumer. This scale was developed using whole-term life insurance, although it is meant to be adapted to fit the specific industry which is being studied. This will involve modification of some of the wording of the instrument in order to make it more box office-specific. This also means some relationship selling factors specific to sport ticket sales may not be present in the instrument. Obviously, an instrument specifically developed for measuring relationship selling practices in sport ticket sales would be preferable. 
This study will be limited to individuals volunteering to participate in the study, and it may be difficult to create a sample which is representative of the entirety of NCAA Division I college football spectators. The data will be collected using Amazon Mechanical Turk (MTURK), which is a digital platform for survey solicitation. It would be preferable to have the survey sent out to the season ticketholders of each institution and to allow for a broader range of potential responses; however, that method would not be pragmatic given the time needed to recruit so many schools combined with the likelihood of proper participation.

Another limitation to this study will be the time of collection. Respondents will be asked to recall their experiences throughout the season during the football off-season. It is never ideal to ask respondents to recall a previous memory, experience, or concept however the study involves the purchase intentions of renewal customers. This, unfortunately, requires the conclusion of the season before consumers can judge their likelihood of renewal. While it would be ideal to capture customer opinions during the season or immediately after box office contact, the current study will collect data during the off-season, despite the memory recall limitation due to the fact that this timeframe is the general selling period of college athletics, and most appropriate time for collecting the information related to the outcome variables of interest.

The last limitation of this study will include the collection of outcome variables which measure the likelihood of renewal. This is not the same as actual purchase behavior, as a consumer's actual purchase behavior may differ from what they claim. That is to say, customers may claim they are not going to renew their tickets and have a change of heart closer to the actual season. Ideally, participant information would be 
collected immediately following the conclusion of the football season and the participants would be re-contacted after the first game of the following season to gather information on actual purchase behavior. Unfortunately, MTURK does not allow researchers to collect personal information such as email addresses or phone numbers of the participants, thus re-contacting them would be challenging.

\section{Definitions of Terms}

Adaptive Selling: The degree to which salespeople shape their message and behavior as an interaction continues (Weitz ,1981)

Box Office: Branch of the athletics department responsible for ticket sales operations Commitment (Relationship Quality): “An enduring desire to maintain a valued relationship" (Moorman, Zaltman, \& Deshpande, 1992, p. 319)

Customer Loyalty: Expressed preference for a company and intention to continue purchasing from it (Homburg et al., 2011, p. 799)

Customer Orientation: "The altering of sales behaviors during a customer interaction or across customer interactions based on perceived information about the nature of the selling situation" (Weitz, Sujan, \& Sujan, 1986, p. 175)

Cross-Sell: Selling a different product to an existing customer as the result of a solicitation when purchasing the primary product (Hallowell, 1996)

Hedonic Consumption: Consumption of a product which relates to "multisensory, fantasy, and emotive aspects" of one's experience with the product (Jiang \& Wang, 2006, p. 212)

Intimacy (Relationship Quality): The degree of familiarity, openness, and closeness in the relationship (Kim \& Trail, 2011) 
Passion: A strong inclination toward an activity which people like (Valerand, 2008) Reciprocity (Relationship Quality): A social norm which obligates behavior based on past behavior (Gouldner, 1960)

Relationship Marketing: "All marketing activities directed towards establishing, developing, and maintaining successful relational exchanges" (Morgan \& Hunt, 1994, p. 22)

Relationship Quality: Measurement focusing on the strength of the relationship between the customer and the organization (Palmatier, 2006).

Relationship Selling: A multi-stage process which emphasizes personalization and empathy as key ingredients in identifying prospects, developing them as costumers, and keeping them satisfied (Jolson, 1997)

Self-Connection (Relationship Quality): Personal identification which leads customers to develop a deep loyalty towards a product due to protective feelings of dependency (Drigotas \& Risbult, 1992)

Service Quality: The bundle of benefits to the customer, through the experience that is created for that customer (Bateson, 1989)

Social Exchange Theory: Theory which suggests consumers will engage in the activity that they feel provides the most value (Emerson, 1976)

Trust: Confidence in an exchange partner's reliability and integrity (Morgan \& Hunt, 1994)

Utilitarian Consumption: The use of a product to achieve a "functional consequence" (Kempf, 1999) 
Upsell (ticketing): Purchasing additional or more expensive tickets than was purchased in the previous year

Value: The ratio of money spent to benefits perceived by the customer (Mullin, Hardy, \& Sutton, 2014) 


\section{CHAPTER II}

\section{REVIEW OF LITERATURE}

This study's purpose is to investigate the impact of relationship quality and relationship selling techniques on consumer behavior in Division I college football. The focus of this chapter will be to review the relevant literature associated with the current study. This chapter will include the conceptual frameworks which have grounded past studies, general literature describing themes of the study, literature specific to the sport industry, and consumer behavior effects associated with the topics discussed. While no studies have studied college athletics box office relationship quality or relationship selling specifically, implications from this literature will be used to guide the direction of this study.

This review of literature is divided into four sections. The first section begins by investigating conceptual frameworks of service quality as well as literature suggesting why service quality is unique in sport. The second section explores relationship marketing and relationship quality. Conceptual frameworks, measurements of relational quality, and the applications of relationship marketing and relationship quality in sport are all reviewed in this section. The third section includes the development of relationship selling as a specific outgrowth of relationship quality and relationship marketing. Relationship selling tenets of customer orientation, adaptive selling, relationship building, and selling expertise will all be discussed along with their respective outcomes on 
consumer behavior. Finally, the fourth section of this literature review includes the current sport management literature on ticket sales in spectator sport, including policy development in college athletics ticket sales, sport ticket sales management, and possible pitfalls in college athletics ticketing which address the problem this study will target.

\section{Service Quality, Value, and Satisfaction}

Service quality literature is largely based on the foundational studies of Parasuraman, Zeithaml, and Berry $(1985 ; 1988)$ (hereafter referred to as PZB), who posited service quality has a positive relationship with customer satisfaction; leading to repeat purchase intention. Bateson (1992) defined service quality as a "bundle of benefits to the customer, through the experience that is created for that customer" (p. 6). These benefits provide value to the customer, which makes them more likely to engage in postpurchase behavior, including additional purchases such as renewals (Bateson, 1992). This subsection of literature review will contain two parts. First literature will be reviewed regarding service quality theoretical frameworks and the fundamental concepts of service quality derive from general business literature. Second, elements which make service quality unique or different in sport will be reviewed. This will include literature regarding service quality in service industries, core vs. peripheral service quality, service quality related to hedonic vs. utilitarian consumption, and finally studies which have specifically examined service quality within the sport context.

\section{Theoretical Frameworks and Fundamentals of Service Quality}

The service quality literature predominantly covers two different frameworks. PZB (1988) developed the SERVQUAL instrument and methodology, which measures service quality based largely on Gap Theory (also called expectation disconfirmation). 
Gap theory states service can be assessed by subtracting the actual level of service received with the level of service the customer believed they would receive ( $\mathrm{SQ}=\mathrm{P}-\mathrm{E})$ (Gronroos, 1984). Despite widespread use, Gap Theory still has challenges in its application. Businesses with low expectations of service still perform well in Gap Theory measurements since the "bar" is set low. This lends applications of Gap Theory to "penalize" industries in which service quality is expected to be high since, at best, they can only meet customer standards and not exceed them. Such concerns led Cronin and Taylor (1992) to criticize the SERVQUAL scale; stating Gap Theory lacked theoretical and practical evidence, as they developed a similar scale using performance-only measures of the original RATER model (SERVPERF). Since then, many researchers endorse SERVPERF due to the shorter nature and favored methodological approach (Babakus \& Boller, 1992) while questioning Gap Theory measurements as "one dimensional" (Boulding et al., 1993).

The original work of PZB (1985) includes 10 dimensions of service quality. However, multiple dimensions were later combined by Zeithaml, Parasuraman, and Berry (1990) to form the current model often still used today. The five dimensions of service quality identified by Zeithaml et al. (1990) include: reliability, assurance, tangibles, empathy, and responsiveness (RATER). Berry et al. (1994) provided further literature defining the relative importance of each dimension of the RATER model. In this work, reliability is the core of service quality as it accounted for $32 \%$ of the importance in the minds of consumers (Berry et al., 1994), followed by responsiveness (22\%), assurance $(19 \%)$, empathy (16\%), and tangibles (16\%). It is important to note from Berry et al. (1994)'s study the tangible offerings of service quality are considered least important in 
measuring relative importance among dimensions of service quality. Since the tangibles dimension encompasses how customers act in the business's environment (PZB, 1985), it may include things such as cleanliness, organization and visual appeal of the facility. Thus, over $80 \%$ of the customer's perception of service quality is derived from their interactions with staff, and not the facility itself. Such an emphasis on staff interaction as the core of service quality is important for the current study.

Ultimately the early work of PZB (1985) and Zeithaml et al. (1990) posited the relationship between service quality and consumer behavior. Since then, numerous other studies have since confirmed such a relationship and expanded the RATER model into more specifically-targeted realms of general business (Parasuraman, Berry, \& Zeithaml, 1993; Cronin \& Taylor, 1992; Bishop Gagliano \& Hathcote, 1994). Since the current study will target a specific industry (sport), it is important to review the relevant literature which has been done in this industry.

\section{Service Quality in Sport}

Many researchers have established the link between high service quality and repeat purchase intention (PZB, 1988; Cronin \& Taylor, 1992; Baker \& Crompton, 2000; Zeithaml \& Bitner, 2003). While PZB (1988) did not include any sport industries in their original instrument, they specifically stated the SERVQUAL foundation was designed to provide a "skeleton" across a broad range of services and is most effective when "the skeleton... can be adapted or supplemented to fit the characteristics or specific research needs of a particular organization" (p. 30). Since then, it has become common for researchers to adapt the SERVQUAL (and later SERVPERF) items to fit specific 
industries. This requires a review of unique elements of sport as well as the characteristics of sport service quality which have been studied in the past.

Theodorakis and Alexandris (2008) suggested service quality literature in spectator sport is scarce due to the impact of other factors on purchase intentions in sport. The authors posit factors such as team identification (Trail, Fink \& Anderson, 2003; Robinson et al., 2005), fan motivation (Mahoney et al., 2002; Robinson et al., 2004) and involvement (Funk, Mahoney, \& Ridinger, 2002; Funk et al, 2004) all have significant impacts on consumers, leading to additional challenges for researchers trying to isolate service quality. Additionally, the nature of sport business itself justifies unique measurement and characteristics of service quality for multiple reasons: sport business itself is a service industry, the core product is largely uncontrollable, and it is based on hedonic vs utilitarian consumption. Therefore, it is important to discuss unique elements or challenging elements of service quality in sport.

\section{Service Quality Regarding Hedonic vs. Utilitarian Consumption. Service}

quality literature differentiates products based on the level of need from the consumer. Oftentimes, business functions are segmented as hedonic and utilitarian. Hedonic consumption has been described as a product which "relates to multi-sensory, fantasy, and emotive aspects of one's experience with the products" (Jiang \& Wang, 2006, p. 212). Alternatively, utilitarian consumption refers to the use of products to achieve a "functional consequence" (Kempf, 1999). Sport consumers are highly identified and emotional towards the consumption of their product (Trail \& James, 2001; Fink \& Trail, 2002; Trail et al., 2003; Wann, Haynes, \& McLean, 2003; Wann, 2006). Since service 
quality differs in products which would be characterized as hedonic, such differences would certainly be of interest, and warrant attention.

Jiang and Wang (2006) investigated differences in perceived service quality between hedonic and utilitarian consumption of products, finding both perceived service quality as well as satisfaction are moderated by pleasure and arousal in industries which were identified as hedonic. This suggests one's level of emotion during the consumption of the product may have a significant impact on perceived service quality. Unfortunately, implications from this study would suggest factors of sport which result in emotions from consumers (wins, losses) are largely outside of the control and unavoidable by sport managers. Other studies involving hedonic consumption have found consumers are more willing to justify the purchase of a hedonic service, and are more willing to invest additional resources, including both time and money into the behavior (Okada, 2005). Implications from research regarding service quality and behavioral intention of hedonically consumed products suggest a double-edged sword: offering both increased value to the consumer, as well as the possibility of negative consequences from unfavorable experiences.

Service Quality in Service Industries. High levels of service quality have been suggested as a competitive advantage in businesses (Zeithaml et al., 1990), and highlighted as an essential business practice specifically in businesses which are considered service industries, (Price \& Farrell, 2003). While service quality is still present in businesses which provide material goods, it is even more important in businesses which offer a service as their primary product (Price \& Farrell, 2003). Sport is hardly the only service industry in which service quality may be important, however the 
literature noting high levels of service quality as an advantage in such industries merit attention as to whether sport qualifies as a strict service industry.

Kotler and Keller (2006) identified four characteristics of service industries: an intangible nature, simultaneous production and consumption, variability, and perishability. As an intangible product, services cannot be seen, heard, or touched. Additionally, services are simultaneously produced and consumed. These first two characteristics are key challenges when customers are trying to assess service quality. Since the product cannot be examined, and the simultaneous production and consumption leaves little time to examine or assess the product, the quality of the product is often up to the perception of the customer (Kotler \& Keller, 2006). Ultimately, literature suggests while the sport product package may contain the physical goods (merchandise, concessions, novelties), the primary product of sport business is most likely the event on the field, classifying sport as a clear service industry.

Core vs. Peripheral Service Quality. Sport is also unique in its limitations regarding the nature of its core product. Service quality has been described as having both core and peripheral attributes. This concept was first introduced by Phillip and Hazlet (1995), who described the core attributes as the primary organizational structure or process in which the customer intends to gain from their purchase. Additionally, the peripheral services are the ones which add "roundness" to the core product. Phillip and Hazlet (1995) initially posited the core product's service quality is of higher importance, and ultimately leads to the "pivotal fundamental" which determines whether or not the customer repurchases the product. 
The importance placed on the core product service quality may prove troubling for sport managers. Murray and Howat (2002) characterized the core product as the actual spectator event on the field, and the peripheral products as those which support the core product. This creates a problem which makes improving service quality in sport uniquely difficult. A sport marketer has little control over the core product. Thus, sport businesses must rely on the improvement of peripheral services to influence customer decisions. If the peripheral product truly is less influential (Phillip \& Hazlet, 1995), this would suggest sport management must improve peripheral product services significantly to impact consumer decisions.

Byon, Zhang, and Baker (2013) examined separate measurements of core vs. peripheral service quality in sport to determine whether the core product or the peripheral can predict increased perceived value as well as behavioral intentions. The core product service quality was measured using five variables: home team, opposing team, economic considerations, game promotion, and schedule convenience. Peripheral variables included game amenities, ticket service, and venue quality. Byon et al. (2013) found positive predictive relationships between behavioral intentions and three of the five core service quality variables: home team, opposing team, and game promotion. Only the home team variable predicted increased perceived value. However, it may be argued the two teams playing each other (two of the three significant variables) are outside of the control of many sport managers or organizations; providing further evidence of challenges in making meaningful difference through improved core service quality. Two of the three variables measured for peripheral quality were found to significantly predict behavioral intentions: game amenities and venue quality. Only venue quality predicted an increase in 
perceived value. The findings of Byon et al (2013) suggest there are differences in elements of service quality based on the categorization of core vs. peripheral and add to the literature regarding the controllability (or lack thereof) regarding core service quality.

Sport-Specific Literature of Service Quality. When customers are evaluating

the quality of a service, they evaluate from many angles (Chelladurai \& Chang, 2000). Langeard, Bateson, Lovelock, and Eiglier (1981) highlighted three interrelated components of service quality from the customer perspective: the inanimate environment, the service personnel, and a bundle of service benefits. Greenwell, et al., (2002) shed light on these three factors within a sport context, explaining the inanimate environment as the stadium itself, the service personnel as the staff who interact directly with customers, and the service benefits as the core product. While the purpose of Greenwell et al. (2002) involved isolating the effects of the environment (stadium), it highlighted an opportunity to further investigate another one of Langeard et al.'s (1981) components. The implications from Greenwell et al., (2002) demonstrate the value in isolating individual components of (traditional business) service quality and investigating them within the sport context.

Koo, Hardin, and Dittmore (2015) found a significant relationship between service quality and customer satisfaction in college football season ticketholders using a three-factor model of service evaluation which included functional quality, environmental quality, and technical quality. Functional quality items described the employees working inside the gates of the stadium and their interaction with the fans. Environmental quality was concerned with the stadium and venue itself, including signage, concessions, and merchandise shops. Lastly technical quality was concerned with the record of the visiting 
team, rivalry effects, and excitement of the event (Koo et al., 2015). While these factors certainly may describe service quality, the scope of Koo et al. (2015)'s covered the event only on game day, and disregards service which the customer may have experienced prior to the day of the game. Regardless, the positive relationship between service and satisfaction may suggest the possibility of similar relationships from the box office and warrants attention.

Shapiro (2010) measured service quality from the perspective of athletics donors. His work was not intended to measure any particular game or event, but instead the level of service provided by the athletics fundraising department. This study represents the sole piece of literature which addresses service quality in college athletics with a focus outside of game day events. Drawing off the performance-based SERVEPERF framework, an instrument was developed based on three factors: responsiveness, feedback, and effectiveness. These factors were regressed against measurements of donor satisfaction, where all three factors were found to be significant predictors (Shapiro, 2010). Additionally, the factors of service quality were compared to donor longevity and gift amount. Interestingly, service quality was not found to significantly predict the amount a donor contributes nor the number of years in which they have been a donor. Donor relations and ticket sales are tied very closely, since most college ticket sales require a donation. This finding may suggest there is not a clear relationship between service and donations, though it is notable many athletics donations are required as part of a ticket purchase, bringing the philanthropic nature of such donations into question. Additionally, this study included no control variables, and it has been shown factors such as team identification (Kwon, Trail \& James, 2007) and passion (Wakefield, 2016) impact sport 
consumer behavior. Thus, the findings by Shapiro (2010) also suggests the importance of controlling for variables which must be considered when trying to study possible relationships between customer service and consumer behavior in athletics settings.

While much of the literature previously discussed involved professional or amateur sport, research has also been done involving recreational models of sport. Ko and Pastore (2005) identified four major dimensions in recreational sport service quality: program quality, interaction quality, outcome quality and environmental quality; each of which consists of multiple sub-dimensions. Program quality was described as the customer's perceived excellence of the program and included sub-dimensions surrounding the range of programs, operating time, and information. The second dimension (interaction quality) focused on how the product was delivered. Ko and Pastore (2005) suggested this dimension can occur in two different forms: interaction between the customer and the employees, as well as interaction between customers themselves. Additionally, a third dimension of outcome quality was observed which described the degree to which the customer actually gained what they intended from the transaction. This is demonstrated in three sub-dimensions: physical change, sociability, and valence. Lastly, the fourth dimension of service quality identified was physical environment quality which is largely considered one of the most important dimensions of service quality in recreational sport (Ko \& Pastore, 2005) and includes three subdimensions: ambience, design, and equipment.

While not directly in spectator sport context, the implications from Ko and Pastore (2005) are relevant to the current study because it included an in-depth evaluation of elements of service quality from a customer-employee perspective, while the majority 
of previous literature focuses on service quality from a customer-organization perspective. The highlighted importance of variables such as operating time, information, and interaction quality may all be important to consumers when evaluating box office service quality, and these constructs are absent from much of the spectator sport literature.

All areas of sport are not the same, and therefore areas of service quality which exist in one area of sport may not carry over to another. Similarly, certain forms of sport may contain additional unique service dimensions not seen in others. Sport tourism has been described as sporting events where a large percentage of the attendees were traveling to attend (The Super Bowl, for instance). Shonk and Chelladurai (2008) found such in a study surrounding sport tourism events. Their work suggested sport tourism includes a dimension of access quality which incorporates the destination location, hotel, and accommodations of the event into the customer's perception of service quality. Implications from this work suggest the unique nature of sport results in unique dimensions of sport service quality not found in general service quality literature. Furthermore, the work of Shonk and Chelladurai (2008) suggested customer satisfaction as an antecedent to service quality while value was found as a precedent of service quality, conflicting with existing service quality research from other industries (Kotler, 1991; Fornell et al., 1996).

Ko, Zhang, Cattani, and Pastore (2011) developed a framework for event quality of spectator sports. Their findings resulted in the Sport Event Quality for Spectator Sports (SEQSS), which consisted of 12 sub-dimensions: skill, hours, information, entertainment, concessions, staff-fans, fan interaction, valence, sociability, ambience, design, and 
signage. The measurement was validated and found to be a good fit for data collected at a professional baseball game (Ko et al., 2011). The SSEQS provided more specific dimensions of service quality for spectator events, which differed from previous instruments which were much more generalized (Theodorakis et al., 2001; Westbrook \& Shillbury, 2003).

Theodorakis, Kambitsis, Laios, and Koustelios (2001) developed the SPORTSERV instrument which intended to identify and measure service quality in sporting events. The instrument was developed using a sample of international professional basketball spectators and included five dimensions: access, reliability, responsiveness, tangibles, and security. Regression analysis concluded all five factors significantly predicted increased levels of customer satisfaction, with the reliability factor being the most influential. These findings suggest service can positively influence customer satisfaction, which is often discussed in service literature as a mediating variable for purchase intentions. Additionally, their findings suggested further generalizability overseas, since international findings mirrored North American findings of service quality.

Customer Satisfaction and Value. Customer satisfaction has been described as the post-purchase evaluation of a product or service given pre-purchase expectations (Kotler, 1991). Scholars have suggested customer satisfaction and value are both antecedents of service quality impacting both customer loyalty and future purchase intentions (Fornell, Johnson, Anderson, \& Bryant, 1996). As shown in Figure 1, Fornell et al. (1996) suggested the level of perceived quality of the product as well as the 
customer expectations will determine the value to the customer. In turn, customer value influences satisfaction, and ultimately consumer behavior

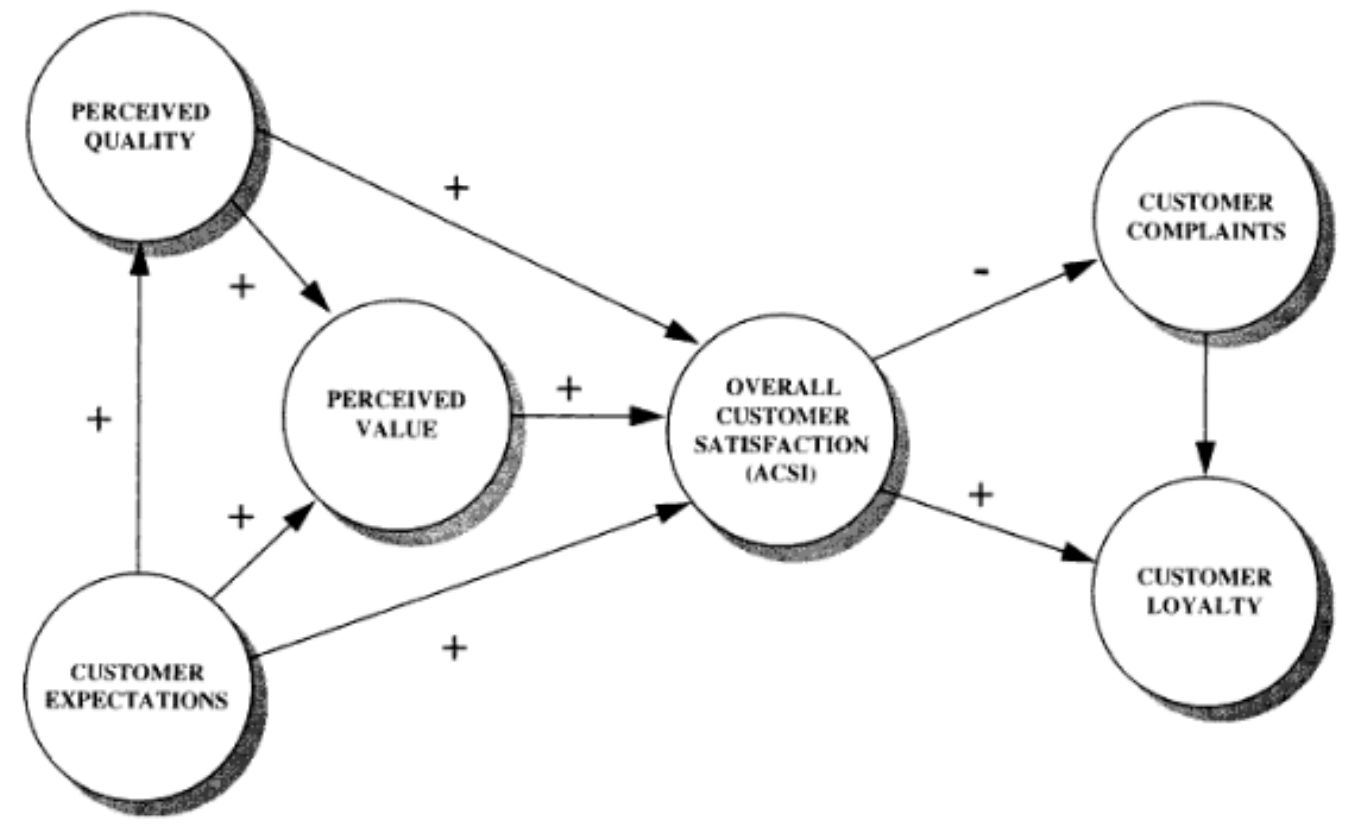

Figure 1.

The American Customer Satisfaction Index (ACSI) Model (Fornell et al., 1996)

Similar to service quality, elements of customer satisfaction can be contextspecific and influenced in many ways. Biscaia, Correia, Ross, Rosado, and Maroco (2013) studied the specific dimensions of game Atmosphere, referees, and player performance as three contributing sub-dimensions which have a positive relationship with service. Additionally, Biscaia et al. (2013) provided additional support of satisfaction mediating a relationship between service quality and future purchase intentions.

Further investigation into customer satisfaction by Yoshida and James (2010) revealed two distinct forms of customer satisfaction: game and service. Game satisfaction 
was most strongly predicted by game atmosphere, while hypotheses of a link between game satisfaction with opponent satisfaction and player performance were not supported. More importantly, service satisfaction was found to be significantly tied to stadium employees and stadium access. Since service satisfaction is more controllable than game satisfaction (which includes scheduling and team performance), implications from these findings should contribute to the argument for a heavier emphasis on service quality. However, the hypothesized connection between service satisfaction and future purchase intentions was only supported in one of the samples (Japanese), which is both puzzling and concerning since these findings would conflict with existing literature on broader service quality (Biscaia et al., 2013; Ko et al., 2005; Murray \& Howet, 2002). This finding could be interpreted as evidence against the investment of resources into improving service quality in the U.S., as the U.S. sample was more influenced by the outcome of the game and players, not service. This leads to the final implication of Yoshida and James (2010), which includes international differences in service quality of some countries as their study included a sample of Japanese fans as well as U.S. fans. The findings were consistent among items of service quality between the two groups, however the lack of subsequent ties to purchase intentions suggests while the factors of satisfaction remain the same overseas, the amount of influence this satisfaction imparts on customers may differ.

\section{Summary of Service Quality, Value, and Satisfaction Literature}

Service quality is based largely around seminal authors Parasuraman, Zeithaml, and Berry $(1985 ; 1988)$ and was shown to have a positive influence on consumer behavior, including purchase behavior. Additionally, service quality was shown to 
provide higher levels of customer satisfaction and increased perceived value, which moderate additional positive benefits between service quality and consumer behavior (Fornell et al., 1996). PZB (1985; 1988) suggested five dimensions of general service quality: reliability, assurance, tangibles, empathy, and responsiveness (RATER).

However, PZB also suggested the RATER model was a "skeleton" and should be adapted to business-specific contexts.

Sport business contains many elements which make it unique or different from general business, and the literature regarding each of these elements and their impact on service quality is important. First, since sport involves a dynamic, perishable product which is produced and consumed simultaneously, it meets the criteria of a service industry. Service quality in service industries is especially important; even considered a competitive advantage since the consumer cannot examine the product in depth prior to purchase. Additionally, service industry quality is more difficult to measure since it more subjective to the perceptions of the customer.

Business contain both core and peripheral products, and service quality can be evaluated for each. The core product consists of the primary process or structure which customers expect. Meanwhile, the peripheral products add "roundness" to the core product. Unfortunately, the core product in sport (the game on the field) is largely outside of the control of the organization, thus potential for improvement in service quality lies primarily in the context of peripheral products associated with the event. This suggests significant improvements in peripheral product service quality are required to influence consumer behavior. 
Hedonic consumption involves products in which the consumer is engaged in the transaction to achieve some emotion or arousal, vs. utilitarian consumption which involves functional practicality to the purchase. Sport consumers are highly identified with their respective teams, and such emotions tend to have a significant effect on service quality (Jiang \& Wang, 2006), suggesting sport consumption is a form of hedonic consumption. Thus, literature regarding service quality of hedonic products suggests perceptions of service quality will be heavily driven by emotions, marking yet another difference between sport and traditional business in the service quality context.

Sport service quality has been studied in many different areas. While many retained at least a few attributes of the RATER model developed by PZB (1985), few have retained all five. Common sport service quality literature has maintained the importance of the physical venue (Bateson et al., 1981; Theordorakis et al., 2001; Ko \& Pastore, 2005; Ko et al., 2011; Koo et al, 2015) as well as the peripheral items such as concessions, signage, and merchandise (Theordorakis et al., 2001; Ko et al., 2011; Koo et al., 2015). Many studies have also specifically targeted the interaction of stadium personnel and their impact on the perceived service or satisfaction of the customer (Langeard et al., 1981; Greenwell et al., 2002; Ko \& Pastore, 2005; Shapiro, 2010). While these studies found a positive relationship between service quality and consumer behavior on gameday, there is a lack of literature regarding customer interactions with personnel prior to the day of the game. Shapiro (2010) shed light on the pre-purchase consumers as his study of service quality on donor intentions found service quality did predict donor satisfaction but failed to predict longevity or donation amount. 
Ultimately, the literature suggests sport as a business is quite unique, and its consumers have unique needs and reasons for their consumption. Service quality literature has highlighted peripheral service attributes as the most promising element of service quality to target for improvement, yet the spectrum of the existing literature usually only encompasses consumers on the day of the game or event. Ultimately, the topic warrants additional research into the effectiveness and outcomes of service quality from a pre-purchase (box office) interaction, since this represents most consumers' first point of contact with the organization.

\section{Relationship Marketing and Relationship Quality}

Marketing, in its simplest sense, is intended to facilitate exchanges between customers and an organization (Houston \& Gassenheimer, 1987). More recently, attention has been brought to a more specific application of relationship-based marketing. Morgan and Hunt (1994) defined relationship marketing as "all marketing activities directed towards establishing, developing, and maintaining successful relational exchanges" (p. 22). Relationship marketing is also described as both an extension of- as well as a parallel to- service quality. Berry (1995) noted "The object of improving service quality, after all, is to engender customer loyalty. A natural extension of the strong interest in service quality is growing interest in relationship marketing" (p. 237). Thus, it is appropriate to review relationship marketing literature for the current study. Berry (1983) suggested a relationship-based marketing approach would center around building longer-lasting relationships with customers, rather than constantly marketing towards new customer acquisition. Studies have since suggested focusing marketing efforts 
towards long-lasting relationships reduce both costs and time expended (Nufer \& Buhler, 2010; Nufer, 2011).

\section{Relationship Marketing: The Process, Purpose, and Parties}

Relationship marketing literature typically identifies three distinct fundamentals: the process, the purpose, and the parties (Sheth \& Parvatiyar, 2000). Kim and Trail (2011) described the process as the activities which establish, enhance, and maintain relationships between the customer and the business. This would include the specific actions or promotions being taken on behalf of the organization which intends to build longer lasting relationships with their customers. The purpose of relationship marketing is generally straightforward; longer lasting relationships with customers have been shown to cost less and require less time (Buhler \& Nufer, 2010) as well as increased customer retentions (Kim \& Trail, 2011) and finally increased brand loyalty (Williams \& Chinn, 2010).

The parties of relationship marketing identify who is involved in the relationship. Morgan and Hunt (1994) identified 10 types of parties: (1) goods suppliers, (2) service providers, (3) competitors, (4) nonprofit organizations, (5) government (6) ultimate customers, (7) intermediate customers, (8) functional departments, (9) employees, and (10) business units. Morgan and Hunt (1994) posited these ten parties group into four different partnerships: supplier partnerships, lateral partnerships, buyer partnerships, and internal partnerships. Morgan and Hunt's (1994) model of relational exchanges was designed to conceptualize the different relationship marketing relationships which exist in business and is intended to allow future researchers to target individual, industry-specific relationships when studying relationship marketing. 
To this regard, Kim and Trail (2011) noted for sport organizations, the primary relationship marketing partner is the ultimate consumer, or sport consumer, which is part of the buyer partnership category. Kim and Trail's (2011) implication may suggest there is limited relational exchanges in sport, highlighting the need for further research into relationship marketing effectiveness, given its lack of outlets compared to many traditional business operations

\section{Relationship Marketing Mediators and Outcomes}

Morgan and Hunt (1994) noted two "essential ingredients" for effective relationship marketing: commitment and trust, both of which have become focal points for much of the relationship marketing literature. Palmatier et al. (2006) noted studies range in their emphasis on these two principles; some measure and highlight only one, while others may highlight both. Commitment refers to "an enduring desire to maintain a valued relationship" (Moorman, Zaltman, Deshpande, 1992, p.319). This represents the degree to which the exchange partner intends to remain in the partnership. Additionally, trust has been defined as "confidence in an exchange partner's reliability and integrity" (Morgan \& Hunt, 1994, p.23). While commitment and trust may be the two most common mediators, David (1995) noted customer involvement also maintains a high positive relationship with relationship marketing practices, and relationship marketing reduces the economic or social risk in some high involvement products.

The literature has measured successful relationship marketing using several different outcomes. Obviously, the goal of almost all relationship marketing activities is tied to increased profitability (Gronroos, 1990; Morgan \& Hunt, 1994; Davis, 1995; Shani 1997; Stavros et al., 2008). However, several other outcomes are often found in the 
literature. Increased customer loyalty is one common outcome of successful relationship marketing techniques (Palmatier et al., 2006) though some researchers have criticized this measurement due to other variables which may become barriers to customer loyalty (Oliver, 1999). Other outcome variables of interest in relationship marketing literature included relationship quality (Crosby et al., 1990) as well as positive word-of-mouth outcomes (Kim, Han, \& Lee, 2001), decreased risk in the relational exchange (Sheth \& Parvatlyar, 1995), and the acceptance of marketer-induced choice reduction (Kotler, 1994)

\section{Relationship Marketing in Sport}

Shani (1997) provided one of the first comprehensive models of relationship marketing in sport. Shani's (1997) work was developed upon the foundation of Gronroos (1990) who provided the initial three conditions for relationship marketing to be effective: it must be a product or service the customer desires on an ongoing basis, the ability for the customer to choose the business supplier, and an industry in which there are alternative suppliers. Shani (1997) posits sport to meet all three of these criteria. Drawing off the earlier works of Shani (1992) and Gronroos (1990), Shani (1997) posited a four-step approach to relationship marketing which included segmentation, niche marketing, database marketing, and ultimately relationship marketing. Additionally, the model developed by Shani (1997) posited the database marketing step of the process also benefited the database of the organization, providing a better ability to develop additional relationship marketing resources. Figure 2 shows the implementation of relationship marketing activities in the sport industry as described by Shani (1997) and visualizes the continuum between transactional marketing and relationship marketing. This model can 
be used to determine how effectively a particular business is implementing relationship marketing activities into their operations.

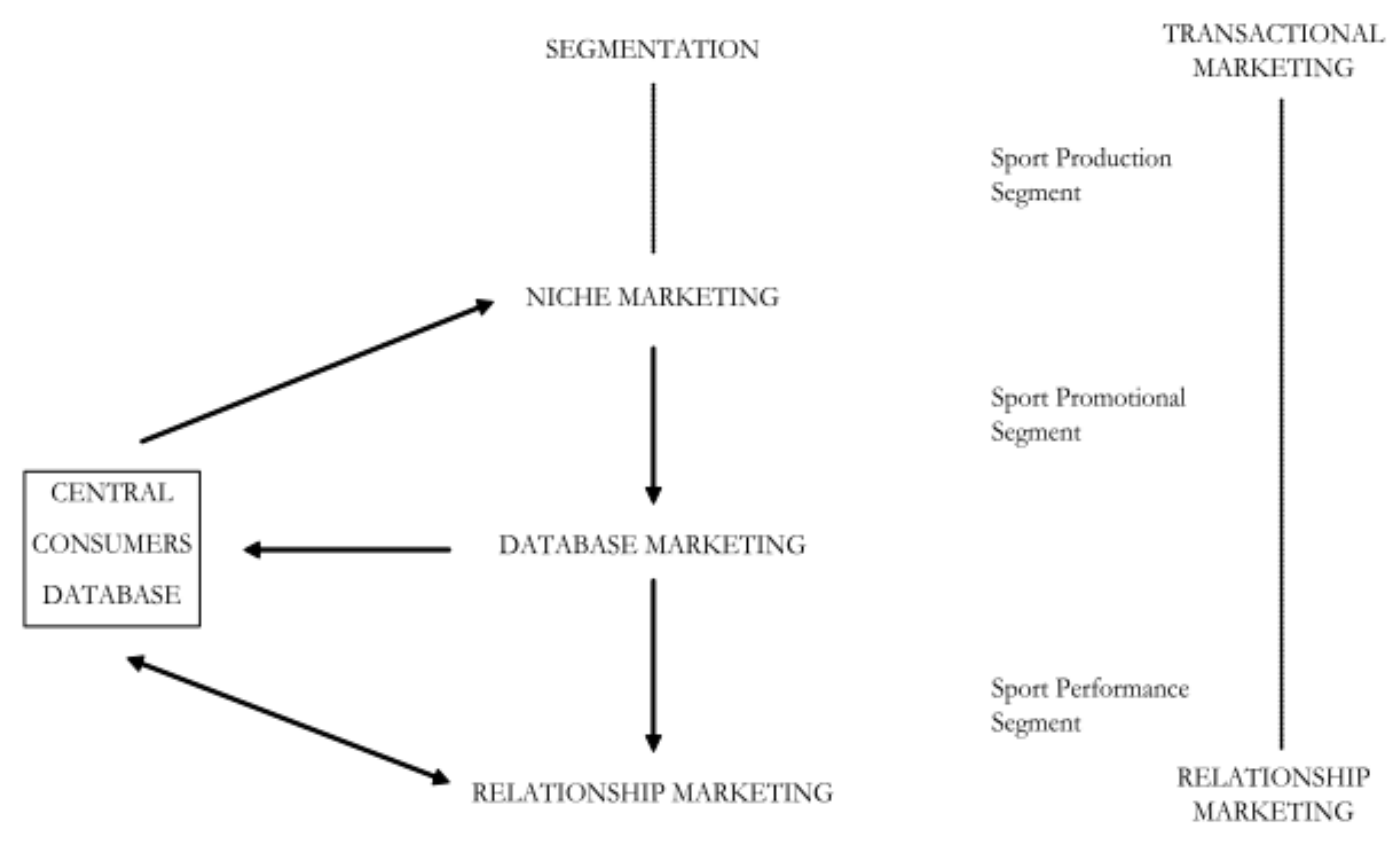

Figure 2.

Relationship Marketing Implementation in the Sport Industry (Shani, 1997, p. 13)

Other models regarding relationship marketing effectiveness have approached relationship marketing from a more applied approach. Bee and Kahle (2006) examined the literature surrounding attitude change along with its precedents and antecedents. Findings suggested compliance from sport consumers is superficial and temporary, requiring a constant commitment to relationship building. Additionally, the authors suggested identification plays a large role in relationship marketing and consumer internalization is the result of similar values between the sport organization and the consumer. Their conceptualization also brought unique aspects of sport to light: the authors noted sport consumers have many levels of attachment, commitment, and trust 
with the organization. As previously mentioned, trust and commitment are "essential ingredients" (Morgan \& Hunt, 1994), thus measuring relationship marketing effectiveness proves more difficult in a sport setting. Bee and Kahle (2006) noted "consumers may have trust in the sales agents, or people involved in the actual game experience, but have little trust in the coaching or management of the team". This implies researchers studying relationship marketing in sport must be very clear about the segment of the sport organization they wish to research and highlights the need for additional clarification in relationship marketing between the customer and the business operation of the team, rather than the overall team as a whole.

Bee and Kahle's (2006) implications of the need for more specificity have prompted many researchers to target individual aspects of sport for relationship marketing effects. Cousens, Babiak, and Bradish (2006) developed a conceptual framework for relationships between corporate partners in sport and the sport organization. They contended core competencies of the organization, as well as mutual benefits and the strength of the relationship between the organization and the sponsor all effect the degree to which successful relationship marketing practices are feasible. Their Framework for Assessing Sponsorship Relations (FASR) included a large emphasis on joint activity between the sport property and the corporate partners and illustrated the importance of relationship marketing in sport sponsorship.

Additionally, specific studies of relationship marketing on the business operations of sport included Tower, Jago, and Deery (2006), who qualitatively examined such a relationship in the context of Australian nonprofit sport. While the non-profit environment being studied was obviously quite different, the study focused on the 
marketing effects of actual business operations personnel, shining a unique perspective on the dilemma which can be applied across all sport businesses. Tower et al. (2006) concluded complementary expertise and knowledge result in positive relationship marketing outcomes, while poor communication, staff turnover, lack of satisfaction, and incompatible management styles all contribute to unsuccessful relationships. Interestingly, ticket sales researchers examining personnel relationships in unsuccessful box office operations would later mirror nearly identical findings (Bouchet et al., 2011).

\section{Relationship Quality}

More recently, relationship marketing literature has developed the framework of relationship quality, which focuses on measuring the strength of the relationship between the customer and the organization (Palmatier, 2006). While relationship marketing literature discusses different business marketing concepts and their theoretical effects from the business perspective, relationship quality literature differs in its approach by focusing on the perspective of the customers themselves and is generally interested in measuring the strength of the relationship. In essence, relationship quality is often used as an indicator of effective or ineffective relationship marketing and is described as psychological construct developed by the consumer, rather than the organization.

Benefits of Relationship Quality. Kim and Trail (2009) highlighted the lack of literature on relationship quality in sport management and suggested five ways in which measuring relationship quality in sport would be beneficial based on business literature. Relationship quality measurements may be used to diagnose problems in the relationship between the customer and the organization (Roberts, Varki, \& Brodie, 2003) as well as an evaluation tool which may be used to measure the effectiveness of a relationship 
marketing campaign (De Wulf, Oderkerken-Schroder, \& Lacobucci, 2001). Additionally, Kim and Trail (2009) also suggested relationship quality measurement could be used to coordinate various relational constructs in sport. Fourth, relationship quality could be used as a measurement tool to differentiate between successful and unsuccessful relationships (Smit, Bronner, \& Tolboon, 2007). Lastly, Kim and Trail (2009) suggested a scale to measure relationship quality would benefit sport organizations as they would have an effective means of measuring customer equity which is becoming increasingly important to stakeholders (Wiesel, Skiera, \& Villanueva, 2008)

Conceptual Framework of Relationship Quality in Sport. Kim and Trail (2011) suggested a theoretical model of relationship quality in sport. Drawing on the existing literature, the authors proposed five constructs in their theoretical framework: trust, commitment, intimacy, self-connection, and reciprocity. The authors proposed these constructs would be influenced by psychological and demographic characteristics and would ultimately impact consumer behavior in four different outcomes: increased word of mouth promotion, increased media consumption, increase purchase of licensed merchandise, and finally increased attendance to events.

Figure 3 represents Kim and Trail's (2011) proposed conceptual framework which includes the five constructs of relational selling as well as the outcomes of relationship quality in sport. The model suggests the five proposed constructs of relationship quality may be impacted by psychological characteristics (such as passion) as well as demographic characteristics (such as income), this highlights the need for control variables to minimize the effects of some psychological characteristics on the 
behavioral outcomes, as well as the need for a demographically representative sample when conducting research on sport behavioral intentions.

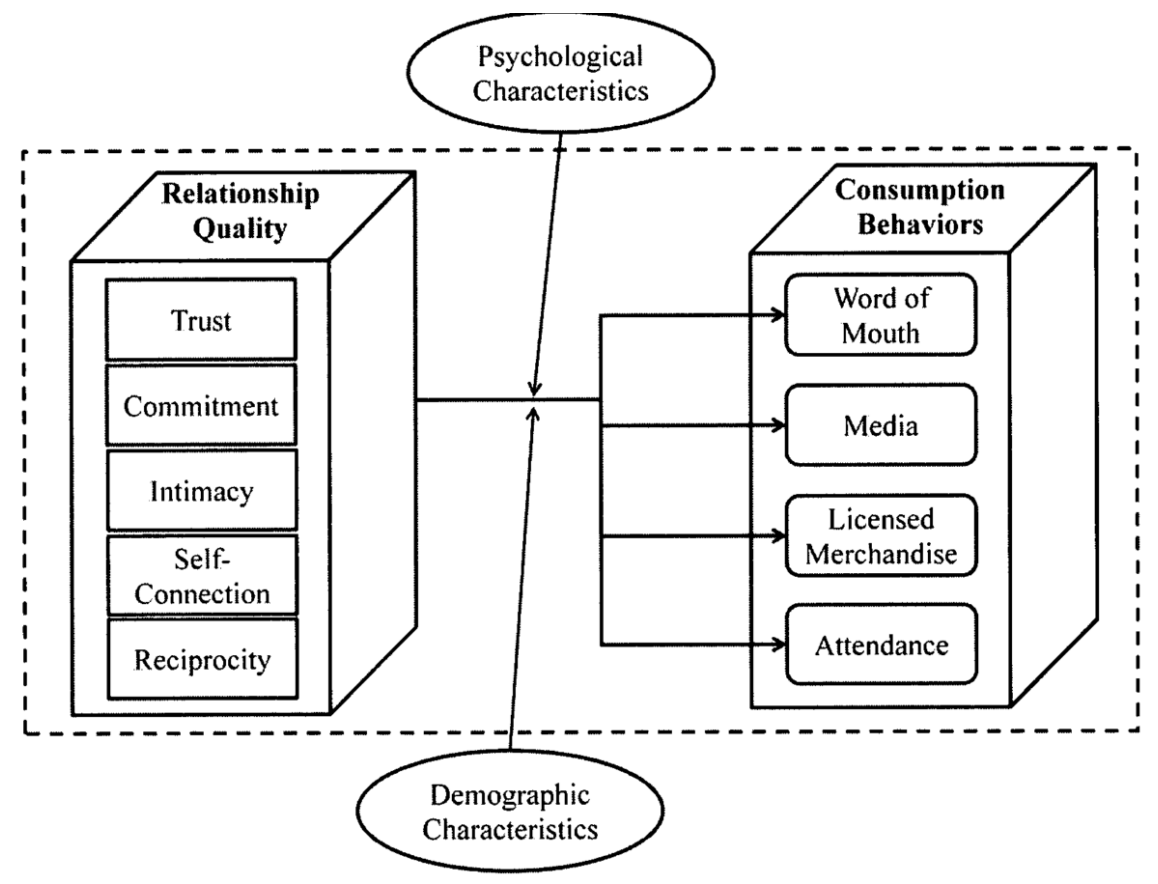

Figure 3.

Proposed conceptual framework for relationship quality in sport (Kim \& Trail, 2011)

Constructs of relationship quality. Trust is one of the most common constructs discussed in relationship quality literature (Dwyer et al., 1987; Morgan \& Hunt, 1994; Palmatier et al., 2006). Trust refers to the degree in which the consumer believes the other person in a relationship is reliable, has high integrity, and unlikely to engage in devious behavior (Morgan \& Hunt, 1994). Trust has been examined in the sport context, with literature suggesting individuals who trust in an organization are more willing to become repeat purchasers and may pay higher prices (Chen, 2006). Commitment, similarly, to trust, has been identified as paramount in relationship quality. Commitment refers to how an exchange partner "believing that an ongoing relationship with another is 
so important that it warrants maximum efforts in maintaining it" (Morgan \& Hunt, 1994, p. 23). The presence of commitment towards a continued relationship is what differentiates relational partnerships from functional ones (Levy \& Weitz, 2004). Selfconnection has been identified as a parallel to team identification (Kim \& Trail, 2011) since both concepts are rooted in Identity Theory (Stryker, 1968). Self-connection leads consumers to develop loyalty towards a product due to protective feelings of perceived uniqueness or dependency (Drigotas \& Risbult, 1992). The construct of intimacy is similar to self-connection, however it includes a degree of separation between the individual and the organization, whereas self-connection refers to overlap between the individual and the organization (Kim and Trail, 2011). Intimacy in a consumer behavior context refers to the degree of familiarity, openness and closeness in a relationship (Fournier, 1998). A third construct of relationship quality described by Kim and Trail (2011) includes reciprocity, which has been defined as a social norm which obligates behavior based on past behavior (Gouldner, 1960). Reciprocity has been discussed as important in relationship quality literature (Miller \& Kean, 1997, De Wulf et al, 2001) and builds on the exchange relationship between the consumer and the organization (Larson, 1992).

Relationship Quality Scale Development. Answering Kim and Trail (2009)'s call for an instrument to measure relationship quality in sport, Kim et al. (2011) developed the Sport Consumer-Team Relationship Quality Scale (SCTRQS). The purpose of the SCTRQS was to develop a measure which allows for the assessment of service quality between the sport consumer and the team. The SCTRQS was developed through a multi-step process. First, items were developed through the literature and input 
of primary researchers of the study. Next, a focus group of undergraduate and graduate students were given the definitions of each subscale and asked to assign each item in the appropriate subscale. After revisions were made based on student feedback, the items were sent to a panel of experts in both scale development as well as relationship marketing. Finally, the items in the scale were evaluated using an exploratory factor analysis. Results of the EFA indicated good fit $\left(x^{2} / \mathrm{df}=463.74 / 242=1.92\right.$, RMSEA $=.08$, $\mathrm{CFI}=.91, \mathrm{SRMR}=.07)$ and the researchers proceeded to the second phase of the study (Kim et al., 2011).

The second phase of Kim et al.'s (2011) study consisted of a quantitative examination of relationship quality using the SCTRQS. 652 individuals associated with a southeastern university. A confirmatory factor analysis fit the data well (S-B $\mathrm{x} 2 / \mathrm{df}=232.43 / 80=2.91, \mathrm{RMSEA}=.06, \mathrm{CFI}=.98, \mathrm{SRMR}=.04$ ), and the data confirmed the five-factor model suggested by Kim and Trail (2011) with trust, commitment, intimacy, self-connection, and reciprocity as subscales of the SCTRQS. Lastly an additional quantitative cross-validation used spectators at two minor league baseball games. Model fit indices showed no significant changes, suggesting the SCTRQS may be used in various sport settings, despite its development using a college student sample.

\section{Relationship Marketing and Relationship Quality Summary of Literature}

Relationship marketing refers to marketing with an emphasis on long-term relationships rather than short term transactions. Implementation of a relationship-based marketing approach is identified through three fundamentals: the process, the purpose, and the parties (Sheth \& Parvatiyar, 2000). Kim and Trail (2011) suggest the sport marketing process involves the actions taken by the sport organization, while the purpose 
is tied to customer loyalty and revenue generation, and finally that the customer is the party of interest.

Effective relationship marketing has numerous positive outcomes. Studies show marketing is tied to increased profitability (Gronroos, 1990; Morgan \& Hunt, 1994; Davis, 1995; Shani 1997; Stavros et al., 2006) as well as increased relationship quality (Crosby et al., 1990), positive word-of-mouth (Kim et al., 2001) and higher likelihood to accept marketer-induced choice restriction (Kotler, 1994). Shani (1997) posited sport meets the criteria for effective relationship marketing and provided a framework for applying relationship marketing concepts to the sport industry. Shani (1997)'s model included a linear four-step process which involves segmentation, niche marketing, database marketing, and ultimately relationship marketing.

Relationship quality is a measurement of the strength of a relationship between customers and the organization. It differs from relationship marketing because it is typically measured from the perspective of the consumer and is subjective from one consumer to another. In other words, relationship marketing is a framework or approach to a business process, while relationship quality tends to be a more specific positive outcome one hopes to achieve through relationship marketing. Relationship quality in sport has been measured using a five-factor structure which includes trust, commitment, intimacy, self-connection, and reciprocity (Kim \& Trail, 2011; Kim et al., 2011). Additionally, it has been suggested specific outcomes of relationship quality in sport would include positive word-of-mouth communication, increased media consumption, increased licensed apparel purchases, and increased attendance (Kim \& Trail, 2009; Kim \& Trial, 2011; Kim et al., 2011). 


\section{Relationship Selling}

The current study will involve an element of service quality which is specific to the interaction between the customer and the box office. In business literature, interactions with sales representatives designed to promote long-term relationships are often discussed as Relationship Selling (RS) techniques. RS has been defined as a "multistage process that emphasizes personalization and empathy as key ingredients in identifying prospects, developing them as customers, and keeping them satisfied.” (Jolson, 1997). Additionally, relational approaches to selling have been identified as important to developing long term relationships (Dwyer, Schurr, \& Oh, 1987).

Many studies in relational selling are grounded in Social Exchange Theory (SET), which suggests behaviors during interactions are governed by a balance of rewards and costs consciously or subconsciously weighed by the individuals engaging in the conversation (Emerson, 1976). SET suggests people only engage in relationships to the degree in which the outcomes from such a relationship are favorable. When customers recognize a strong relationship between themselves and a sport organization, it can add value to the exchange decision. As such, relational selling could be identified as a factor which leads to more favorable exchanges and ultimately a higher perceived value to the product (tickets).

Avila and Inks (2017) outlined exchange theory in their detailed process for relational selling (also described in the article as "trust-based sales"). The authors posited the relational selling process includes a three-step process: first the salesperson will initiate a relationship with the customer. This consists of strategic prospecting, as well as assessing the situation of the customer, their needs, and their wants. Next, the sales 
representative will develop the relationship with the customer by adding value-based dialogues which validate the value added to the customer and earns their commitment. Finally, the salesperson will enhance the customer relationship with post-sale follow up, continual assessment of the performance of the relationship, and the creation of new opportunities to add value. While many studies have discussed adding value to the exchange between the customer and the sales representative, Avila and Inks (2017) demonstrated a concise process which offered a clear and direct roadmap to relationship selling practices, while being general enough to apply to all industries

While no study currently investigates relationship selling in a college athletics setting directly, the theoretical framework and literature surrounding relational selling may provide insight and implications which will guide the current study. Literature regarding relational selling commonly includes four primary themes: a customer-oriented selling philosophy, the use of adaptive selling techniques, the development of a relationship with the customer, and the presence of an expertise or competitive advantage from the interaction with a salesperson. This section will cover literature on social exchange theory, as well as all four of these themes found in the conceptual frameworks, and their outcomes.

\section{Customer Orientation}

Customer Orientation Framework. One tenet of relationship-based selling includes an emphasis on a customer-oriented business perspective (Keillor, Parker, \& Pettijohn, 1999; Arli, Bauer, \& Palmatier, 2017). Customer Orientation (CO) has been described as "the altering of sales behaviors during a customer interaction or across customer interactions based on perceived information about the nature of the selling 
situation" (Weitz, Sujan, \& Sujan, 1986, p. 175). However, prior to the term "Customer Orientation" being coined and further researched, scholars have described similar concepts using terminology such as "concerned with self" vs "concerned with others" (Blake \& Mouton, 1970) as well as "customer" vs. "task" oriented. Such terminology is inconsistent, though more recent literature typically describes the phenomena as "customer orientation".

Saxe and Weitz (1982) provided a detailed review of customer orientation, suggesting it as a salesperson behavior trying to offer a solution to customer needs during the selling process. Salespeople who demonstrated high levels of customer orientation were those who provided a low-pressure sales environment, a genuine concern for the best interest of the customer, and a problem-solution approach to selecting the most appropriate products for their customer. These hypotheses were studied in a survey of 208 salespeople within 48 sales firms to identify specific items which predicted the level of customer orientation each salesperson demonstrated. The result of Saxe and Weitz (1982)'s work framed the development of the Service Orientation Customer Orientation (SOCO) scale and provided an opportunity to measure the effects of a customer-oriented selling approach in business.

Customer Orientation Outcomes. The development of the Service Orientation Customer Orientation (SOCO) allowed researchers to draw initial relationships between customer orientation and performance. Saxe and Weitz (1982) found the SOCO scale to positively predict success in a sample of retail salespeople and suggested customer orientation led to long-term customer satisfaction and low pressure selling. 
Continued research on customer orientation has shown a primarily positive association with many consumer behavior outcomes. Stock and Hoyer (2005) distinctly separated and measured customer orientation attitudes with customer orientation behavior and found customer orientation attitudes has a significant impact with customer satisfaction directly, while a second significant path was shown as customer orientation attitudes also increased customer orientation behavior which was significantly related to satisfaction. The authors noted this as an interesting finding because the customer satisfaction was not entirely moderated by the behaviors of the salesperson. Thus, Stock and Hoyer (2005) concluded a customer may "pick up" positive attitudes and emotions from the salesperson and are more satisfied with their purchase even if the salesperson wasn't performing customer-oriented tasks. This conclusion implies businesses who are weak on customer orientation practices at the firm level (such as college athletics) may improve satisfaction through the salesperson's attitude. In other words, even if a business were not practicing customer-oriented marketing concepts, an individual salesperson may be able to increase customer satisfaction themselves by adopting a customer-oriented attitude.

Keillor, Parker, and Pettijohn (1999) noted relationships between customer orientation and performance in their examination of relational selling approaches and its effect on the performance and job satisfaction of salespeople. Their study involved a nationwide sample of 126 responses from a professional sales organization. Results from regressions suggested both customer and service orientations significantly predicted increased satisfaction with sales performance, while adaptability and professionalism did not. This finding suggests not only an increase in sales performance itself from a 
customer-oriented selling philosophy, but also an increase in the level of job satisfaction from employees. The lack of a significant relationship between adaptability and job satisfaction as a seller are interesting since the findings conflict with the existing literature.

Loyalty has also been shown as a positive outcome of customer orientation. A hierarchal model developed by Homburg, Muller, and Klarmann (2011) tested hypotheses regarding customer loyalty, defined as "expressed preference for a company and intention to continue purchase[ing] from it" (p. 799). Their data included a collection of not only salespeople, but sales managers as well. Data was collected from six difference industries and included samples from 12 organizations. Homburg et al.'s (2011) findings suggest increased levels of customer orientation over a task orientation results in higher customer loyalty. While confirming another implication regarding the performance of salespeople, this study was one of the first to highlight intention of continued purchasing behavior, which draws similarities to the season ticket renewal aspect of the current study. Since season ticket renewals are the largest revenue stream among ticket sales, the Homburg et al.'s findings are important for the current study, suggesting customer orientation (and relationship selling practices in general) may be beneficial in promoting season ticketholder loyalty.

\section{Adaptive Selling}

Adaptive selling behavior framework. Adaptive selling behavior (ASB) is characterized by the degree to which salespeople shape their message and behavior as an interaction continues. Weitz (1981) discusses characteristics of ASB in his conceptual framework involving the interactions of effective salespeople. Weitz (1982) noted 
salespeople who are practicing high levels of adaptive selling behavior will gather information before the interaction and customize content for more effective communication. Additionally, those practicing ASB will also change their message throughout the interaction when needed. Those not practicing ASB are more likely to recite a "canned" or scripted message which is universal to customers.

Spiro and Weitz (1990) further investigated the framework of ASB, identifying several characteristics, traits, and practices which would lead to increased levels of ASB. The authors found the level of ASB was predicted by the factors of presentation modification, sensitivity, androgyny, perspective talking, social self-confidence, intrinsic motivation, personal efficacy, and interpersonal control. The authors also hypothesized the factors of "sales experience" and "tolerance of freedom" from sales managers would yield a significant correlation, though the results did not justify these hypotheses. Spiro and Weitz (1990)'s work suggests ASB is complex, and the salespeople who practice it have a wide variety of personal characteristics which may contribute to their ASB behavior.

It is worth noting not all literature agrees on the order of ASB and relational selling practices. Han, Herjanto, and Gaur (2014) proposed a conceptual framework for information overload in adaptive selling. Their model (Figure 4) suggested relational selling is actually an antecedent of ASB as opposed to previous research which has described ASB as a characteristic of relational selling. Their model suggested the relationship between sales performance and ASB is moderated by the relational selling activities and the customer orientation of the salesperson. More importantly, Han et al., (2014) suggested when salespeople provide an abundance of options or "information 
overload", it would negatively affect their ability to practice ASB as well as their sales performance. Implications from this study would suggest it is important for sellers to provide necessary information without overwhelming the customer. This becomes a fine balancing act for the salesperson when fit into context with the relational selling literature on the necessity of product knowledge and expertise usually seen as a benefit to relational selling.

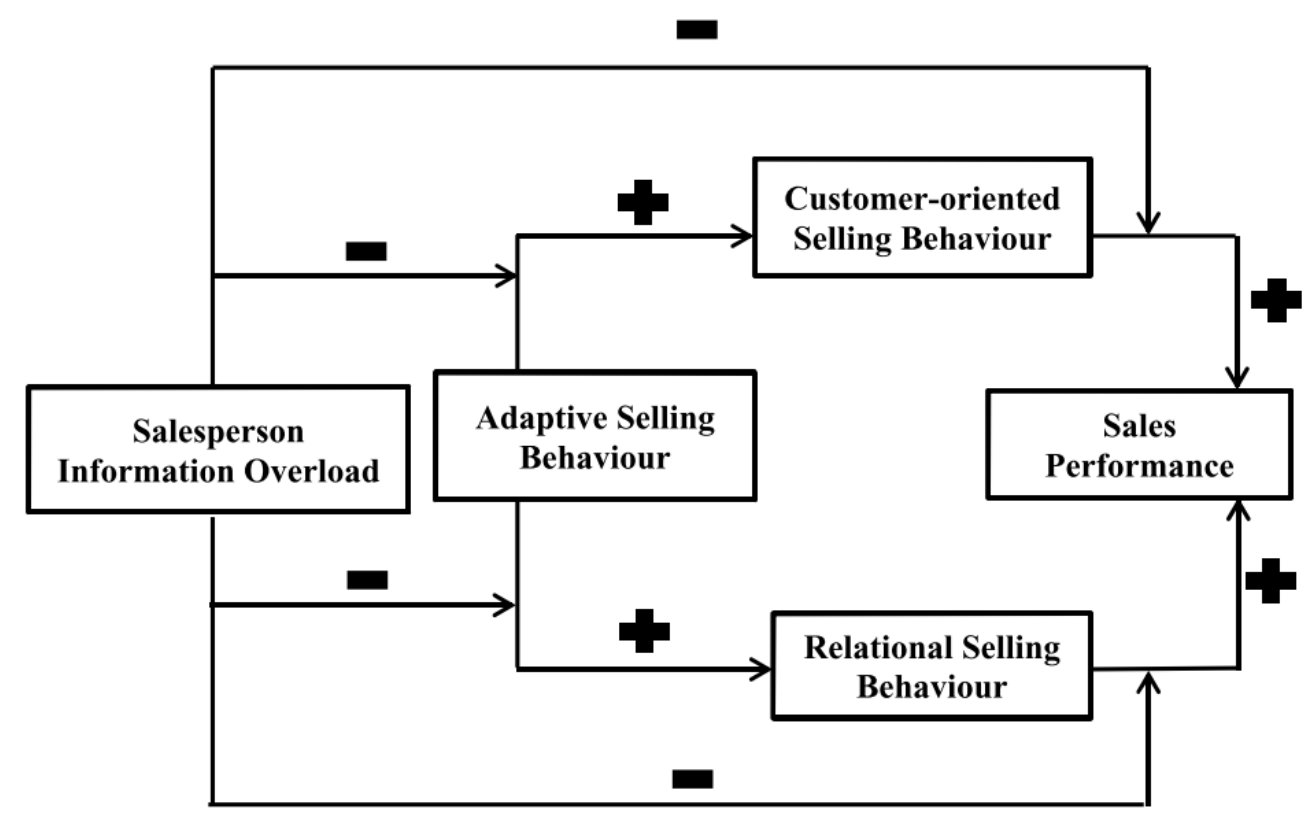

Figure 4.

Proposed Model for Salesperson Information Overload (Han et al., 2014)

Adaptive selling behavior outcomes. When sales success is demonstrated by achievement of sales goals, Weitz (1981) supported the notion that ASB leads to increased sales performance, though the literature conflicts in some regards. Much of the literature establishes a positive link between ASB and performance among studies which examined multiple different industries (Goolsby, Lagace, \& Boorom, 1992; Porter et al., 2003). However, some studies which have targeted specific industries and the 
relationship between ASB and performance have yielded mixed results. For instance, two studies which targeted the success of pharmaceutical sales representatives (Weilbaker, 1990) found no significant relationship between the application of ASB and sales performance in the pharmaceutical industry. This suggests the effectiveness of ASB may be industry-specific; its use will greatly benefit one company, while another in a separate industry may see no significant difference. As a result, the authors encouraged further research to be industry-specific and for researchers to avoid overly-generalized samples.

In a study of expensive retail sales (jewelry and others), Wieske, Alavi, and Habel (2014) studied the multiple different sales concepts and their relationship to customer loyalty. One piece of this study involved the degree to which negotiation and adaptive selling impacted the loyalty of the customer. The authors found loyal customers expected to be rewarded for their loyalty, however ASB techniques could alleviate some pricing concerns and negative impacts of high-value items. Results of their study is generalizable to ASB behaviors (and sport sales) because many retail industries rely on salespeople for their higher inventory items (such as premium tickets in a sport setting). Thus, ASB are deemed appropriate and effective for increasing customer loyalty for high-priced items.

Other researchers have investigated performance indirectly similarly to Wieske et al. (2014). Roman and Iacobucci (2010) studied the relationship between 210 salesperson-customer dyads. This work took a unique approach by measuring the ASB of the seller, but also the outcome behaviors of their respective buyer, offering a unique perspective on the relationship. ASB increased the performance of not only the seller, but the customer's evaluation of the seller and the perceived customer orientation of the salesperson's firm. Additionally, confidence mediated ASB and performance (though 
ASB was correlated with performance directly as well). This study's findings suggest ASB behaviors have numerous positive outcomes, including increasing perceived trust of the company, as well as perceive customer orientation. Ultimately, the authors conclude ASB behaviors further develop relationships between not only the salesperson and the customer, but also between the customer and the organization for whom the salesperson works.

\section{Relationship Building and Customer Perspectives.}

The seminal studies in relational selling (Weitz, 1981; Weitz, 1982; Weitz, 1990) identified relationship building as an important pillar, though much of the literature fails to address this concept specifically. This phenomenon may be largely due to the emphasis on collecting data from the salespeople themselves. Measuring the level of relationship building in a salesperson/customer relationship would require input from the customer, which is not within the scope of many early studies on RS. Crosby, Evans, and Cowles (1990) targeted not only the marketing philosophy of customer orientation, but specific areas of relationship selling practices. Their work was unique as it focused on the quality of the salesperson-customer relationship as perceived by the customer. By drawing from literature surrounding personal interaction and customer satisfaction, authors identified four components of relationship selling development which can be identified by the customer themselves: One of such components is mutual disclosure (Derlega, Winstead, Wong, \& Greenspan, 1987), which was noted to be a reciprocal event; customer disclosure and salesperson disclosure were both separately measured. Additional indicators of RS included cooperative intentions (Pruitt 1981) and interaction intensity (Williamson, 1983). In Crosby et al. (1990)'s study, trust and customer satisfaction were 
identified as attributes of relationship quality (RQ) towards the salesperson; a higherorder construct.

Aside from the four factors of relationship building factors described by Crosby et al. (1990), other researchers have discovered additional factors. Drollinger and Comer (2012) identified listening skills as an important component of relationship development, which was positively correlated with the salesperson's communication skills, relationship quality and trust. Furthermore, relationships between customer and salesperson have been found to exist both at the employee levels well as the firm level, as trust in a salesperson and trust in an organizational firm may differ (Foster \& Cadogan, 2000), though it was also found trust in the salesperson led to higher levels of trust in the organization and increased purchase intentions.

While previous literature highlighted the importance of relationship building practices from firms, few studied the effectiveness of different relationship building strategies themselves. Ryu and Feick (2007) studied how referral programs develops the relationship between the customer and the organization. They found the way firms emphasize the importance of the relationship with the customer includes the use of loyalty programs which often include an incentive to refer other customers to the company. Their findings showed loyalty programs as effective in developing relationships between an organization and the customer. Furthermore, organizations with such strong relationships were more likely to benefit from customer referrals. The findings were especially true among weaker brands and bolster current relational selling literature. 
Relationship building outcomes. Crosby et al. (1990) noted initial positive correlations with salesperson performance. Their study measured sales success as a gross amount of life insurance purchased through the salesperson, as well as the likelihood an individual may recommend their salesperson to others and the likelihood a customer would increase their policy (upselling). However, since the initial findings of Crosby et al. (1990), the outcomes of relationship building from a sales perspective has been measured in many ways.

Anderson and Weitz (1989) studied long-term relationships in business in a study of over 690 salespeople and their respective firms. They found the strength and age of the relationship were important in predicting not only sales success, but also trust towards the organization, two-way communication. Implications of Anderson and Weitz (1989) suggest trust is both an important precedent for relationship building, as well as an antecedent to a strong relationship. Additionally, the study suggests two-way communication is imperative in building long term relationships and promotes trust between the parties. However, it is important to note this study was conducted within the context of business-to-business sales, which may limit generalizability to business-tocustomer sales.

Hughes, Le Bon, and Rapp (2013) studied relationship building in the form of relationship strength between the customer and the organization along with the relational selling components of customer orientation and adaptive selling. Their study aimed to predict the impact of such behaviors on competitive intelligence, while also measuring the effect of competitive intelligence on perceived value to the customer, and profit 
margin on sales. Their findings suggest building relationship quality creates a competitive intelligence in business which gives the firm an advantage over other firms. This advantage is then translated to the customer using adaptive selling techniques, which in turn increase the perceived value to the customer. While their work suggests a complex relationship, it also highlights the use of relationship building practices and customer orientation as an actual competitive advantage for organizations who choose to invest their resources into it. Their findings also suggest adaptive selling techniques assist in leveraging the perceived value to the customer.

Ultimately, literature suggests an emphasis on relationship building from the salesperson leads to positive consumer behavior, which is not uncommon from other literature. However, the inclusion of the above studies highlighting the same phenomena from the perspective of the buyer themselves further strengthens the argument for the use of relational selling techniques.

Expertise and Competitive Advantages. Crosby et al. (1990) first suggested relational selling strategies are most effective in an industry where the product is complex, or when the buyer is unsophisticated. However, the literature has developed this idea into suggesting the use of relational selling strategies creates a "competitive advantage" or "competitive intelligence" for many different products and organizations (Hughes, Le Bon, \& Rapp, 2013).

According to Thompson et al. (2005), products which are complex require a greater share of the customer's cognitive resources. Thus, as the product becomes more complex, the customers face a greater uncertainty and rely on the salesperson to 
understand its features and potential consequences (McQuiston, 1989). This thought is connected to the relational selling literature of Homburg Muller, and Klarmann (2011), who studied the degree to which product complexity had a moderating effect on the effectiveness of customer orientation and relational selling. Their results suggested customer orientation is significantly moderated by the complexity of the product, however interestingly there was not found to be a moderating effect on customer loyalty based on complexity. Their findings suggest mixed implications; on one hand, the complexity of the product was significantly related to the level of perceived customer orientation. Previously literature shows support customer orientation's correlation with multiple consumer behavior outcomes, (Saxe \& Weitz, 1982; Homburg et al., 2011; Hughes, Le Bon, \& Rapp, 2013). However, Homburg et al (2011) found no significant differences in customer loyalty with regards to the complexity of the product.

\section{Relational Selling Literature Summary}

Social exchange theory suggests consumers will engage in the activity they feel provides the most value. Relationship selling techniques have been suggested to add value in the social exchange, thus making consumers more likely to purchase tickets. Additionally, ticket sales representatives are often the first point of contact between a spectator or consumer and the athletics departments. Since ticket sales tends to be the "front lines" of communication between the school and the customer, "interaction quality" mentioned in previous literature will be first represented in the relationship between the customer and the box office. This means the ticket sales representative is responsible for making the first impression on the customer (and theoretically, the beginning of the social exchange). Business literature on relational selling includes a 
framework of four concepts: a customer-oriented business philosophy, the use of adaptive selling techniques, the development of a long-term relationship with the customer, and the value of the salesperson's expertise.

While all four of these concepts have been shown to increase sales effectiveness in terms of purchase likelihood (Saxe \& Weitz, 1982; Crosby et al., 1990; Thompson, 2005; Roman \& Iacobucci, 2009), each of these concepts has shown distinct outcome benefits as well. For instance, customer orientation offers increased salesperson job satisfaction (Keillor, Parker, \& Pettijohn, 1999), while adaptive selling behaviors is connected to increased loyalty (Weiske et al., 2014) and relationship building techniques provided higher levels of trust among customers (Anderson \& Weitz, 1989) and builds "competitive intelligence" (Hughes, Le Bon, \& Rapp, 2013). The expertise of the salesperson was found to be especially important for complex businesses or those catering to unsophisticated customers (Homburg, Muller, \& Klarmann, 2011).

Ultimately, the relational selling literature consistently suggests benefits of relational selling are industry-specific (Crosby et al. 1990; Weilbaker, 1990; Wieske, Alavi, \& Habel, 2014), suggesting each study and measurement should be adapted to the specific business industry which is targeted. Lastly, to properly examine relational selling literature measurements to the college athletics landscape, it is necessary to review the literature on ticket sales in college athletics.

\section{Ticket Sales in Spectator Sport}

There has been little attention given to the topic of ticket sales regarding box office operations, as much of the ticket sales-specific research has been devoted to pricing (Drayer, \& Shaprio, 2009; Shapiro \& Drayer, 2012; Dwyer, Drayer, \& Shapiro, 
2013). Pricing is outside the scope of this study, however there are other areas of the literature which may be useful in drawing implications for the current study. The following subsection will address three areas of literature on ticket sales in spectator sport: First, the box office's direct impact on consumer behavior in sport will be discussed. Next, the literature surrounding ticket sales training in sport will be reviewed from both organizational and educational perspectives. Lastly, literature investigating possible pitfalls or unsuccessful box office operations will be highlighted.

\section{Box Office Influence on Consumer Behavior}

Theodorakis and Alexandris (2008) investigated the connection between service quality and behavioral intensions in professional soccer and included ticket personnel in their measurements. The previously mentioned SPORTSERV instrument (Theodorakis et al., 2001) was utilized as a predictor variable in measuring outcomes of repurchase intentions as well as word-of-mouth communications (intention of saying positive things). Findings suggest personnel and reliability predicted repurchase intentions, while tangibles, responsiveness, and reliability all predict increased word of mouth communication. Results from this study suggest the actions of service personnel influence repurchase intentions. Drawing implications of box office employees from this study is difficult, as the instrument references the employees of the organization as a whole. Additionally, the SPORTSERV model only encompasses the customer experience close to game day. This suggests further research is still necessary to draw implications specifically pertaining to box office employees and warrants more attention to the broader spectrum of the customer experience. 
In a more recent study, Warren (2016) studied the impact of ticket sales using social media as a platform to develop a relationship between the sales representative and the customer. Warren (2016) posited social media selling can benefit the sales representative throughout the sales process, allowing for personal communication and the discovery of customer needs in a way which was less intrusive than the "cold call" concerns identified by Theodorakis and Alexandris (2008). Warren (2016) found the social media platform LinkedIn was the most popular method of active social selling, though social media was used scarcely across of sport for sales purposes. Additionally, the study found high-performing salespeople tended to be more active on social media with their customers than low-performing salespeople, further implicating relational selling techniques as an effective tool in the sport sales process.

Greenwell, Brownlee, Jordan, and Popp (2008) identified the importance of service fairness in box office operations. Their study aided in policy development revolving around college athletics ticketing, noting customers felt less dissatisfied with unfavorable policies when they felt they had a choice in the implementation of the policy, as well as when the tickets were free. This study did not directly measure customer interaction with box office employees, however instead targeted the policies enforced by the box office and its effect on customer satisfaction. Since previously literature has linked satisfaction closely with service quality and purchase intentions (Taylor \& Baker, 1994; Cronin, Brady, \& Holt, 2000; Kuo, Wu \& Deng, 2009), this suggests service fairness (and ultimately service quality) may play a role in satisfaction, and ultimately customer purchase intentions in college sport. 
Reese and Bennett (2010) investigated the importance of several box office strategies and their effects on consumer behavior regarding spectators of a minor league franchise. This study did not collect perceptions of interactions between the customer and the box office per se, however it measured the perceived value and satisfaction of strategies such as television, radio, ticket discounting, and phone sales. The authors found phone sales were not perceived as an effective method of increasing ticket sales from the fans. However, Reese and Bennett (2010) concluded phone sales are still effective, despite being disliked and possibly considered "intrusive" from some fans. Accordingly, the authors suggest more research into the cause of negative perceptions of "cold calling" warrants more attention.

Answering the call from Reese and Bennett (2010), Smith and Roy (2011) addressed the negative perception of sales representatives and suggested a marketing oriented, long-term focus on customer retention may lead to increased customer retention. The purpose of their study was to develop a conceptual framework for ticket sales organizations to follow in their selection, training, and incentive structure of ticket sales professionals. Their framework tied together elements of both relationship quality as well as relationship selling, emphasizing the need for a marketing orientation from the organization.

Smith and Roy (2011) claimed a marketing focus from a sales perspective would place importance on building long-term relationships between the organization and the customer. This implication would parallel much of the relationship marketing literature and further justify the current study. Additionally, Smith and Roy (2011) addressed the perspective of the salesperson themselves, their model noting a customer orientation as 
more important in creating customer satisfaction and loyalty. This implication also mirrors the relationship selling literature, grounding the second purpose of the study.

\section{Ticket Sales Operational Failures}

The current study addresses the problem of how to improve box office operations in intercollegiate athletes. While there is a gap in the literature providing example of successful box office operations, some researchers have highlighted the pitfalls of athletics ticket sales. Bouchet et al. (2011) outlined a detailed account of a failed ticket sales operation at the University of Miami. The qualitative study involved years of personal notes as well as interviews conducted with multiple stakeholders in the outbound sales effort. One of the major findings from their work included the lack of priority placed on ticket sales from upper administration. The researchers found ticket sales offices were often viewed as entry level and less desirable than other high-profile jobs. Such findings are consistent with other researchers suggesting the entry level perception of ticket sales as a problem (Smith \& Roy, 2010; Irwin \& Sutton, 2011; Popp, 2014)

Additionally, the researchers found administrators in charge of athletics ticket sales often came from backgrounds of corporate sponsorship or development (donations). While claiming solicitation of a million-dollar donation is no easier or harder than selling a million dollars' worth of tickets, the authors posit the skills required to do so are quite different. This lack of experience in ticket sales led to a high turnover from both the sales force as well as administration, as the direct supervisor to the department was replaced four times in ten years (Bouchet et al., 2011). Interestingly, the factors of unsuccessful ticket sales operations were nearly identical to the factors of unsuccessful relationship 
marketing campaigns from Tower et al. (2006), suggesting one of the reasons in which box office ticket sales are struggling may be related to the lack of relationship-driven activities.

Adding to the literature on box office operations, Irwin and Sutton (2011)

discussed many issues in the sport ticket sales landscape by highlighting areas of inefficiency similarly to Bouchet et al. (2011). Their work was separated into two areas: hiring/recruitment and sales training. The purpose of their study was to offer tactics which could be implemented by box office management to improve sales operations, while also highlighting areas in which the existing practices of box office practices may be performing poorly. Two primary areas for improvement were detailed in the study: recruitment/retention and training. Suggestions for recruitment and retention included more full-time positions, additional full-time training and recruiting staff, and acquiring both new talent (young sales representatives) as well as veteran talent on the sales team.

Many researchers have suggested additional full-time employees may prove useful in improving box office operations (Irwin \& Sutton, 2011, Popp, 2014) however the financial reality of limited budgets and inflexible organizational structures prove to be barriers in this regard, especially in college athletics (Popp, 2014). Thus, researchers trying to improve ticket sales operations are left with attempting to improve the existing staff for many organizations rather than expand them, highlighting the need for literature regarding sales training.

\section{Ticket Sales Training in Sport}

Previous research has highlighted inefficient sales practices as a cause of ticket sales struggles, and the current study wishes to examine relational selling practice in 
sport. Thus, it is important to review the literature regarding the current training practices in order to determine whether concepts of relationship quality or relational selling behaviors are cultivated in ticket sales professionals to begin with.

Despite recommendations for at least two weeks of training before with new employees (Irwin, Sutton, \& McCarthy, 2008), Popp and McEvoy (2012) found such a training policy is almost non-existent as over 78 percent of athletics departments spent fewer than 20 hours per year, and 32 percent of departments reported no formal training whatsoever. Irwin and Sutton (2011) also suggested much of the troubles of box office operations stem from too little training, both initially and ongoing. Instead of 3-10 day "Crash courses" in ticket sales training, they suggest organizations invest into continuing training processes. The implications from McEvoy et al., (2012) as well as Irwin and Sutton (2011) highlight the need for additional training, and the warrant further investigation into what sales training methods have proven effective. The context from Irwin and Sutton's (2011) work was applied to collegiate sport specifically when Wanless \& Judge (2014) reviewed the findings of Irwin \& Sutton (2011) and emphasized them as a possible remedy to financial issues caused by increased coaching salaries and facility costs in college sport.

Effectiveness in sales training was examined by Popp, Simmons, and McEvoy (2017) in their study regarding differences of different training methods, highlighting differences in perceived effectiveness between sales managers and sales representatives. Eleven common training methods were included a survey to both sales representatives and sales managers, asking the perceived effectives of each method. Effectiveness of five of the eleven training methods were found to be significantly lower in sales 
representatives than sales managers: informal coaching, manager reviews, role playing, face to face reviews, and formal self-evaluation. Additionally, informal coaching was found to be most effective from the perspective of the sales managers and sales representatives. Popp et al.'s (2017) findings suggest managers should place increased importance on the continued coaching of their sales representatives.

Shreffler, Schmidt, and Weiner (2018) investigated the effectiveness of sport management education on training sales personnel. As the literature has noted, ticket sales tends to be an entry-level job in sport, and the education which students receive during higher education may be the first framework in sales training for young ticket sales professionals. The study interviewed hiring managers for sales positions and examined what factors these managers found important in making their hiring decision. While experience appeared to be the most prominent factor in predicting sales success, multiple managers emphasized the need for sales professionals to acquire "soft skills", such as the ability to listen and understand a customer or have a comfortable conversation. In fact, multiple managers referenced relationship building specifically and suggesting long-term relationship building has become more important in their training

and hiring processes. Thus, the findings of Shreffler et al., (2018) suggest the importance of relational selling skills in sales training at all levels, including those prior to employment.

\section{Ticket Sales in Spectator Sport Literature Summary}

No literature directly has measured relational selling or relationship quality among box office employees in college athletics. However, ticket sales literature shines light on both the problem as well as the purpose of this study indirectly by highlighting 
the current state of ticket sales operations in spectator sport. Implications from the literature in ticket sales guides the current study by examining purchase intentions, the perceived impact of service quality (and possibly relationship quality) on consumer behavior, the presence (or lack thereof) of relationship quality in modern-day ticket operations, and finally the reasons for the possible lack of relationship quality which is suggested in the literature.

Interactions involving service personnel in a sport organization have been shown to predict customer satisfaction and repurchase intention (Theodorakis et al., 2008), though the spectrum of service personnel varies, and box office effects were not specifically separated. However, the effects of the box office have been shown to have similar impacts on constructs such as service fairness (Greenwell et al., 2008). Specific strategies to increase positive consumer behavior were identified by Reese and Bennett (2010), who found digital platforms such as email were preferable to customers as opposed to phone calling, which may be intrusive (though effective) suggesting while the effectiveness of phone-based ticket sales is important, there may be problems with the current landscape of box office operations (Reese \& Bennett, 2010.

Such problems are specifically highlighted in a line of literature examining why box office operations have failed. Multiple researchers have noted the causes of box office pitfalls as a lack of commitment from upper management, constant turnover, lack of training, and inefficient communication (Bouchet et al., 2011). These pitfalls mirror the indicators of poor relationship marketing practices highlighted by Tower et al., (2006), suggesting a lack of training regarding relationship-based approaches to selling may benefit box office operations. This implication is addressed directly in Smith and 
Roy's (2011) framework which highlights the need for long-term relationships in sales organizations.

In order to determine the presence and effectiveness of relationship-based sales practices, literature regarding sales training is addressed. The literature suggests ticket sales operations are often grossly understaffed (Irwin \& Sutton, 2008; Popp, 2012) and viewed as a less desirable position (Bouchet et al., 2011; Popp, 2012). Additionally, sales staffs have been found to be under-trained in general (Irwin \& Sutton, 2011; Popp et al., 2012). Some effective methods of training are identified (Irwin \& Sutton, 2011; Popp et al. 2017), and relationship-building skills have been identified as essential to hiring managers looking to recruit ticket sales professionals (Shreffler et al., 2017), thus confirming speculations suggested by Smith and Roy (2011): a stronger relationshipbased approach is needed in box office operations and further warranting the current study.

\section{Summary of Literature}

Literature regarding service quality, relationship quality, and consumer behavior in college athletics is still in the early stages of development. However, the existing literature outside of sport suggests improving service quality may provide a benefit to businesses looking to improve customer satisfaction or perceived value. Additionally, literature shows the original RATER model used by PZB $(1985 ; 1988)$ should be modified to fit whatever industry is being studied, and results of service quality studies in sport have shown common components as well as some unique components to each realm of sport. 
Relationship marketing is paramount in service industries such as sport, and Shapiro (2010) found pre-purchase service quality is a predictor of donor behavior. Since many athletics donations are related to ticket sales, these findings suggest service quality of the perceived customer may be influenced by those who interact with the customer prior to gameday. However, most of the service quality instruments which have been developed focus on a scope of service quality which begins only at the day of the game, and pre-purchase interactions are often left out of the framework.

Pre-purchase interactions with the customer are most likely to occur at the box office, making the box office a target for improved service quality. One method of improving customer service highlighted in the literature involves a focus on building long-term relationships between the organization and the customer. Building relationships between a sales representative and a customer has been examined in the context of relational selling, which suggests customers engage in a social exchange and will behave in the manner they believe provides the best value. Building a relationship between a sales representative and a customer adds value to the social exchange, thus making the organization or product more desirable to the customer.

Existing literature on ticket sales in college athletics is scarce, however some studies have implicated a possible connection between service quality and purchase behavior in this area. Additionally, studies which highlight failures in college athletics have paralleled those which preceded relationship marketing failure. Thus, the existing literature in college ticket sales may suggest there is a lack of relationship-driven sales approaches in college athletics, and further investigation in the presence and effectiveness of relationship selling is warranted. 


\section{CHAPTER III}

\section{METHOD}

This chapter discusses the methodology which was applied to address the study's purposes and research questions. Specifically, this chapter will reviews the research design of the study, as well as the participants, data collection procedure, instrumentation, and data analysis.

\section{Purpose of the Study}

The purpose of this study was to examine the impact of relationship quality and relationship selling techniques on consumer purchase intentions in Division I college football. Relationship quality refers to the strength of the relationship between the consumer and the organization and has been suggested as diagnostic tools to evaluate relationship marketing efforts (Kim \& Trail, 2009), and associated with increased purchase behavior (Kim et al., 2011). While relationship quality emphasizes the larger scope of the consumer-organization relationship, relationship selling refers to a specific exchange between customers and individual members of the organization (sales representatives). Relationship selling has also been shown as effective in increasing sales performance in other industries (Han et al., 2014). Given the unique nature and strength of the bond between consumers and college sport, it is important to examine how to leverage such relationships in order to potentially benefit the bottom line. 


\section{Research Questions}

RQ1- Which aspects of relationship quality (trust, commitment, intimacy, selfconnection, and reciprocity) predict sport consumer purchase intentions in Division I college football?

RQ1a- Which aspects of relationship quality (trust, commitment, intimacy, self-connection, and reciprocity) predict season ticket renewal intentions for the following season?

RQ1b- Which aspects of relationship quality (trust, commitment, intimacy, self- connection, and reciprocity) predict willingness to purchase additional football season tickets for the following season?

RQ1c- Which aspects of relationship quality (trust, commitment, intimacy, self-connection, and reciprocity) predict willingness to purchase more expensive football season tickets for the following season?

RQ1d- Which aspects of relationship quality (trust, commitment, intimacy, self-connection, and reciprocity) predict willingness to purchase new tickets of any kind to a different sport of the same college or university?

RQ2- Which aspects of relationship selling practices (interaction intensity, customer disclosure, agent disclosure, cooperative intentions) predict sport consumer purchase intentions in Division I college football? 
RQ2a- Which aspects of relationship selling practices (interaction intensity, customer disclosure, agent disclosure, cooperative intentions) predict season ticket renewal intentions for the following season?

RQ2b- Which aspects of relationship selling practices (interaction intensity, customer disclosure, agent disclosure, cooperative intentions) predict willingness to purchase additional football season tickets for the following season?

RQ2c- Which aspects of relationship selling practices (interaction intensity, customer disclosure, agent disclosure, cooperative intentions) predict willingness to purchase more expensive football season tickets for the following season?

RQ2d- Which aspects of relationship selling practices (interaction intensity, customer disclosure, agent disclosure, cooperative intentions) predict willingness to purchase new tickets of any kind to a different sport of the same college or university?

\section{Research Design}

To investigate the research questions listed above, a cross-sectional survey was utilized. Cross-sectional survey design utilizes a sample from a representative subset in order to make implications regarding the larger population. Cross-sectional study designs have the benefits of being able to examine current phenomena while only requiring a relatively short time to achieve the results (Creswell, 2008). Furthermore, a quantitative methodology allows the researcher to statistically investigate responses from the sample 
and interpret the results, which was determined to be the best fit for this study due to the fact that the majority of instruments used to measure both relationship quality as well as relationship selling utilize numerical data.

\section{Study Participants}

The target population for this study included Division I college football season ticketholders in the United States. By examining season ticketholders, the study will highlight consumers who are more likely to develop strong relationships with the institution (Gladden, George, \& Sutton, 1998), and potentially be more impacted by relationship selling practices (Howard \& Crompton, 2004). Additionally, the current study examined Football Bowl Subdivision (FBS) schools only due to the fact that ticket sales make up far more of their revenue portfolio when compared to other divisions or subdivisions (Fulks, 2016). Table 1 demonstrates the sources of revenues and their percentage as a representation of total revenues, emphasizing the decision to focus on

Division I-FBS.

Table 1

Sources of Revenues and Percentage of Ticket Sales as a Revenue Stream

Division I - FBS Division I - FCS Division II

\begin{tabular}{llll}
\hline Ticket Sales (median school) & $\$ 8,992,000$ & $\$ 457,000$ & $\$ 50,400$ \\
Cash Contributions (median school) & $\$ 9,531,000$ & $\$ 909,000$ & $\$ 299,000$ \\
Total Generated Revenues & $\mathbf{\$ 4 7 , 9 6 2 , 0 0 0}$ & $\mathbf{\$ 4 , 0 4 7 , 0 0 0}$ & $\mathbf{\$ 7 3 4 , 0 0 0}$ \\
\hline$\%$ Ticket Sales to Generated Revenue & $18.7 \%$ & $11.29 \%$ & $6.87 \%$ \\
$\%$ Contributions to Generated Revenue & $19.87 \%$ & $22.46 \%$ & $40.74 \%$ \\
\hline
\end{tabular}

* Division III Sources of Revenues are not provided by the NCAA

**Data from the NCAA Revenues and Expenses Report 2004-2015 median values (Fulks, 2016) 
This study required two sets of participants. Research Question 1 sought to examine which aspects of relationship quality predict consumer behavior among Division I football season ticketholders. This research question targeted the entire population of season ticketholders regardless of whether or not they spoke with the box office. However, Research Question 2 examined how aspects of Relationship Selling predicted consumer behavior. This requires the customer to have had a relational exchange with the box office, and therefore was limited to participants who engaged in a phone conversation with respect to purchasing their season ticket. It is worth noting RQ2 included customers who engaged in a conversation with the box office over the phone and purchased at a later date via another method (email, mail, etc.). In order to separate the two sets, all participants were given the questions related to RQ1, while those who indicated they had spoken with the box office were provided with a set of questions pertaining to RQ2 as well.

\section{Sampling and Data Collection Procedure}

This section discusses sampling and data collection procedures. In order to utilize a probability sample, the researcher must be able to claim the sample of participants being examined is representative of the target population, thus allowing the researcher to make generalizations from the sample with respect to the population (Creswell, 2008).

\section{Sampling Technique}

This study implemented a voluntary-response sample. Voluntary response sample techniques include a solicitation from the researcher and a voluntary participation from the respondents. This technique is popular with researchers in situations where 
guaranteed access to the entire population is indefinite or impractical. Since it is unlikely or impossible to be granted access to every college football season ticketholder, this study invited subjects to participate. Voluntary-response sampling maintains two considerable disadvantages in research design. First, the researcher loses control of the makeup of participants (Moore \& Kirkland, 2007). This is best addressed by examining demographics of the sample in order to make sure it is representative of the population. Additionally, voluntary-response sampling lends the risk of responses being weighted by strongly opinionated participants. While it is difficult to mitigate this risk entirely, it is minimized when the topic being examined is not one of an extremely controversial nature (Moore, 1997) and will be further addressed in the next section regarding reasons for selecting the Mechanical Turk sampling procedure.

\section{Sampling Method}

The Amazon Mechanical Turk platform (MTurk) was utilized to access the sample for this study. MTurk offers the ability for researchers to reach large, diverse groups of sports fans in an affordable and timely nature. MTurk data collection is conducted when the researcher (or "Requester") posts a specific Human Intelligence Task (HIT) to for a group of individuals (called "Workers") to complete. When a Worker completes a HIT, they are given a monetary reward which can be used on the Amazon.com marketplace.

There are multiple benefits of using MTurk for data collection. Most notably, the relatively inexpensive cost for each completed HIT (as low as \$.01) allows for affordable mass data collection. Also, having over 500,000 potential Workers allows for timely data 
collection, often within days. Furthermore, MTurk allows for researchers to demand higher levels of accuracy, as some Workers are classified as Master-level after demonstrating qualifications of the ability to accurately complete HITs. Master Workers are generally more desirable to researchers due to their pre-qualification as quality survey participants. Furthermore, MTurk allows the ability to instantly disqualify respondents who do not meet the criteria to be included in the sample. Lastly, MTurk allows for better generalizability than many other forms of commonly accepted research methodology; a study by Berinsky, Huber, and Lenz, (2012) found MTurk samples to be more representative than convenience samples or student samples, both of which are common in educational research. Furthermore, MTurk responses from Master Workers have been shown to contain less non-serious and pattern responses.

While there are many benefits of MTurk utilization, there are also reasons for concern. MTurk Workers tend to be younger than the general population, report a lower income, and more likely to be unmarried (Berinsky et al., 2012). Comparing Berinsky et al., (2012) MTurk demographic data to SBRnet (a service which provides sport demographic information), it appears younger MTurk workers are more representative of college football fans than the general population in some regards. Table 2 combines literature of SBRnet college sports fans and Berinsky et al. (2012) MTurk workers in both age and income. While general MTurk workers are actually more representative of college football fans in terms of age and race, they are less representative in terms of marital status and income. However, this study examined college football season ticketholders within MTurk workers, rather than the general MTurk population. This 
highlights the importance of capturing the demographic data of MTurk college football season ticketholders for examining generalizability, as they may differ from general MTurk workers. Demographic comparisons between the participants of this study and the general population of college football fans is discussed in more depth within Chapter IV.

Table 2

Demographic Comparisons Between College Football Fans and MTurk Workers

$\begin{array}{ccc}\text { MTurk Workers } & \text { College FB Fans } & \text { US Population } \\ \text { (Berinsky et al., } & \text { (SBRnet, 2014) } & \text { (Berinsky et al., }\end{array}$
2012) 2012)

\begin{tabular}{lccc}
\hline Age & 32.3 (mean years) & 34 (median years)* & 49.7 (mean years) \\
Racial Majority & $83.5 \%$ (white) & $82 \%$ (white) & $77.3 \%$ (white) \\
Marital Status & $39 \%$ (married) & $51 \%$ (married) & $56.8 \%$ (married) \\
Income (household) & $\$ 45,000$ (median) & $\$ 72,900$ (median) & $\$ 69,000$ (median)
\end{tabular}

*Data regarding mean age was not available through SBRnet.

Additionally, researchers have highlighted concerns of MTurk workers predisposed knowledge of the study impacts results. Follmer, Sperling, and Suen (2017) note it is important to determine the level of knowledge the researcher wishes the participants to have. Studies which require the participant to be naïve to the subject matter would not be appropriate to MTurk utilization. Additionally, Follmer et al. (2017) mirrored the concerns of Berinsky regarding demographic generalizability, noting the overrepresentation of Asians among the minorities of MTurk workers in the United States. Lastly, Follmer et al. discussed concerns over trends of MTurk workers gravitating towards study topics of which they already have an interest, limiting their use in studies which desire a truly random sample to include individuals who may have no interest in the topic. 
Concerns regarding MTurk generalizability of samples warrant examination for the current study. The data collected in the MTurk sample were compared with demographic data from previous studies as well as data from SBRnet. These demographics were compared for similarity to ensure the sample for this study was representative to the population of college football season ticket holders. Additionally, the minority representation specifically should be examined in-depth, as Follmer et al. (2017) noted even among the racial minority, some demographics may be overrerepeated. Furthermore, the concern regarding workers being attracted to studies in which they already have an interest is not necessarily a problem for the current study, given the fact that our desired population must be a season ticketholder, and therefore likely to already have an interest in sport regardless of sampling method.

While Amazon MTurk provides both benefits and challenges to the current study, it was ultimately deemed appropriate for two reasons: First, it allows for a pragmatic collection of a nationwide sample. While soliciting multiple athletics departments to access season ticketholder databases was an option, it was unlikely the necessary amount for a generalizable, nationwide sample could be recruited. If only a few schools participated, the sample would be skewed towards the characteristics and demographics of those schools, limiting generalizability. Additionally, relationship quality has already been examined in the context of a single institution (Kim et al., 2011; Wang, Ho, \& Zhang, 2012), thus to add robustness to the literature, a nationwide sample is more appropriate. 
Secondly, MTurk was chosen as an appropriate method of collection to limit sample bias. While soliciting schools for access to season ticketholders may offer an opportunity for direct contact to the population, it also creates voluntary-response bias. Voluntary response samples often include a bias towards individuals with strong opinions or experiences, positive or negative (Wilson \& Journell, 2011). This study examined the strengths of relationships between consumers and organizations and interactions with box office personnel. A sample skewed by those with either extremely positive or extremely negative experiences would significantly impact the implications. Since MTurk workers' motivations are more likely to be driven by the financial incentive, the sample is less likely to be skewed towards passionate responders. This becomes especially important when interpreting the normality assumption given the nature of Likert scales. This will be discussed in more detail later.

\section{Data Collection Procedure}

The study was hosted using Qualtrics survey software and stored on a password protected computer only accessed by the primary researcher. Following Institutional Review Board approval, the Qualtrics survey was made available on MTurk. This study also utilized a two-step data collection procedure, first qualifying the respondents as appropriate for the sample and then administering the survey.

All participants were first shown a confidentiality statement and IRB approval notification prior to beginning the survey, and the contact information for the primary researcher was provided. The first step of the data collection procedure involved a highvolume qualification survey. An initial qualifying HIT was posted on MTurk asking 
workers to identify whether they are season ticketholders, as well as whether or not they spoke with the box office when purchasing their tickets in the prior season. This method is preferable as it limits the possibility of workers lying to access the survey. In fact, workers did not know which qualifications are required to participate in the larger survey, and all workers were compensated $\$ .03$ for their participation in the brief qualification survey, regardless of whether they were selected for the larger, longer survey for this study. This first step allowed the researchers to generate a large amount of qualified, confirmed season ticketholders for both required samples of this study.

After the initial larger qualification survey, respondents were "tagged" in the MTurk system based on their season ticketholder status and whether or not they spoke with the box office in purchasing their tickets. The larger MTurk HIT including the instrument for this study was offered to all participations who were pre-qualified. Respondents were be compensated $\$ .50$ after completion of the survey. Respondents who elected not to finish the survey were removed from the data. No identifying information was collected. Following data collection, the MTurk task was closed and the data exported to SPSS for analysis.

\section{Instrument}

The questionnaire contained four sections: (1) relationship quality, (2) relationship selling, (3) purchase behavior, and (4) demographic information. The full survey can be found in Appendix A. 


\section{Relationship Quality}

RQ1 involves measuring the strength of the relationship between consumers and the sport organization as a whole (relationship quality). The most popular instrument in measuring sport relationship quality was developed by Kim and Trail (2011), who further examined the proposed model from their earlier (2009) literature and found a five-factor model. The five factors in Kim et al.'s (2011) Sport Consumer-Team Relationship Quality Scale (SCTRQS) included: trust (3 items), commitment (3 items), intimacy (3 items), self-connection ( 3 items), and reciprocity (3 items). All of the items were measured using a 7-point Likert scale $(1=$ Strongly disagree to $7=$ strongly agree $)$. The SCTRQS was developed using a sample of 154 college students. Kim et al.'s (2011) SCQRTS model fit the data well (RMSEA=.06, CFI=.98, SRMR=.04), and the Cronbach's alpha coefficients ranged from .83 to .95 , indicating good internal consistency (Nunnally, 1978). Furthermore, the Average Variance Extracted value ranged from .62 to .86 , indicating good construct reliability, since large amounts of explained variance (greater than .5) suggest evidence of convergent validity (Hair et al., 1998).

The SCTRQS has also been used empirically as well. After initially developing the scale, Kim et al. (2009) cross-validated its use in a sample of college baseball fans. The SCTRQS showed good fit to the data $(\mathrm{RMSEA}=.041, \mathrm{CFI}=.980, \mathrm{SRMR}=.033)$ and Cronbach's alpha coefficients ranged from .82 (reciprocity) to .95 (commitment). Thus, while still a relatively new instrument, the SCTRQS has shown to be an effective measurement in college athletics settings. 


\section{Relationship (Relational) Selling}

RQ2 examines which aspects of relationship selling (also called relational selling) affect purchase behavior in Division I college football. Relationship selling measurements have largely been measured the seminal work of Crosby et al. (1990). Crosby et al. (1990) identified three aspects of relationship selling activities: interaction intensity, mutual disclosure, and cooperative intentions. Additionally, mutual disclosure is a multi-factor construct consisting of agent disclosure as well as customer disclosure. Interaction intensity refers to the frequency in which the salesperson communicates with the customer, for either personal or business purposes, and demonstrates a commitment to the relationship (Williamson, 1983). Additionally, mutual disclosure measures the degree to which the relational selling behavior is regarded as a reciprocal relationship, strengthening the trust in the relationship (Derlega et al., 1987). Finally, cooperative vs. competitive intentions measures the degree to which the customer believes the salesperson has their best interest in mind (Crobsy et al., 1990; Kim \& Cha, 2002).

The original instrument of Crosby et al. (1990) consisted of 27 items: interaction intensity included 8 items, mutual disclosure included 13 items ( 5 items for agent disclosure and 8 items for customer disclosure), and cooperative intensions included 5 items. However, considering the specific and individual nature of relationship selling, authors have adapted the scale for industry-specific applications. The initial measurement from Crosby et al. (1990) studied whole-term life insurance as the sales industry. However, the three factors of Crosby et al.'s (1990) instrument have been utilized in service industries such as the hotel industry (Kim \& Cha, 2002), as well as communications firms (Boles, Johnson, \& Barksdale, 2000), online banking (Mukherjee 
\& Nath, 2003), commercial banking (Perrien, Filiatrault, \& Richard, 1993), and upscale retail stores (Macintosh \& Lockshin, 1997).

While the context of the items is often quite different as it is adapted to the industry, factors of interaction intensity, mutual disclosure, and cooperative intentions often remain. The current study will maintain all of Crosby et al.'s (1990) original factors of measurement, however the wording of the questions will be adapted from the context of whole-term life insurance to college ticket sales. For instance, the item "I was contacted by my sales agent who wanted to make changes to my policy to better suit my needs" was changed to "The [university] box office contacts me if there are tickets that better suit my needs". Appendix A contains the full instrument which was used, though modifications was done following the panel of experts and pilot procedures.

\section{Consumer Purchase Intentions}

Consumer purchase intentions were the outcome variables of interest for the current study. The study focused on four aspects of purchase intention: season ticket renewal (RQ1a, RQ2a), season ticket upsell in ticket volume (add-on tickets) (RQ1b, RQ2b), season ticket upsell in ticket value (RQ3a, RQ3b), and finally the cross-sale of season tickets to another sport (RQ4a, RQ4b). These items were measured using singleitem measurements. Single item constructs have been found acceptable in cases where the construct being measured is a "concrete singular," "easily understood," "easily and uniformly imagined," and when the researcher believes additional items will add no further robustness to the factor being studied (Rossiter, 2002; Bergvist \& Rossiter, 2007). 
RQ1a and RQ2a center around the likelihood season ticketholders will renew their tickets for the following year. This was measured using a single-item measurement of "I plan to renew my season tickets in the future" anchored in (1) strongly disagree to (7) strongly agree. RQ1b and RQ2b center on the likelihood of purchasing additional season tickets and were measured with the item "I plan to purchase additional season tickets in the future". RQ3a and RQ3b involve upselling in regard to purchasing more desirable tickets and asked "I would upgrade my season tickets into a better location, if given the opportunity". It is important to note the wording of this item since there is a qualifying statement at the end of the question. This is due to the popular nature of sporting events, and the possibility a fan may wish to upgrade their tickets but be unable to do so due to availability. By adding a qualifying statement to the end of the question, it measures the research question under the assumption fans may have an opportunity to upgrade. RQ4a and RQ4b examine the likelihood of a "cross-sell," which is uncommon in many sport organizations, though a unique opportunity for college sport. This item read "I plan on purchasing season tickets for a different [university athletics department name] team which I did not purchase this previous year." This item was also anchored in (1) strongly disagree to (7) strongly agree. The use of single item measures were used according to guidelines of Rossiter (2002) and Rossiter (2007), since the question is direct enough that little robustness would be added through multiple items on the same outcome.

\section{Control Variables}

Passion. In order to isolate the variables of interest for this study (relationship quality and relationship selling), it was necessary to control for outside variables which 
may influence the outcome variable (purchase intentions). Passion has been shown to be a significant predictor of sport attendance (Wakefield, 2016), and thus important as a control variable to ensure any differences being examined can be attributed to the predictor variables and not a fan's level of passion. The four-item passion scale was selected because it more strongly predicted attendance when compared to several popular measurements used in the past such as fan identification (Wann \& Branscombe, 1993), social identification (Mael \& Ashforth, 1992), and team commitment, familiarity, and image (Kim et al., 2011). The passion scale AVE (.89) was greater than the recommended value of .5, and the Cronbach's alpha (.90) was greater than the recommended .80 (Wakefield, 2016), therefore the convergent and discriminant validity of the scale were found acceptable, and the scale was deemed a good fit for the study. Passion was also measured on a 7-point Likert scale anchored in 1 (strongly disagree) to 7 (strongly agree).

Team performance. Along with passion, the performance of the team following the season has been shown to be a significant predictor of intention to renew tickets (McDonald \& Stavros, 2007; Pan \& Baker, 2005; Tapp, 2004). Again, this effect must be controlled to isolate the variables targeted for this study. A measurement of wins and losses would not be appropriate because success is subjective. One fan may be very happy with an 8-win season, while another may be disappointed. Thus, the customer's perceptions of success in the previous season was measured using a single-item measurement of "please rate your level of satisfaction with your team's performance for the 2017 season". 


\section{Demographic and Ticket Information}

Several demographic variables were collected in order to ensure the sample is representative of the target population. Common demographic variables to ensure representativeness include age, gender, marital status, education level, and household income. Additional demographic information including the length of season ticketholder status, estimated amount of purchase, and alumni or employee status was collected to ensure the sample is representative of not only the customer population, but also finer demographics related more specifically to ticket sales. This helped identify any skewness among the specific population (i.e. over-representation of high-end donors or customers, over-representation of university employees, etc.).

\section{Pretesting}

It is important for a researcher to pre-test the instrument they plan on examining the larger population. Thus, a series of pretests were performed for this study. The pretest phase of this study included three steps: (1) a panel of experts, (2) a field test, and (3) a pilot study. Dillman et al., (2008) suggested this three-step approach to evaluate the instrument from multiple angles.

The panel of experts included several experienced researchers who are also familiar with the topic of ticket sales. The panel of experts were asked to evaluate the instrument for content validity. Specifically, for the instrument related to relationship selling and modified to fit college sport ticket sales, the panel of experts were given the seminal authors' explanations of the three constructs (interaction intensity, mutual disclosure, and cooperative intentions) to judge whether the modified items fit the nature of the constructs. This step was important in order to ensure the nature of the constructs 
being examined is maintained (DeVellis, 2016). Following the panel of experts' recommendations, the instrument was modified. Details on modifications following the panel of experts is detailed in Chapter IV.

Next, a field test was conducted with graduate and doctoral members of a research university's sport administration program. Those participating in the field test were asked for the readability and understandability of the instrument. Furthermore, the members of the field test were asked to provide explanations or comments regarding any particular challenges with the instrument. Following the field test, the instrument was modified again. Details of modifications following the field test are also explained further in Chapter IV

Finally, a pilot study was conducted on a smaller sample of college football season ticketholders. Approximately 50 season ticketholders were recruited using Amazon MTurk and given the full instrument for RQ1 and RQ2. It is important to note all of the respondents had to have spoken with a sales representative over the phone since this is a qualification of the second research question population. The results of the pilot test were checked for internal consistency using Cronbach's alpha, which were deemed acceptable if greater than .80 (Henson, 2001).

\section{Data Analysis}

Before analyzing the data for results, it is important to pre-examine the data for factor loadings, internal consistency and reliability. The factor structure of the model was examined using a Confirmatory Factor Analysis through the SPSS Amos Statistical Package. Additionally, internal consistency of the instrument was assessed using 
Cronbach's alpha coefficient. Following the initial examination of the data, RQ1 and RQ2 were examined using multiple regression.

\section{Confirmatory Factor Analysis}

In order to use a multi-factor instrument for statistical analysis, it is useful to perform a confirmatory factor analysis to determine whether the items in the instrument are properly grouped into the factors intended by the instrument. A confirmatory factor analysis is most appropriate when there is a strong theoretical basis associated with the items included in the factor. Since the items for this study was adapted using the same multi-dimensional model established by Crosby et al. (1990), a CFA was deemed appropriate to confirm the structure of the instrument.

CFA requires several assumptions to be met prior to performing the analysis. First, an adequate sample size must be obtained. A sample size of 250 with communalities greater than .70 or a sample size of 200 with communalities greater than .60 which include a scree test have been recommended (Stevens, 2009). Additionally, outliers and incomplete data should be removed. The CFA is analyzed using several standard of fit indices: good fit can be established by a TLI or CFI of greater than $.95(\mathrm{Hu}$ \& Bentler, 1999), or an NFI of greater than .9 (Bentler, 1992). Additionally, an RMSEA value of less than .08 is deemed acceptable, and less than .05 is deemed good (Browne \& Clark, 1993).

\section{Measures of Internal Consistency and Reliability}

The internal consistency and reliability were measured using Cronbach's alpha. According to Nunnally (1978), a score greater than .70 is deemed acceptable for 
exploratory research, though some researchers have suggested a more conservative benchmark of .80 (Lance et al., 2008).

\section{Multiple Regression}

To address RQ1 and RQ2, multiple regression analysis was used. All of the items in this instrument (with the exception of demographic data) use Likert-type responses. Technically, Likert-type scales are ordinal data, and regression analysis requires continuous data. However, scholars have suggested if the nature of the research is "harmless" and it uses a broader scale (1-7 instead of 1-4, for example), the data approaches interval-level and is acceptable (Norman, 2010). Thus, multiple regression was identified as an appropriate method. It is important to note using a Likert scale item as a variable makes statistical regressions more sensitive to the normality assumption (Norman, 2010).

\section{Types of Multiple Regression}

Several forms of regression could have been used to assess the research problem. In stepwise regression, predictor variables are automatically selected in order to maximize the predictive ability of the model (Pituch \& Stephens, 2015). However, stepwise is most often used with many predictor variables, and since this study contains few predictor variables, stepwise regression was not deemed appropriate. Logistic regression could be used if the dependent variable was a categorical question such as “will you renew your football tickets next year?" However, such a definitive binary response is difficult for most fans when the season is over 8 months away, and therefore studying likelihood of renewal should be measured using more of a range of responses in order to allow for a degree of uncertainty in their renewal decision. Lastly, a standard (or 
simultaneous) regression compares all of the predictor variables at once. Since the current study included a simultaneous entry of variables, this form of regression was used. Additionally, the study included two blocks in order to control for outside variables, suggesting a simultaneous entry with block entry, or hierarchical regression, as most appropriate.

\section{Assumptions of Multiple Regression}

Shavelson (1996) noted four assumptions of multiple regression: (a) independence of responses, (b) normal distribution among dependent variables, (c) homoscedasticity among independent variables, and (d) linearity among the dependent variables. Field (2009) suggests an additional test: checking the independent variables for multicollinearity, and Williams, Grajales, and Kurkiewicz (2013) suggested removal of outliers.

Independence of responses. The assumption of independence of responses states each respondent can only complete the survey once, and additionally no respondent influences the responses of another (Field, 2009). This was addressed by filtering out identical IP addresses so individuals who already submitted the survey were redirected to a thank you screen and unable to submit again. As a secondary failsafe, the final question of the survey read "have you personally taken this survey previously?" and any respondents who answered "yes" were removed from the sample.

Normality among dependent variables. The normality assumption in multiple regression states the errors must be normally distributed (Field, 2009). This assumption 
was tested through SPSS scatterplots of the dependent variables. The resulting scatterplot should show a normal distribution.

Homoscedasticity among independent variables. Homoscedasticity is important in multiple regression, as a violation of this assumption means there is too much randomness in the error of the relationship between the independent variable and the dependent variable (Pituch \& Stevens, 2015). This was tested through plotting the standardized residuals with the regression standardized predicted value in SPSS. If the pattern appears in a conical (cone) shape, there is a possible violation of the assumption of homoscedasticity.

Linearity among dependent variables. Since multiple regression is based off of a linear equation; it is no surprise an assumption of a linear relationship between the independent and dependent variables exists. This was tested through scatterplots using SPSS with the values on the vertical axis and the standardized residuals on the horizontal axis. The resulting scatterplot should show a linear pattern. Severely curvilinear or no pattern would suggest a violation of the linearity assumption.

Multicollinearity among independent variables. Predictor variables which are too highly correlated can create errors in the regression model since they are not distinct predictors, or they may measure the "same" effect. This would indicate an issue of multicollinearity. Multicollinearity was assessed using the multicollinearity statistics provided by SPSS in the regression analysis. The most common measures used include the tolerance as well as the Variance Inflation Factor (VIF). Since VIF is simply 1 divided by the tolerance, only one is needed. Early research identified a VIF greater than 
10 as problematic (Marquart, 1970; Neter, Kutner, Nachtsheim, \& Wasserman, 1996). However, more recently, researchers have begun to recommend a more conservative VIF threshold of less than 5 (Rogerson, 2001) or even less than 4 (O'Brien, 2007).

Outliers/Skewness. Multiple regression is sensitive to skewness (Field, 2009), and this effect is multiplied when combined with the use of a Likert scale (Norman, 2010). Thus, some researchers have suggested plotting dependent variables and removing outliers as a standard part of multiple regression (Rousseeuw \& Leroy, 2005). For this study, a scatterplot analysis was used to determine and remove outliers from the data.

\section{Sample size}

Different recommendations for minimum sample size in regression have been offered. Shavelson (1996) recommended 10 cases per predictor variable, while Green (1991) has suggested $N \geq 104+m$, with $m$ equal to the number of independent variables. For this study, the instrument being examined will include eight independent variables, and therefore we will be using Green's (1991) sample criteria since it would be more conservative in this case. This sets a minimum sample size of 112 required for the study. However, it is worth noting the CFA previously mentioned will require a larger sample size than the multiple regression analysis, therefore a sample size of 200 or more was still necessary for this study.

As sample sizes become larger, statistical significance test can become overly sensitive. Thus, it is important to examine practical significance as well as statistical significance. Statistical power (in regression) refers to probability of detecting a significant $R^{2}$ given an alpha level and sample size. G*Power was used to calculate the 
minimum sample size for adequate power, given a moderate effect size $\left(F^{2}=.15\right)$ and an error probability of $p=.05$. G* Power results indicated a sample size of 92 ( 5 predictors for RQ1) or 85 (4 predictors for RQ2) is necessary for adequate power $(1-\beta=.80)$.

Despite the recommended sample sizes above, a larger sample was ideal to account for generalizability of the sample towards the larger population of college season ticketholders. Dillman, Smyth, \& Christian (2014) recommended a sample of 384 to generalize results to a population of greater than 1 million, and thus the current study sought a sample of at least 384 in order to be more conservative and account for the required statistical minimums above.

\section{Multiple Regression Analysis}

RQ1 and RQ2 were both be examined using hierarchical multiple regression. Once the assumptions of multiple regression were met, it is important to note the entry of the variables for the regression equation, as well how the output of the multiple regression analysis was examined for implications.

Entry of the variables. Both research questions aim to measure how box office customer service predicts different consumer behaviors in college athletics. For RQ1, the use of hierarchical regression included the control variable of team success first (block 1). Block 2 independent variables included the five factors of relationship quality from Kim et al.'s (2011) SCTRQS: trust, commitment, intimacy, self-connection, and reciprocity. By a placing control variable in block 1 , and independent variables in block 2 , it allows the researcher to isolate the effects of the independent variables separately from the control variables. 
For RQ2, a separate hierarchical multiple regression analysis was performed. To examine this research question, block 1 included the control variables of passion and team success. Block 2 variables included the factors of Crosby et al. (1990) modified to describe ticket sales: interaction intensity, mutual disclosure (customer and agent), and cooperative intentions.

Model Summary. First, each model was assessed using the model summary from SPSS. The (Big) $R$ value shows the degree of the relationship for the entire linear equation of criterion variables with all of the predictor variables (Pituch \& Stevens, 2015). The $R$ Square value shows the amount of variance in the dependent variables explained by the independent variables. The Adjusted $R$ Square value is a similar measurement, but more conservative. With sample sizes of over 100, these two tend to be similar (Pituch \& Stevens, 2015). The $R$ Square Change value will be of particular interest, which (under block 2) showed the unique variance provided by the independent variables of relationship quality (RQ1) and relationship selling (RQ2) while controlling for passion and team success. This was reported along with the degrees of freedom, $F$ Change value, as well as the $p$ value from the model summary. Any $p$ value below .05 was considered statistically significant.

Coefficients. The Model Summary and ANOVA tables assess the entirety of the model; however, they fail to differentiate the independent variables from one another. The coefficients table allows the researcher to answer the question of which variables are most powerful in the prediction equation. The standardized beta value shows the strength of the relationship in standard deviation units, and therefore allows for an "apples to 
apples" comparison of variables which may be measured differently. The coefficients table also provides the statistical significance of the coefficients for each predictor variable. The unstandardized beta for each statistically significant variable was reported along with the $p$ value. Typically, standardized betas are reported in regression equations where variables were not all collected using the same measurement. Since the data were collected using identical 7-point Likert scales, either standardized or unstandardized betas are appropriate, however the unstandardized beta would allow for easier practical interpretation of results since it can be explained using whole unit changes instead of standard deviation changes. All $p$ values less than .05 were considered statistically significant.

\section{Summary of Method}

The current study examined college football season ticketholders in order to determine the extent to which relationship quality and relationship selling practices can predict multiple types of consumer purchase intentions. Relationship quality was measured using the SCTRQS (Kim et al., 2011), and included five factors: trust, intimacy, self-connection, commitment, and reciprocity. Relationship selling techniques were measured using Crosby et al.'s (1990) instrument consisting of: interaction intensity, mutual disclosure (customer and agent) and cooperative intentions. The original instrument had to be modified to fit the sport ticket sales industry, however the items reflected the original instrument as much as possible.

Prior to collecting the data, a series of pretests were utilized on the entire instrument to check for reliability and validity. These pretests included a panel of experts, a field test, and a pilot study. Additionally, a Confirmatory Factor Analysis was used to 
determine the factor structure of the instrument for relationship selling, since it required modification to fit the industry it is intended to measure. Finally, Cronbach's alpha coefficients were examined to address consistency and reliability.

Multiple simultaneous regressions were used to examine the predictive ability of the independent variables (relationship quality and relationship selling) on the outcome variables of purchase behavior (renewal, upsell, cross-sell). Variables of relationship quality which significantly predict increased likelihood of purchase intentions were used to address RQ1, while variables of relationship selling which significantly predict increased likelihood of purchase intentions were used to address RQ2. 


\section{CHAPTER IV}

\section{RESULTS}

The purpose of this study was to measure the impact of relationship quality and relationship selling techniques on consumer behavior in Division I college football. Specifically, this study aimed to a) investigate the impact of five factors of relationship quality (trust, commitment, intimacy, self-connection and reciprocity) to assess how relationship quality predicts purchase behaviors in Division I college football (renewals, upselling, add-on, and cross-selling). Additionally, this study sought to b) examine the impact of four factors of relationship selling (interaction intensity, agent disclosure, customer disclosure, and cooperative intentions) on the same four purchase behaviors (renewal, upselling, add-on, and cross-selling).

\section{Scale Validation and Pretesting}

To determine content validity, face validity, discriminant validity, reliability, and consistency of the instrument, a series of pre-tests were performed. Three steps: (a) panel of experts, (b) field test, and (c) pilot study proposed by Dillman et al. (2008) were conducted sequentially. Additionally, a fourth step included conducting a Confirmatory Factor Analysis (CFA) to confirm the factor structure of the instrument.

\section{Panel of Experts}

A panel of experts reviewed the modified relationship selling questionnaire to check the questions for content validity. The panel of experts included faculty members 
from research universities experienced in ticket sales research, as well as industry professionals currently working in the field. The panel of experts was provided with the modified items as well as definitions of the constructs being measured provided from the literature. Panel members were asked to examine the items to ensure the wording of the item matched the essence of the construct, and that the item was not modified too heavily from its original wording. The panel of experts recommended minor changes to the wording of the questionnaire and provided general feedback. Notably, the panel recommended the use of the term "ticket sales office" rather than "box office," since customers would probably comprehend the unofficial terminology for the department rather than the label used by the department itself. Additionally, the panel recommended minor changes of wording to make the instrument more ticket-specific. For example, "financial needs" was changed to "budget" when referring to ticket expense. Lastly, the panel raised concerns as to whether the relationship quality factors of commitment, selfconnection, and intimacy were too theoretically similar to the control variable of passion. Thus, passion was excluded as a control variable for research question 1.

\section{Field Test}

Following the panel of experts, a field test was conducted with sport management doctoral students to check for face validity. Those who participated in the field test were given the full instrument as if they were season ticketholders who also spoke to the box office. The participants were asked to provide feedback regarding the readability and general understanding of the questions. Additionally, participants were asked to track the time to complete the instrument, as well as the time between pages of questions. Results of the field test suggested minor changes to the workflow of the survey. For instance, 
each page was limited to 10-12 questions and additional response options were added for some demographic variables, such as season ticketholder longevity.

\section{Pilot Study}

Following the field test, a pilot study was conducted using 50 MTurk workers who identified themselves as both season ticketholders and having spoken to the box office. Participants included in the pilot study were not eligible to be included in the larger dataset of this study. Data from the pilot study were used to calculate the reliability of the instrument and examine factors such as time needed to complete the survey. Participants were given the full survey via Qualtrics.com.

Based on the recommendation of Nunally and Bernstein (1994), Cronbach's alpha estimates greater than .70 were deemed acceptable for adequate scale reliability and consistency. The scale reliability was estimated for each factor of the SCTRQS scale of relationship quality (Kim et al., 2011), as well as the modified relationship selling scale, and finally the passion scale developed by Wakefield (2016). Table 3 shows the number of items as well as the Cronbach's alpha estimates for each construct. Following the results of the pilot study, the survey was deemed appropriate for the study and activated on the MTurk platform.

Table 3 Cronbach's alpha estimates for the Pilot Study

\begin{tabular}{llc}
\hline Scale & Factor & Alpha \\
\hline Relationship Quality & Trust & .840 \\
& Commitment & .768 \\
& Intimacy & .866 \\
& Self-Connection & .869 \\
& Reciprocity & .797 \\
\hline Relationship Selling & Interaction Intensity & .905 \\
& Agent Disclosure & .766 \\
& Customer Disclosure & .822
\end{tabular}




\begin{tabular}{lll} 
& Cooperative Intentions & .880 \\
\hline Control & Passion & .885 \\
\hline
\end{tabular}

\section{Sample Statistics}

Data were collected from MTurk workers who self-identified as a season ticketholder of a Division I FBS college football team for the 2017 season. To minimize the likelihood of MTurk workers being dishonest (lying about season ticketholder status), a two-step data collection method was performed. First, a pre-qualification survey was opened on the MTurk platform to all workers, asking if the worker was a season ticketholder, the team and conference for which the worker held tickets, as well as whether the season ticketholder spoke with the box office prior to purchasing their 2017 tickets. Workers were not told which of the questions qualified them to participate in future studies and were compensated $\$ .03$ through the MTurk platform for each completed survey. A total of 2,500 pre-qualification surveys were completed, generating 702 usable participants. 501 participants indicated they spoke with the box office prior to purchasing tickets and were "tagged" through the MTurk system as eligible for the full instrument, while 201 participants reported no contact with the box office and were tagged as eligible only for the questions pertaining to RQ1.

A total of 571 questionnaires was completed, including 410 who spoke with the box office over the phone (RQ1 and RQ2), as well as 161 who reported no contact with the box office (RQ1). Furthermore, after deleting incomplete responses and those who did not pass the manipulation checks, an additional 18 responses were removed from the "no box office contact" list and an additional 33 responses were removed from the "phone contact" list. Thus, a total of 520 usable surveys were utilized in this study, 
representing a response rate of 74\%. The 520-response dataset for RQ1 as well as the 377-response dataset for RQ2 satisfying the requirements for CFA (Stevens, 2009), as well as multiple regression analysis (Green, 1991), and generalizability to a population greater than 1 million (Dillman et al., 2014). Thus, the sample in the current study met the required specifications for the method described in the previous chapter.

\section{Demographic Information}

The 520-participant sample consisted of 315 males (60.6\%) and 193 females (37.1\%). The respondents' ages ranged from 18 to 68 , with a mean age of 35 and a standard deviation of 10.92 . In regard to marital status, $40 \%$ of the respondents were married, while $45 \%$ of the respondents indicated they were in a partnership, and $7.5 \%$ were divorced. $75.4 \%$ of the respondents were white, and income of the median respondent was between $\$ 75,000$ and $\$ 99,000$. Table 4 shows the frequency distributions of demographic variables included in the survey

Table 4

Frequency of Distributions for Demographic Variables

\begin{tabular}{llrc}
\hline Variables & & Percentage & $\boldsymbol{N}$ \\
\hline Gender & & \\
& Female & 37.1 & 193 \\
& Male & 60.6 & 315 \\
& Other & 2.3 & 12 \\
\hline Race & & & \\
& Asian & 6.2 & 32 \\
& Black & 9.8 & 51 \\
& Hispanic & 5.6 & 29 \\
& White & 75.4 & 392 \\
& Other* & 3.0 & 16 \\
\hline Age** & & & \\
& $18-29$ & 36.2 & 188 \\
& $30-39$ & 39.8 & 207 \\
& $40-49$ & 11.0 & 57 \\
& $50-59$ & 10.4 & 52 \\
$60-69$ & 3.1 & 16 \\
\hline
\end{tabular}




\begin{tabular}{|c|c|c|c|}
\hline \multicolumn{4}{|l|}{ Marital Status } \\
\hline & Single & 45.4 & 236 \\
\hline & Married & 40.6 & 211 \\
\hline & Divorced & 7.5 & 39 \\
\hline & Partnered & 6.2 & 32 \\
\hline & Other & $<1.0$ & 2 \\
\hline \multicolumn{4}{|c|}{ Household Income } \\
\hline & Less than $\$ 35,000$ & 2.9 & 15 \\
\hline & $\$ 35,000-\$ 49,999$ & 19.4 & 201 \\
\hline & $\$ 50,000-\$ 74,999$ & 22.3 & 116 \\
\hline & $\$ 75,000-\$ 99,999$ & 40.4 & 210 \\
\hline & $\$ 100,000-\$ 149,999$ & 7.5 & 39 \\
\hline & $\$ 150,000-\$ 200,000$ & 2.5 & 13 \\
\hline & $\begin{array}{l}\text { Greater than } \\
\$ 200,000\end{array}$ & 5 & 26 \\
\hline
\end{tabular}

* Several variables representing less than $1.5 \%$ of the sample were combined for this table

**Actual age was collected and bracketed for this table

Ultimately, with a few exceptions, the sample was far more representative of college football fans than the general MTurk population, alleviating many concerns addressed in Chapter III. Table 5 shows the comparable demographic makeup of the general population of MTurk workers (Berinsky, 2012), as well as the demographic information of college football fans (SBRnet, 2014) and the comparative demographic information of the current sample. The sample showed slightly less white respondents, and respondents were less likely to be married. However, it is worth noting the Berinsky (2012) data included fewer selections for race than the current study and did not include the option of "partnered" for marital status which was included in the current study. In sum, the representativeness of the sample was deemed appropriate to draw implications for collegiate football fans.

Table 5

Demographic Comparisons of MTurk Workers, College Football Fans, and The Current Study 


\begin{tabular}{lccc}
\hline & $\begin{array}{c}\text { MTurk Workers } \\
\text { (Berinsky et al, 2012) }\end{array}$ & $\begin{array}{c}\text { College Football Fans } \\
\text { (SBRnet, 2014) }\end{array}$ & Current Study \\
\hline Age & 32.3 (mean years) & 34 (median years) & 34.8 (mean years) \\
Racial Majority & $83.5 \%$ (white) & $82 \%$ (white) & $75.4 \%$ (white) \\
Marital Status & $39 \%$ (married) & $51 \%$ (married) & $40.6 \%$ (married) \\
Income & 45,000 (median) & $\$ 72,900$ (median) & $\$ 75,000-\$ 99,999 *$
\end{tabular}

*Income data collected using brackets to limit desirability and nonresponse bias

\section{College Football Demographic Information}

After comparing the traditional demographic information, it is also useful to compare demographic and information specific to the population being studied. Factors such as student season ticketholder status, favorite team, and conference may contribute to the implications of the data. The current study reflects all 10 major athletics conferences, as well as independent teams. Furthermore, the study had at least one response from 94 of the 129 FBS teams. Table 6 demonstrates the football demographics which directly concern the nature of the study.

Table 6

College Football-Specific Demographic Information

\begin{tabular}{llrr}
\hline Demographic & N & Percentage \\
\hline Conference & & \\
& ACC & 37 & 7.1 \\
& American & 56 & 10.8 \\
& Big 12 & 57 & 11 \\
& Big Ten & 73 & 14 \\
C-USA & 36 & 6.9 \\
& Independent & 17 & 3.3 \\
& Mountain West & 41 & 7.9 \\
& Pac-12 & 77 & 14.8 \\
& SEC & 76 & 14.6 \\
& Sun Belt & 49 & 9.4 \\
\hline Student ticketholder status & & \\
& Did not purchase student tickets & 498 & 95.8 \\
& Purchased student tickets & 22 & 4.2 \\
\hline
\end{tabular}




\begin{tabular}{|c|c|c|c|}
\hline \multicolumn{4}{|l|}{ Alumni Status } \\
\hline & Alumni of the indicated university & 138 & 26.5 \\
\hline & Not alumni of the indicated university & 382 & 73.4 \\
\hline \multicolumn{4}{|c|}{ Employees Status } \\
\hline & Employee of the indicated university & 77 & 14.4 \\
\hline & Not an employee of the indicated university & 443 & 85.6 \\
\hline \multicolumn{4}{|c|}{ Longevity (years as a season ticketholder) * } \\
\hline & $1-5$ years & 292 & 56.2 \\
\hline & $6-10$ years & 210 & 40.4 \\
\hline & $11-15$ years & 22 & 4.2 \\
\hline & Greater than 15 years & 3 & $<.1$ \\
\hline \multicolumn{4}{|c|}{ Estimated amount spent on tickets and donations* } \\
\hline & $<\$ 500$ per year & 92 & 17.7 \\
\hline & $\$ 500$ to $\$ 1,000$ per year & 118 & 22.7 \\
\hline & $\$ 1,001$ to $\$ 3,000$ & 125 & 24.0 \\
\hline & $\$ 3,001$ to $\$ 5,000$ & 27 & 5.2 \\
\hline & $\$ 5,001$ to $\$ 10,000$ & 74 & 14.2 \\
\hline & $\$ 10,001$ to $\$ 15,000$ & 83 & 16.0 \\
\hline & Greater than $\$ 15,000$ & 1 & $<.1$ \\
\hline \multicolumn{4}{|c|}{2018 Season ticketholder status } \\
\hline & Renewed season tickets for 2018 & 60 & 11.6 \\
\hline & Added on season tickets for 2018 & 9 & 1.7 \\
\hline & Up-sold season tickets for 2018 & 7 & 1.3 \\
\hline & Cross-purchased tickets for 2018 & 5 & 1 \\
\hline & Have not yet renewed for 2018 & 460 & 88.5 \\
\hline \multicolumn{4}{|c|}{ Preferred box office contact method } \\
\hline & Email & 158 & 30.4 \\
\hline & In-person visit & 7 & 1.3 \\
\hline & Social Media & 33 & 6.3 \\
\hline & Telephone & 314 & 60.4 \\
\hline & Other & 8 & 1.5 \\
\hline
\end{tabular}

*Actual numerical data were collected and bracketed for this table

The sample consisted mainly of individuals who had not yet purchased season tickets for the upcoming season. This was beneficial for the study, since the time of data collection occurred after the start of the sales cycle, and most fans had not yet decided. The sample contained few student season ticketholders, who may have season tickets heavily discounted or included in student fees, thus not representing the target demographic for this study. The sample consisted of 26 percent alumni of the university 
for which they purchased tickets, and 15 percent employees of the university for which they purchased tickets. Furthermore, participant season ticketholder longevity ranged from 1 year to 19 years, with most in the 1-10-year range. There was a noticeable gap in the range of the amount being spent, with most fans spending less than $\$ 3,000$ on tickets, and a large percentage spending over $\$ 5,000$. Only 5 percent of the participants spent between $\$ 3,000$ and $\$ 5,000$. Lastly, most participants preferred contact via telephone, with another large share preferring email, when discussing their ticketing purchase.

\section{Confirmatory Factor Analyses}

In order to confirm the factor structure of the instruments being used, two confirmatory factor analyses were performed on the data. The first CFA consisted of relationship quality factors from Kim et al. (2011), while the second CFA consisted of the modified relational selling instrument adapted from Crosby et al. (1990). Hu and Bentler (1998) suggest at least two fit indices should be utilized in order to assess appropriate model fit to the data. Hooper, Coughlin \& Mullin (2008) noted chi-square analysis nearly always rejects the model fit when large sample sizes are used, so four additional indices were included to support model fit: Comparative Fit Index (CFI) Goodness of Fit Index (GFI), Adjusted Goodness of Fit Index (AGFI) and Root Mean Square Error of Approximation (RMSEA)

CFA for RQ1. The structural model for RQ1 included 5 latent variables (trust, commitment, intimacy, self-connection, and reciprocity) and 15 observed variables; each latent variable included three observed variables. The sample size of 520 was also deemed appropriate by Suhr (2006)'s standard of five subjects per parameter. Missing 
data and outliers had already been removed from the data, thus it was deemed appropriate for factor analysis. Table 7 shows the model fit summary for the RQ1 CFA.

Table 7

Model Fit Summary for RQ1

\begin{tabular}{lrr}
\hline Model Fit Measure & Current Study & \multicolumn{2}{c}{$\begin{array}{c}\text { Model Fit Standard } \\
\text { (Hu \& Bentler, 1999) }\end{array}$} \\
\hline Chi-square & .819 & $<.05$ \\
CFI & $1.0^{*}$ & $>.95$ \\
GFI & $.983^{*}$ & $>.90$ \\
AGFI & $.975^{*}$ & $>.90$ \\
RMSEA & $<.001^{*}$ & $<.06$
\end{tabular}

*Indicates the model fit standard was met

Standards for model fit were met for CFI, GFI, AGFI, and RMSEA, while the standard was not met for chi-square analysis. However, as previously mentioned, chisquare analysis nearly always rejects model fit in large samples sizes. Therefore, the model fit of the instrument for RQ1 (relationship quality) was deemed appropriate and the model could be analyzed for convergent and discriminant validity.

Convergent validity refers to the degree in which items and constructs which should theoretically be related are, in fact, related. Table 8 shows the factor loadings of each item with its corresponding latent variable. Awang (2014) suggested for newly develop constructs, factor loadings for all items should be above .5 while well-developed constructs should include factor loadings of greater than .6. Factor loadings for this study ranged from .63 (reciprocity item \#2) to .85 (commitment \#1), suggesting evidence of convergent validity.

Table 8 


\begin{tabular}{|c|c|c|}
\hline Factor & Item & Loading \\
\hline \multirow[t]{3}{*}{ Trust } & Trust item \#1 & .82 \\
\hline & Trust item \#2 & .82 \\
\hline & Trust item \#3 & .82 \\
\hline \multirow[t]{3}{*}{ Commitment } & Commitment item \#1 & .85 \\
\hline & Commitment item \#2 & .84 \\
\hline & Commitment item \#3 & .83 \\
\hline \multirow[t]{3}{*}{ Intimacy } & Intimacy item \#1 & .74 \\
\hline & Intimacy item \#2 & .69 \\
\hline & Intimacy item \#3 & .73 \\
\hline \multirow[t]{3}{*}{ Self-Connection } & Self-Connection item \#1 & .71 \\
\hline & Self-Connection item \#2 & .68 \\
\hline & Self-Connection item \#3 & .75 \\
\hline \multirow[t]{3}{*}{ Reciprocity } & Reciprocity item \#1 & .73 \\
\hline & Reciprocity item \#2 & .63 \\
\hline & Reciprocity item \#3 & .68 \\
\hline
\end{tabular}

After checking for convergent validity, it is also important to check for discriminant validity, which refers to the degree latent factors are correlated with each other. Correlations between latent variables which have absolute values greater than .85 may suggest poor discriminant validity (Voorhees, Brady, \& Calantone, 2016). Factors which are correlated may mirror each other and leave no way for the researcher to distinguish between the effects of the two variables separately. Correlations between 
factors in the data RQ1 data are shown in Table 9. Correlations ranged from -.28 (Trust $\leftrightarrow$ Commitment) to .04 (Intimacy $\leftrightarrow$ Self-Connection). No absolute values between the factors were found to be greater than .85 , suggesting appropriate discriminant validity between latent variables in the data. Table 9 shows the correlation between the five independent variables in RQ1.

Table 9

Correlation Estimates Between Variables

\begin{tabular}{lrrr}
\hline Factor & & Factor & Correlation Estimate \\
\hline Trust & $\leftrightarrow$ & Commitment & -.280 \\
Trust & $\leftrightarrow$ & Intimacy & -.123 \\
Trust & $\leftrightarrow$ & Self-Connection & -.085 \\
Reciprocity & $\leftrightarrow$ & Trust & -.075 \\
Commitment & $\leftrightarrow$ & Intimacy & -.039 \\
Commitment & $\leftrightarrow$ & Self-Connection & -.044 \\
Reciprocity & $\leftrightarrow$ & Commitment & -.086 \\
Intimacy & $\leftrightarrow$ & Self-Connection & .043 \\
Reciprocity & $\leftrightarrow$ & Intimacy & .043 \\
Reciprocity & $\leftrightarrow$ & Self-Connection & -.062 \\
\hline
\end{tabular}

The factor correlations for RQ1 were quite low, and, interestingly, all but two correlations were negative. While this proves no issue for discriminant validity, it conflicts with existing literature regarding relationship quality in sport and poses implications regarding the theoretical framework underlying relationship quality measurements in sport. These implications will be discussed in greater depth in the next chapter. Ultimately the confirmatory factor analysis performed in RQ1 (shown in full in 
figure 5) suggests the data collected was a good fit to the model, and appropriate for further analysis.

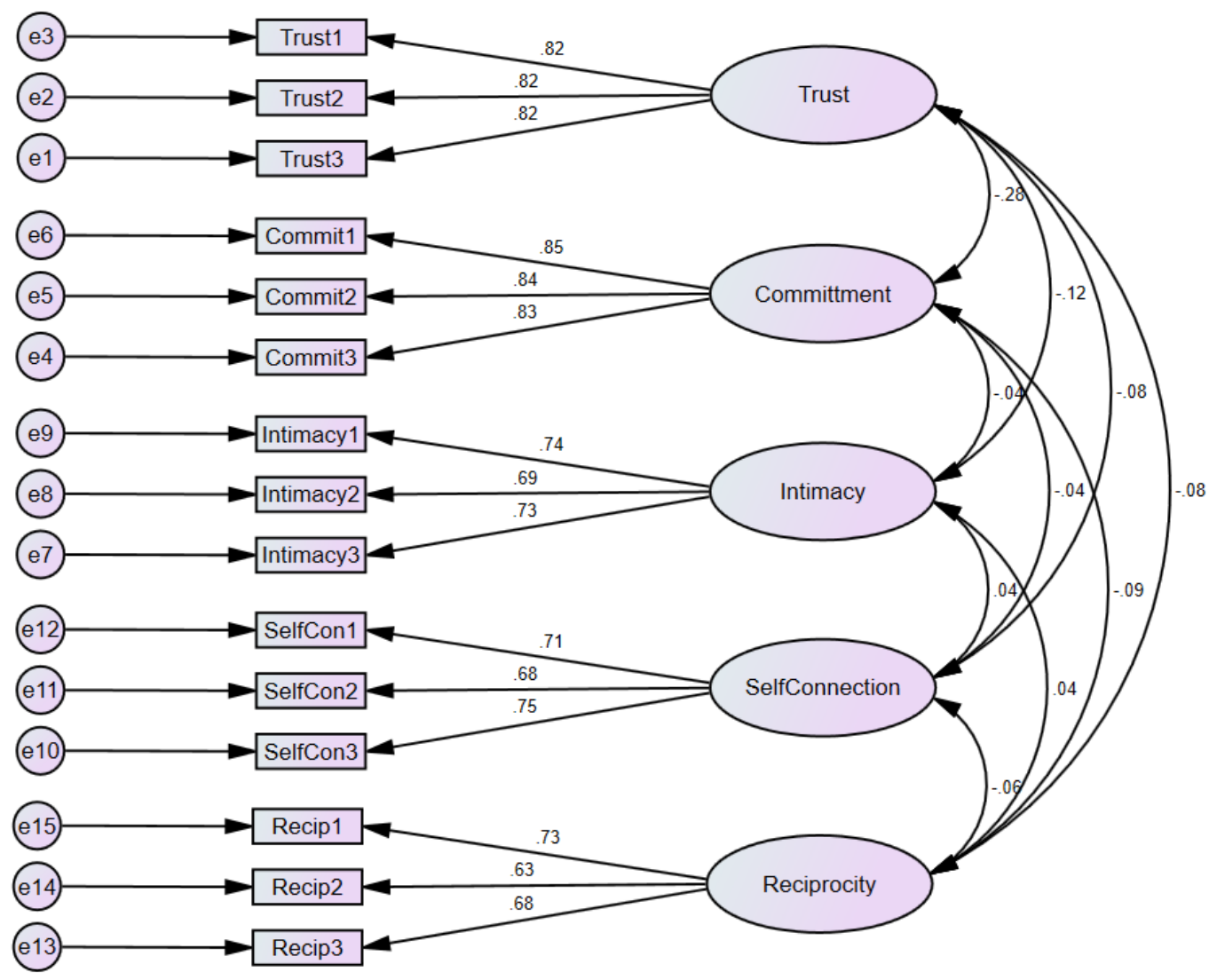

Figure 5

Confirmatory Factor Analysis of Relationship Quality Instrument (RQ1)

CFA for RQ2. The structural model for RQ2 included four latent variables (interaction intensity, agent disclosure, customer disclosure and cooperative intentions) and 16 observed variables. Each latent variable included four observed variables. The sample size of 377 was deemed appropriate by Suhr (2006)'s standard of five subjects per parameter. Missing data and outliers were removed from the data before analysis. Table 10 shows the model fit summary for the RQ2 CFA. Standards for model fit were met for the CFI, GFI, AGFI, and RMSEA. However, again the chi-square statistic was found not 
to be significant and may be attributed to sample size. Therefore, the model fit of the instrument developed for RQ2 (relationship selling) was deemed appropriate and the model could be further analyzed.

Table 10

Model Fit Summary for RQ2

\begin{tabular}{lcr}
\hline Model Fit Measure & Current Study & $\begin{array}{r}\text { Model Fit Standard } \\
(\text { Hu \& Bentler, 1999) }\end{array}$ \\
\hline Chi-square (p) & .084 & $<.05$ \\
CFI & $.994^{*}$ & $>.95$ \\
GFI & $.963^{*}$ & $>.90$ \\
AGFI & $.948^{*}$ & $>.90$ \\
RMSEA & $.023^{*}$ & $<.06$
\end{tabular}

*Indices in which the current data met the standard for model fit

Convergent and discriminant validity for the second CFA were assessed to analyze the relationship selling instrument. Factor loadings to determine convergent validity ranged from .73 to .89 , well above the threshold of .50 for newly developed instruments and .60 for established instruments. Factor loadings for each item and its corresponding factor are listed below in table 11. Factor loadings ranged from .65 (Customer Disclosure \#2) to .89 (Agent Disclosure \#4).

Table 11

Factor Loadings for $R Q 2$

\begin{tabular}{llr}
\hline Factor & Item & Loading \\
\hline Interaction Intensity & Interaction Intensity Item \#1 & .74 \\
& Interaction Intensity Item \#2 & .79 \\
& Interaction Intensity Item \#3 & .82 \\
& Interaction Intensity Item \#4 & .82 \\
\hline
\end{tabular}




\begin{tabular}{lcc} 
Agent Disclosure & Agent Disclosure Item \#1 & .81 \\
& Agent Disclosure Item \#2 & .77 \\
& Agent Disclosure Item \#3 & .82 \\
& Agent Disclosure Item \#4 & .89 \\
\hline Customer Disclosure & Customer Disclosure Item \#1 & .85 \\
& Customer Disclosure Item \#2 & .65 \\
& Customer Disclosure Item \#3 & .73 \\
& Customer Disclosure Item \#4 & .87 \\
\hline Cooperative Intentions & Interaction Intensity Item \#1 & .83 \\
& Interaction Intensity Item \#2 & .80 \\
& Interaction Intensity Item \#3 & 80 \\
& Interaction Intensity Item \#4 & .89 \\
\end{tabular}

After checking for convergent validity, the data was also analyzed for discriminant validity to ensure the factors were distinct enough to measure separately. Correlations between the factors were analyzed, ranging from .139 (Agent Disclosure $\leftrightarrow$ Customer Disclosure) to .664 (Customer Disclosure $\leftrightarrow$ Cooperative Intentions). The absolute value of each correlation was less than .85 , suggesting good discriminant validity between variables in the data. Table 12 shows the full list of correlations between each factor.

Table 12 Correlation Estimates Between Variables

\begin{tabular}{lllc}
\hline Factor & Factor & Correlation Estimate \\
\hline Interaction Intensity & $\leftrightarrow$ & Agent Disclosure & .273
\end{tabular}




$\begin{array}{llll}\text { Interaction Intensity } & \leftrightarrow & \text { Customer Disclosure } & .270 \\ \text { Interaction Intensity } & \leftrightarrow & \text { Cooperative Intentions } & .309 \\ \text { Agent Disclosure } & \leftrightarrow & \text { Customer Disclosure } & .139 \\ \text { Agent Disclosure } & \leftrightarrow & \text { Cooperative Intentions } & .383 \\ \text { Customer Disclosure } & \leftrightarrow & \text { Cooperative Intentions } & .664\end{array}$

Factor correlations were lower than the discriminant validity threshold of .85 , however not close to 0 , suggesting the factors were appropriate as subscales for a larger construct (relationship selling) however distinct enough that each variable measured a different aspect of the larger construct. Ultimately, the confirmatory factor analysis performed on the instrument for RQ2 (shown in full in figure 6) suggests the data collected was a good fit to the model, and appropriate to analyze RQ2.

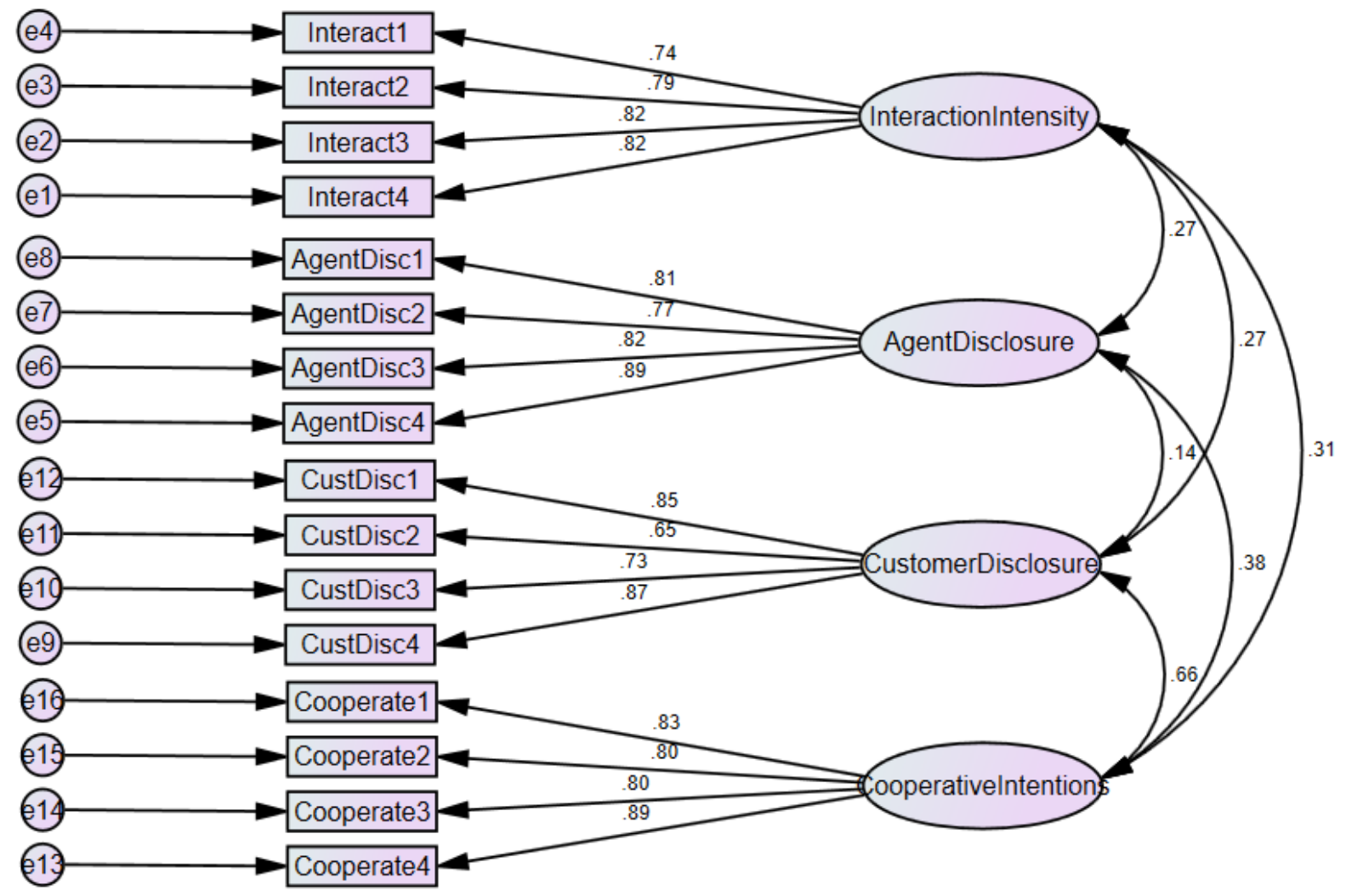


Figure 6

Confirmatory Factor Analysis of Relationship Selling Instrument (RQ2)

\section{Summary of Pretesting Scale Validation, and Sample Statistics}

In sum, the content validity and face validity as well as the consistency and reliability of the instruments used in the survey are deemed acceptable, and the use of the modified relational selling instrument were deemed appropriate. Additionally, the sample collected was representative of college football fans in terms of age, racial majority, and income, though the MTurk workers used for this study were less likely to be married than college football fans, per SBRnet. The sample used for this study represented over 75 percent of all athletics departments, and all the major athletics conferences. Participants reported varying ranges in their season ticketholder status, longevity, amount spent, and preferred contact method. Thus, the sample was considered well representative of the target population of Division I FBS college football season ticketholders. The data was found to appropriately fit the model suggested in the literature. The convergent and discriminant validity of both the relationship quality instrument was found to be appropriate, though the factors of relationship quality reported low correlations with each

other. Ultimately, the data for relationship quality and relationship selling were found to be acceptable to analyze the respective research questions.

\section{Data Analysis}

This study used a series of eight hierarchical linear regressions to address two research questions regarding relationship quality and relationship selling in Division I college athletics. The following section will report assumptions and detailed results of each research question. 


\section{Assumptions of Multiple Regression}

To calculate and interpret a linear regression, four assumptions must be met: (a) independence of responses, (b) normal distribution among dependent variables, (c) homoscedasticity among independent variables, and (d) linearity among the dependent variables. Additionally, Field (2009) suggests researchers check for multicollinearity among variables. Independence of responses was ensured two ways; first, Amazon MTurk accounts were only allowed to complete one task per account. Additionally, Qualtrics software IP-filtered responses to ensure the survey could not be completed more than once from the same IP address. Normality among the dependent variables was examined by plotting a histogram of the frequencies of responses. Figure 7 shows the combined histograms for each of the dependent variables of RQ1, while Figure 8 shows the combined histograms for the same dependent variables of RQ2. Since the two RQs were analyzed using different sample sizes, it is necessary to calculate each dataset separately. Frequency histograms showed skewness in the data, most notably with the renewal intention variable. This suggests the assumption of normality may have been violated. However, Stevens (2009) noted multiple regression is robust to the normality assumption with a large sample size, while Schmidt and Finan (2018) also noted the normality assumption does not noticeably impact results, given appropriate sample size. Therefore, despite the violation of the normality assumption, the data was further analyzed.

Figure 7

Frequency Histograms of RQ1 Dependent Variables

Renewal Intention Add-On Intention Upsell Intention Cross-Sell Intention



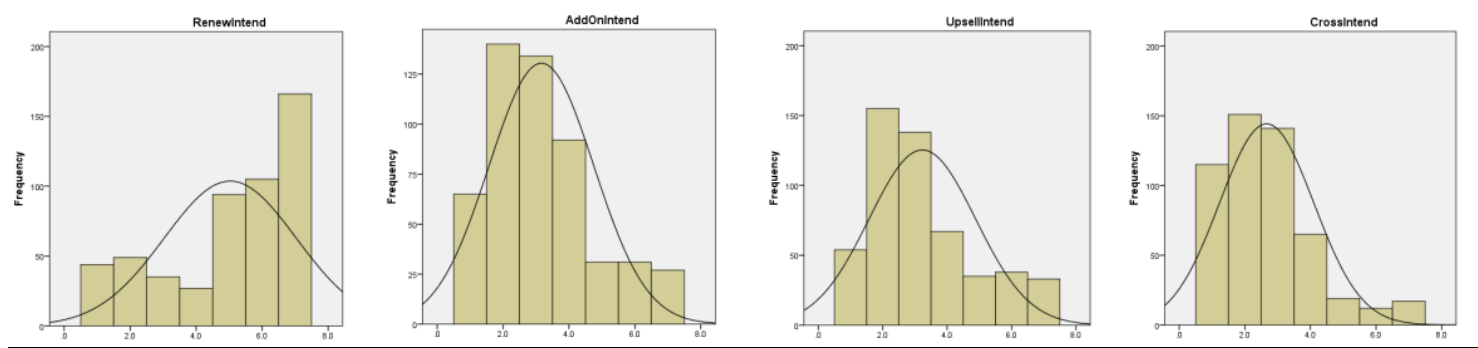

Figure 8

Frequency Histograms of RQ2 Dependent Variables

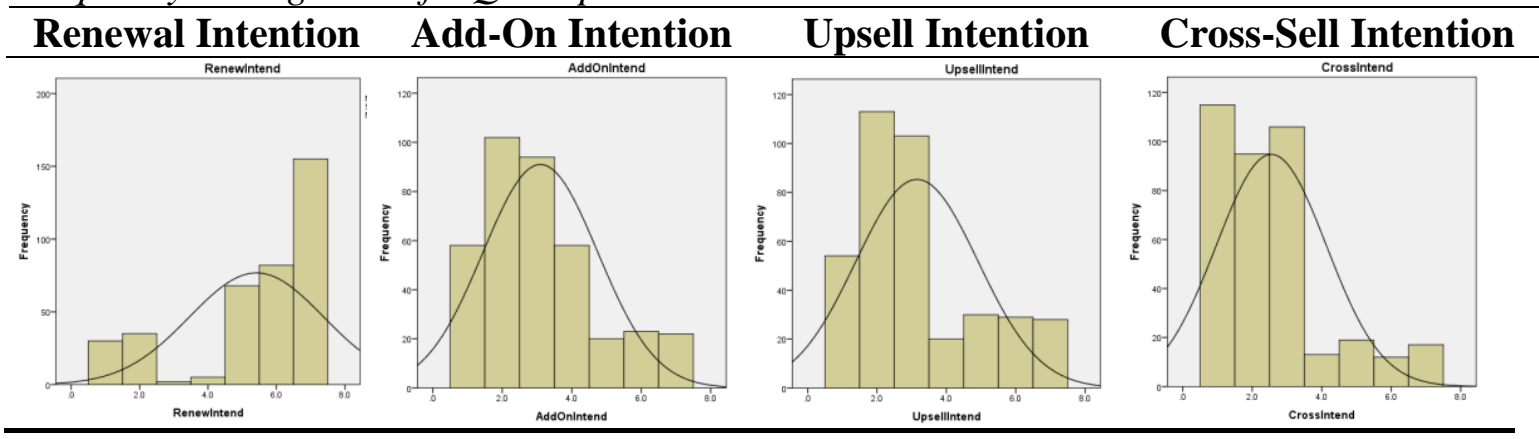

After checking assumptions of independence and normality, the data were checked for the assumption of homoscedasticity. Scatterplots were developed by plotting the regression standardized residuals with the standardized regression predicted value for each dependent variable and analyzing the scatterplot for conical (cone-shaped) patterns. No conical patterns were found. Lastly, the assumption of linearity was assessed by using a probability plot of standardized residuals. This assumption was assessed by determining how closely the residuals follow the least squares regression line plotted on the scatterplot. Figure 9 (RQ1) and Figure 10 (RQ2) show the residuals closely follow the least squares regression line for all eight regression models, indicating a linear relationship between the dependent and independent variables.

Figure 9

P-Plot of Regression Standardized Residuals (RQ1)

\begin{tabular}{llll}
\hline Renewal Intention Add-On Intention & Upsell Intention & Cross-Sell Intention \\
\hline
\end{tabular}



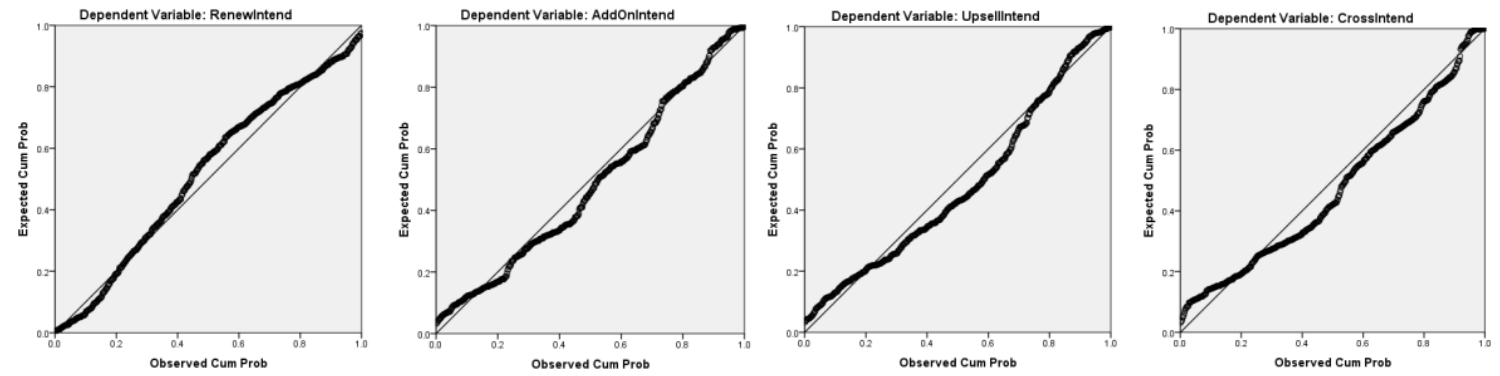

Figure 10

P-Plot of Regression Standardized Residuals (RQ2)
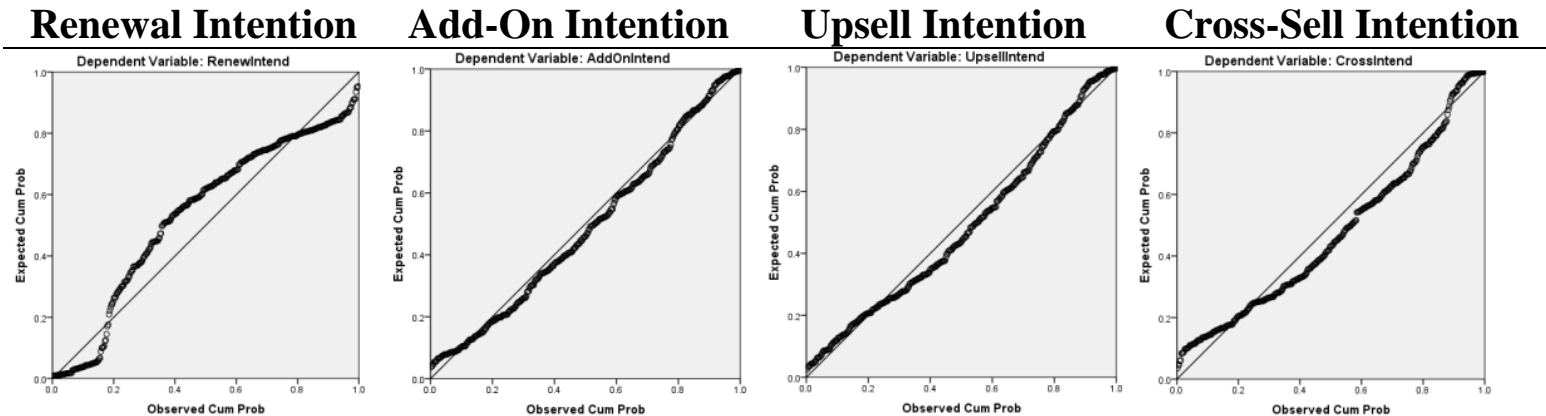

Lastly, the data were checked for multicollinearity among variables. As

previously mentioned in the CFA analysis, multicollinearity among the independent variables would prevent the researcher from being able to distinguish which of the variables was predicting the change in the dependent variable with a substantial degree of accuracy. For this study, multicollinearity was analyzed using the Variance Inflation Factor (VIF) of each independent variable. VIF statistics greater than 4.0 have been suggested as benchmarks for multicollinearity (O’Brien, 2007). The VIFs of RQ1 were reported for the following variables: trust $(\mathrm{VIF}=1.093)$, commitment $(\mathrm{VIF}=1.139)$, intimacy $(\mathrm{VIF}=1.020)$, self-connection $(\mathrm{VIF}=1.014)$, and reciprocity $(\mathrm{VIF}=1.013)$. VIFs of RQ2 were reported for the following variables: interaction intensity (VIF $=$ 1.129), agent disclosure $(\mathrm{VIF}=1.178)$, customer disclosure $(\mathrm{VIF}=1.565)$, and cooperative intentions $(\mathrm{VIF}=1.752)$. Taken together, the results of the collinearity 
statistics suggest there was no issues with multicollinearity in the data and further analysis was deemed appropriate.

\section{Descriptive Statistics}

Descriptive data were examined for any abnormalities or patterns. In general, the averages for both the independent and dependent variables were low comparative to a 7point Likert scale, apart from renewal intentions. For research quality (RQ1) predictor variables, mean scores ranged from 3.25 (trust) to 4.30 (commitment). For RQ1 dependent variables, mean scores ranged from 2.67 (cross-sell intention) to 5.03 (renewal intention). For relationship selling predictor variables (RQ2) mean scores ranged from 3.38 (agent disclosure) to 3.71 (cooperative intentions). Even though the dependent variables were the same as RQ1, descriptive data was analyzed again since the data included a different sample. Dependent variable mean scores ranged from 2.55 (cross-sell intention) to 5.42 (renewal intention). Complete descriptive statistics are shown in Table 13

Table 13

Descriptive Statistics of Independent and Dependent Variables

\begin{tabular}{|c|c|c|c|}
\hline & Variables & Mean & Standard Deviation \\
\hline RQ1 & Trust & 2.25 & 1.16 \\
\hline & Commitment & 4.30 & 1.55 \\
\hline & Intimacy & 3.64 & 1.23 \\
\hline & Self-Connection & 3.47 & 1.19 \\
\hline & Reciprocity & 4.04 & 1.16 \\
\hline & Renewal Intention & 5.03 & 2.00 \\
\hline & Add-On Intention & 3.16 & 1.59 \\
\hline
\end{tabular}


Upsell Intention $\quad 3.23 \quad 1.65$

$\begin{array}{lll}\text { Cross-Sell Intention } & 2.67 & 1.44\end{array}$

\begin{tabular}{|c|c|c|}
\hline RQ2 Interaction Intensity & 3.57 & 1.16 \\
\hline Agent Disclosure & 3.38 & 1.32 \\
\hline Customer Disclosure & 3.63 & 1.34 \\
\hline Cooperative Intentions & 3.72 & 1.42 \\
\hline Renewal Intention & 5.42 & 1.96 \\
\hline Add-On Intention & 3.01 & 1.65 \\
\hline Upsell Intention & 3.15 & 1.76 \\
\hline Cross-Sell Intention & 2.55 & 1.59 \\
\hline
\end{tabular}

\section{Results and Analysis of Research Question 1}

RQ1- Which aspects of relationship quality (trust, commitment, intimacy, selfconnection, and reciprocity) predict sport consumer purchase intentions in Division I College Football?

To address the first research question, a series of four hierarchical linear regressions was performed to determine the predictive validity of five independent variables (trust, commitment, intimacy, self-connection and reciprocity) on four purchase intentions (renewal, add-on, upsell, cross-sell). Research question 1 contained four subquestions; one for each of the purchase behaviors of interest. All respondents $(n=520)$ completed the STCRQS scale for relationship quality developed by Kim et al., (2011) and reported the likelihood of renewal using a single-item measure of purchase intention. 
Correlations between independent variables for RQ1 are shown below in Table 14. Low correlations between independent variables suggest no issues with multicollinearity.

Table 14

Pearson's Correlation Between Independent Variables (RQ1)

\begin{tabular}{|c|c|c|c|c|c|}
\hline & Trust & Commitment & Intimacy & $\begin{array}{c}\text { Self- } \\
\text { Connection }\end{array}$ & Reciprocity \\
\hline Trust & - & -.244 & -.011 & -.064 & -.104 \\
\hline Commitment & -.244 & -- & .056 & -.061 & .013 \\
\hline Intimacy & -.011 & .056 & -- & .033 & .030 \\
\hline Self-Connection & -.064 & -.061 & .033 & -- & -.047 \\
\hline Reciprocity & -.104 & .013 & .030 & -.047 & -- \\
\hline
\end{tabular}

RQ1a. Which aspects of relationship quality (trust, commitment, intimacy, selfconnection, and reciprocity) predict season ticket renewal intentions for the following season?

To address RQ1(a) a hierarchical linear regression was performed using two blocks. First, the control variable of performance satisfaction was entered the regression equation to determine the predictive nature of performance satisfaction by itself. Next, the independent variables of trust, commitment, intimacy, self-connection, and reciprocity were entered into the equation (block 2), allowing the researcher to test for significant change in the linear equation, and therefore unique variance predicted by the independent variables and not the control variable.

The control variable (win satisfaction) entered into the equation with the dependent variable (renewal intentions) resulted in a statistically significant amount of variance explained $\left[R^{2}=.092, F(1,518)=52.41, p<.001\right]$ with its unstandardized 
coefficient of $.489(t=7.239, p<.001)$, suggesting win satisfaction accounted for $9.2 \%$ of the variance in renewal intentions. Block 2 of the linear equation also resulted in a statistically significant amount of variance explained $\left[\Delta R^{2}=.103, F(5,513)=13.15, p<\right.$ .001] suggesting the combination of independent variables uniquely accounted for $10.3 \%$ of the variance in renewal intentions. Among the combination of independent variables, statistically significant relationships were found for commitment $(B=.410, t=7.49, p<$ $.001)$ as well as reciprocity $(B=-.147, t=-2.14, p=.033)$. Notably, win satisfaction was found as a significant predictor in block 2 as well $(B=.373, t=5.65, p<.01)$, and contributed to the explained variance of the independent variables.

Results suggest that when controlling for win satisfaction, the strongest predictor of renewal intentions was commitment. Furthermore, reciprocity was found as a weaker, yet still significant (negative) predictor of renewal intentions. None of the other independent variable were found to significantly predict the dependent variable. Table 15 shows the results of the hierarchical linear regression for RQ1a.

Table 15

Results of Hierarchical Linear Regression Analysis for RQ1a

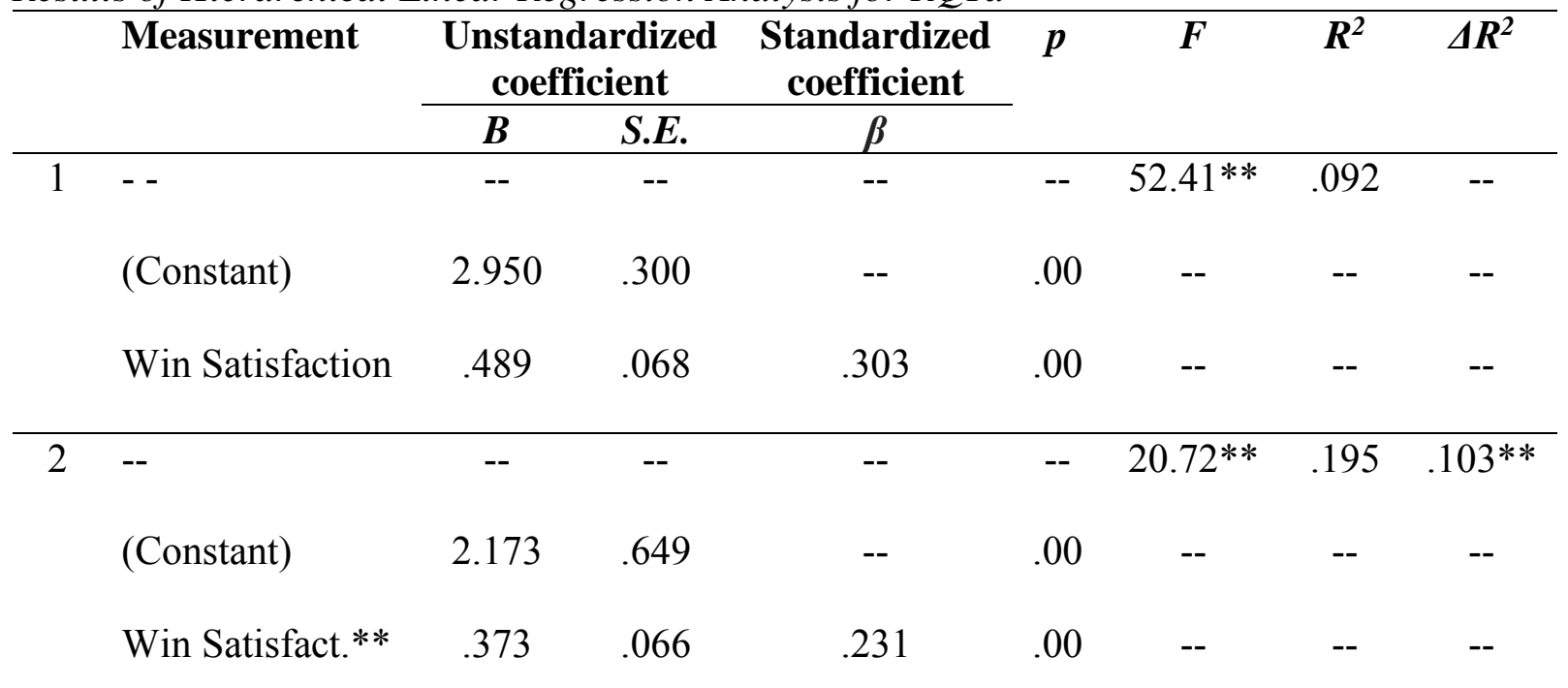




$\begin{array}{lccccccc}\text { Trust } & .108 & .071 & .063 & .13 & -- & -- & - \\ \text { Commitment** } & .410 & .055 & .317 & .00 & -- & -- & -- \\ \text { Intimacy } & -.006 & .065 & -.004 & .92 & -- & -- & -- \\ \text { Self-Connect. } & -.065 & .067 & -.038 & .34 & -- & -- & -- \\ \text { Reciprocity* } & -.147 & .069 & -.085 & .03 & -- & -- & --\end{array}$

** Indicates significance at the $p<.01$ level

* Indicates significance at the $p<.05$ level

RQ1b. Which aspects of relationship quality (trust, commitment, intimacy, selfconnection, and reciprocity) predict season ticket add-on intentions for the following season?

To address RQ1(b) another hierarchical linear regression was performed using two blocks. The control variable of performance satisfaction was entered first to determine the predictive nature of win satisfaction on add-on intentions. Next, the variables of trust, commitment, intimacy, self-connection, and reciprocity were entered into the equation (block 2) in order to determine significant change in the linear equation, and therefore the unique variance predicted by the independent variables.

The control variable (win satisfaction) entered into the equation with the dependent variable (add-on intentions) resulted in a statistically significant amount of variance explained $\left[R^{2}=.010, F(1,518)=5.339, p=.021\right]$ with its unstandardized coefficient of $.130(t=7.239, p=.021)$, suggesting win satisfaction accounted for $10 \%$ of the variance in add-on intentions. Block 2 of the linear equation also resulted in a statistically significant amount of variance explained $\left[\Delta R^{2}=.063, F(5,513)=6.782, \mathrm{p}<\right.$ .001] suggesting the combination of independent variables uniquely accounted for $6.3 \%$ 
of the variance in add-on intentions. Among the combination of independent variables, statistically significant relationships were found for commitment $(B=.260, t=5.57, p<$ $.001)$. Results of this data suggest win satisfaction as a significant predictor in add-on intentions. Additionally, commitment was found to be a significant predictor of add-on intentions, and no other independent variables were found to have statistically significant relationships with the dependent variable. Table 16 shows the results of the hierarchical linear regression for RQ1b.

Table 16

Results of Hierarchical Linear Regression Analysis for RQ1b

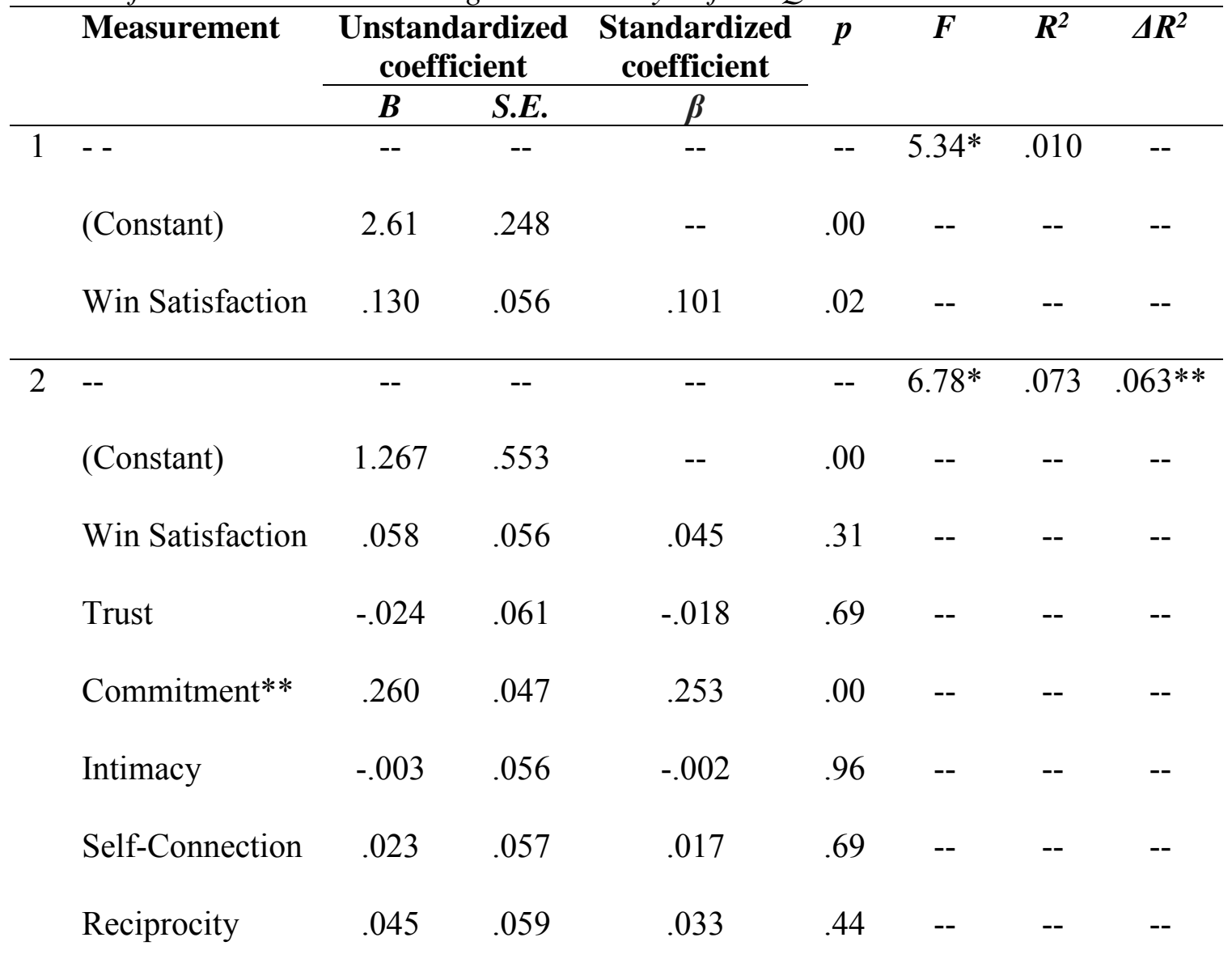

* Indicates significance at the $p<.05$ level

** Indicates significance at the $p<.01$ level 
RQ1c. Which aspects of relationship quality (trust, commitment, intimacy, selfconnection, and reciprocity) predict season ticket upsell intentions for the following season?

To address RQ1(c) a third hierarchical linear regression was performed, again using two blocks. The control variable of win satisfaction was entered first to determine the predictive nature of win satisfaction on upsell intentions. Next, the variables of trust, commitment, intimacy, self-connection, and reciprocity were entered into the equation (block 2) in order to determine significant change in the linear equation, and therefore the unique variance predicted by the independent variables.

The control variable (win satisfaction) entered into the equation with the dependent variable (upsell intentions) resulted in a statistically significant amount of variance explained $\left[R^{2}=.078, F(1,518)=43.85, p<.001\right]$ with its unstandardized coefficient of $.373(t=6.623, p<.001)$, suggesting win satisfaction accounted for $7.8 \%$ of the variance in upsell intentions. Block 2 of the linear equation also resulted in a statistically significant amount of variance explained $\left[\Delta R^{2}=.029, F(5,513)=3.286, \mathrm{p}=\right.$ .006] suggesting the combination of independent variables uniquely accounted for $2.9 \%$ of the variance in upsell intentions. Among the combination of independent variables, statistically significant relationships were found for commitment $(B=.332, t=3.50, p<$ .001). Notably, win satisfaction was found as a significant predictor in block 2 as well ( $B$ $=.373, t=5.78, p<.01)$, and contributed to the explained variance of the independent variables.

Results of this data suggest win satisfaction as a significant predictor in add-on intentions. Additionally, commitment was found to be a significant predictor of upsell 
intentions, and no other independent variables were found to have statistically significant relationships with the dependent variable. Table 17 shows the results of the hierarchical linear regression for RQ1c.

Table 17

Results of Hierarchical Linear Regression Analysis for RQ1c

\begin{tabular}{|c|c|c|c|c|c|c|c|c|}
\hline & Measurement & $\begin{array}{r}\text { Unstan } \\
\text { coef }\end{array}$ & $\begin{array}{l}\text { rdized } \\
\text { ient }\end{array}$ & $\begin{array}{c}\text { Standardized } \\
\text { coefficient }\end{array}$ & $p$ & $\boldsymbol{F}$ & $R^{2}$ & $\Delta R^{2}$ \\
\hline & & $\boldsymbol{B}$ & S.E. & $\beta$ & & & & \\
\hline 1 & -- & - & - & -- & -- & $43.86 * *$ & .078 & - \\
\hline & (Constant) & 1.646 & .249 & -- & .00 & -- & -- & -- \\
\hline & Win Satisfaction & .373 & .056 & .279 & .00 & -- & -- & -- \\
\hline 2 & -- & -- & -- & -- & -- & $10.21 * *$ & .107 & $.029 * *$ \\
\hline & (Constant) & .330 & .565 & -- & .56 & -- & -- & -- \\
\hline & Win Satisfact.** & .332 & .057 & .249 & .00 & -- & -- & -- \\
\hline & Trust & .065 & .062 & .046 & .30 & -- & -- & -- \\
\hline & Commitment** & .167 & .048 & .156 & .00 & -- & -- & -- \\
\hline & Intimacy & -.039 & .057 & -.029 & .50 & -- & -- & -- \\
\hline & Self-Connection & .090 & .058 & .064 & .13 & -- & -- & -- \\
\hline & Reciprocity & .096 & .060 & .067 & .11 & -- & -- & -- \\
\hline
\end{tabular}

* Indicates significance at the $p<.05$ level

** Indicates significance at the $p<.01$ level

RQ1d. Which aspects of relationship quality (trust, commitment, intimacy, selfconnection, and reciprocity) predict season ticket cross-sell intentions for the following season?

To address research question 1(d) a fourth hierarchical linear regression was performed, again using two blocks. The control variable of win satisfaction was entered 
first to determine the predictive nature of win satisfaction on cross-sell intentions. Next, the variables of trust, commitment, intimacy, self-connection, and reciprocity were entered into the equation (block 2) in order to determine significant change in the linear equation, and therefore the unique variance predicted by the independent variables.

The control variable (win satisfaction) entered into the equation with the dependent variable (cross-sell intentions) did not result in a statistically significant amount of variance explained $\left[R^{2}=.003, F(1,518)=1.587, p=.208\right]$. However, block 2 of the linear equation resulted in a statistically significant amount of variance explained $\left[R^{2}=.055, F(5,513)=4.982, \mathrm{p}<.001\right]$ suggesting the combination of independent variables uniquely accounted for $5.5 \%$ of the variance in upsell intentions. Among the combination of independent variables, statistically significant relationships were found for trust $(B=.205, t=3.681, p<.001)$ as well as reciprocity $(B=.114, t=2.127, p<$ .034) Results of this data suggest win satisfaction is not a significant predictor in crosssell intentions. Additionally, trust was found to be the most significant predictor of upsell intentions while reciprocity was found to have a weaker, yet significant relationship. No other independent variables were found to have statistically significant relationships with the dependent variable. Table 18 shows the results of the hierarchical linear regression for RQ1d.

Table 18

Results of Hierarchical Linear Regression Analysis for RQ1d

\begin{tabular}{|c|c|c|c|c|c|c|c|c|}
\hline & \multirow[t]{2}{*}{ Measurement } & \multicolumn{2}{|c|}{$\begin{array}{c}\text { Unstandardized } \\
\text { coefficient }\end{array}$} & \multirow{2}{*}{$\begin{array}{c}\begin{array}{c}\text { Standardized } \\
\text { coefficient }\end{array} \\
\boldsymbol{\beta} \\
\end{array}$} & \multirow[t]{2}{*}{$p$} & \multirow[t]{2}{*}{$F$} & \multirow[t]{2}{*}{$R^{2}$} & \multirow[t]{2}{*}{$\Delta R^{2}$} \\
\hline & & $B$ & S.E. & & & & & \\
\hline \multirow[t]{2}{*}{1} & -- & -- & -- & -- & -- & 1.587 & .003 & -- \\
\hline & (Constant) & 2.393 & .225 & -- & .00 & -- & -- & -- \\
\hline
\end{tabular}




\begin{tabular}{lccccccc} 
Win Satisfaction & .064 & .051 & .055 & .21 & -- & -- & -- \\
\hline 2 -- & -- & -- & -- & -- & $5.647^{* *}$ & .055 & $.052^{* *}$ \\
& & & & & & & \\
(Constant) & 1.553 & .505 & -- & .00 & -- & -- & -- \\
Win Satisfaction & .071 & .051 & .061 & .17 & -- & -- & -- \\
Trust** & .205 & .056 & .165 & .00 & -- & -- & -- \\
Commitment & -.058 & .043 & -.062 & .18 & -- & -- & -- \\
Intimacy & .067 & .051 & .057 & .19 & -- & -- & -- \\
Self-Connection & -.083 & .052 & -.069 & .11 & -- & -- & -- \\
Reciprocity* & .114 & .054 & .092 & .03 & -- & -- & -- \\
\hline
\end{tabular}

* Indicates significance at the $p<.05$ level

** Indicates significance at the $p<.01$ level

\section{Results and Analysis of Research Question 2}

RQ2- Which aspects of relationship selling (interaction intensity, agent disclosure, customer disclosure, and cooperative intentions) predict sport consumer purchase intentions in Division I College Football?

To address the second research question, a series of four hierarchical linear regressions was performed to determine the predictive validity of four independent variables (interaction intensity, agent disclosure, customer disclosure, and cooperative intentions) on four purchase intentions (renewal, add-on, upsell, cross-sell). RQ2 contained four sub-questions; one for each of the purchase behaviors of interest. All respondents $(n=377)$ completed the modified relational selling instrument adapted from Crosby et al., (1990) and reported the likelihood of renewal using a single-item measure 
of purchase intention. Correlations between independent variables for RQ1 are shown below in Table 19.

Table 19

Pearson's Correlation Between Independent Variables (RQ2)

\begin{tabular}{l|cccc}
\hline & $\begin{array}{c}\text { Interaction } \\
\text { Intensity }\end{array}$ & $\begin{array}{c}\text { Agent } \\
\text { Disclosure }\end{array}$ & $\begin{array}{c}\text { Customer } \\
\text { Disclosure }\end{array}$ & $\begin{array}{c}\text { Cooperative } \\
\text { Intentions }\end{array}$ \\
\hline Interaction Intensity & -- & .249 & .222 & .273 \\
Agent Disclosure & .249 & -- & .121 & .334 \\
Customer Disclosure & .222 & .056 & -- & .589 \\
Cooperative Intentions & .273 & .334 & .589 & - \\
\hline
\end{tabular}

RQ2a. Which aspects of relationship selling (interaction intensity, agent disclosure, customer disclosure, and cooperative intentions) predict season ticket renewal intentions for the following season?

To address RQ2(a) a hierarchical linear regression was performed using two blocks. First, performance satisfaction and passion were entered into the regression equation to control for these variables. Next, the independent variables of interaction intensity, agent disclosure, customer disclosure, and cooperative intentions were entered into the equation (block 2), allowing the researcher to test for significant change in the linear equation, and therefore unique variance predicted by the independent variables and not the control variable.

The control variables (win satisfaction and passion) entered into the equation with the dependent variable (renewal intentions) did not result in a statistically significant amount of variance explained $\left[R^{2}=.001, F(2,274)=.169, p=.845\right]$. However, block 2 of the linear equation resulted in a statistically significant amount of variance explained 
$\left[\Delta R^{2}=.081, F(4,370)=8.137, \mathrm{p}<.001\right]$ suggesting the combination of independent variables uniquely accounted for $8.1 \%$ of the variance in renewal intentions. Among the combination of independent variables, statistically significant relationships were found for interaction intensity $(B=-.188, t=-2.11, p=.036)$ as well as customer disclosure $(B$ $=.470, t=5.164, p<.001)$ and cooperative intentions $(B=-.216, t=-2.373, p=.018)$.

Results of the data suggest the combination of win satisfaction and passion may not be a significant predictor of renewal intentions. Additionally, when controlling for win satisfaction and passion, the strongest predictor of renewal intentions was customer disclosure. Furthermore, interaction intensity and cooperative intentions were found as weaker, yet still significant (negative) predictors of renewal intentions. The remaining independent variables were not found to significantly predict the dependent variable.

Table 20 shows the results of the hierarchical linear regression for RQ2a.

Table 20

Results of Hierarchical Linear Regression Analysis for RQ2a

\begin{tabular}{|c|c|c|c|c|c|c|c|c|}
\hline & Measurement & $\begin{array}{r}\text { Unsta } \\
\text { Co }\end{array}$ & $\begin{array}{l}\text { Irdized } \\
\text { cient }\end{array}$ & $\begin{array}{c}\text { Standardized } \\
\text { coefficient }\end{array}$ & $p$ & $F$ & $R^{2}$ & $\Delta R^{2}$ \\
\hline & & $\boldsymbol{B}$ & S.E. & $\beta$ & & & & \\
\hline 1 & -- & -- & -- & -- & -- & .169 & .001 & -- \\
\hline & (Constant) & 5.219 & .582 & -- & .00 & -- & -- & -- \\
\hline & Passion & -.010 & .077 & -.006 & .90 & -- & -- & -- \\
\hline & Win Satisfaction & .060 & .106 & .029 & .57 & -- & -- & -- \\
\hline 2 & -- & -- & -- & - & -- & $5.485 * *$ & .082 & $.081 * *$ \\
\hline & (Constant) & 5.231 & .683 & -- & .00 & -- & -- & -- \\
\hline & Passion & -.016 & .074 & -.011 & .83 & -- & -- & -- \\
\hline & Win Satisfaction & .065 & .102 & .032 & .52 & -- & -- & -- \\
\hline
\end{tabular}




\begin{tabular}{|c|c|c|c|c|c|c|c|}
\hline Interact. Intensity* & -.188 & .089 & -.111 & .04 & -- & -- & -- \\
\hline Agent Disclosure & -.070 & .081 & -.047 & .39 & -- & -- & -- \\
\hline Cust. Disclosure** & .470 & .091 & .322 & .00 & -- & -- & -- \\
\hline Cooperative Int.* & -.216 & .091 & -.156 & .02 & -- & -- & -- \\
\hline
\end{tabular}

** Indicates significance at the $p<.01$ level

* Indicates significance at the $p<.05$ level

RQ2b. Which aspects of relationship selling (interaction intensity, agent disclosure, customer disclosure, and cooperative intentions) predict season ticket add-on intentions for the following season?

To address research question 2(b) a second hierarchical linear regression was performed using two blocks. First, the control variables of performance satisfaction and passion were entered into the regression equation. Next, the independent variables of interaction intensity, agent disclosure, customer disclosure, and cooperative intentions were entered into the equation (block 2). The control variables (win satisfaction and passion) entered into the equation with the dependent variable (add-on intentions) did not result in a statistically significant amount of variance explained $\left[R^{2}=.001, F(2,374)=\right.$ $1.581, p=.207]$. However, block 2 of the linear equation resulted in a statistically significant amount of variance explained $\left[\Delta R^{2}=.161, F(4,370)=17.931, \mathrm{p}<.001\right]$ suggesting the combination of independent variables uniquely accounted for $16.1 \%$ of the variance in add-on intentions. Among the combination of independent variables, statistically significant relationships were found for customer disclosure $(B=.306, t=$ $4.19, p<.001)$ as well as cooperative intentions $(B=.260, t=3.589, p<.001)$. Notably, 
win satisfaction was found as a significant predictor in block 2 as well $(B=-.192, t=$ $2.38, p=.02$ ), and contributed to the explained variance of the independent variables.

Results of the data suggest the combination of win satisfaction and passion may not be a significant predictor of add-on intentions. Additionally, when controlling for win satisfaction and passion, the strongest predictor of renewal intentions was customer disclosure. Furthermore, cooperative intentions were found as weaker, yet still significant predictors of add-on intentions. The remaining independent variables were not found to significantly predict the dependent variable. Table 21 shows the results of the hierarchical linear regression for RQ2b.

Table 21

Results of Hierarchical Linear Regression Analysis for RQ2b

\begin{tabular}{|c|c|c|c|c|c|c|c|c|}
\hline & Measurement & $\begin{array}{r}\text { Unstai } \\
\text { coe }\end{array}$ & $\begin{array}{l}\text { rrdized } \\
\text { ient }\end{array}$ & $\begin{array}{c}\text { Standardized } \\
\text { coefficient }\end{array}$ & $p$ & $F$ & $R^{2}$ & $\Delta R^{2}$ \\
\hline & & $\boldsymbol{B}$ & S.E. & $\beta$ & & & & \\
\hline 1 & -- & -- & -- & -- & -- & 1.581 & .008 & -- \\
\hline & (Constant) & 3.782 & .489 & -- & .00 & -- & -- & -- \\
\hline & Passion & -.007 & .065 & -.006 & .91 & -- & -- & -- \\
\hline & Win Satisfaction & -.157 & .089 & -.091 & .08 & -- & -- & -- \\
\hline 2 & -- & -- & -- & -- & -- & $12.576^{* *}$ & .169 & $.161 * *$ \\
\hline & (Constant) & 2.416 & .548 & -- & .00 & -- & -- & -- \\
\hline & Passion & -.012 & .060 & -.010 & .84 & -- & -- & -- \\
\hline & Win Satisfaction* & -.192 & .082 & -.111 & .02 & -- & -- & -- \\
\hline & Interact. Intensity & -.061 & .072 & -.043 & .40 & -- & -- & -- \\
\hline & Agent Disclosure & -.099 & .065 & -.078 & .13 & -- & -- & -- \\
\hline & Cust. Disclosure** & .306 & .073 & .248 & .00 & -- & -- & -- \\
\hline
\end{tabular}


$\begin{array}{lllllllll}\text { Cooperative Int. }^{* *} & .261 & .073 & .225 & .00 & -- & -- & --\end{array}$

** Indicates significance at the $p<.01$ level

$*$ Indicates significance at the $p<.05$ level

RQ2c. Which aspects of relationship selling (interaction intensity, agent disclosure, customer disclosure, and cooperative intentions) predict season ticket upsell intentions for the following season?

To address research question 2(c) a third hierarchical linear regression was performed using two blocks. First, the control variables of performance satisfaction and passion were entered into the regression equation to determine the predictive nature of performance satisfaction and passion by itself. Next, the independent variables of interaction intensity, agent disclosure, customer disclosure, and cooperative intentions were entered into the equation (block 2). The control variables (win satisfaction and passion) entered into the equation with the dependent variable (upsell intentions) did not result in a statistically significant amount of variance explained $\left[R^{2}=.015, F(2,374)=\right.$ $2.892, p=.057]$. However, block 2 of the linear equation resulted in a statistically significant amount of variance explained $\left[\Delta R^{2}=.148, F(4,370)=16.422, p<.001\right]$ suggesting the combination of independent variables uniquely accounted for $14.8 \%$ of the variance in upsell intentions. Among the combination of independent variables, statistically significant relationships were found for interaction intensity $(B=-.180, t=$ $2.35, p=.019)$ as well as customer disclosure $(B=.486, t=6.217, p<.001)$. Notably, win satisfaction was found as a significant predictor in block 2 as well $(B=.205, t=2.34$, $p=.02)$, and contributed to the explained variance of the independent variables. 
Results of the data suggest the combination of win satisfaction and passion may not be a significant predictor of add-on intentions. Additionally, when controlling for win satisfaction and passion, the strongest predictor of renewal intentions was customer disclosure. Furthermore, interaction intensity was found as weaker, yet still significant (negative) predictor of upsell intentions. The remaining independent variables were not found to significantly predict the dependent variable. Table 22 shows the results of the hierarchical linear regression for RQ2c.

Table 22

Results of Hierarchical Linear Regression Analysis for RQ2c

\begin{tabular}{|c|c|c|c|c|c|c|c|}
\hline \multirow[t]{2}{*}{ Measurement } & \multicolumn{2}{|c|}{$\begin{array}{c}\text { Unstandardized } \\
\text { coefficient }\end{array}$} & \multirow{2}{*}{$\begin{array}{c}\begin{array}{c}\text { Standardized } \\
\text { coefficient }\end{array} \\
\beta \\
\end{array}$} & \multirow[t]{2}{*}{$p$} & \multirow[t]{2}{*}{$F$} & \multirow[t]{2}{*}{$R^{2}$} & \multirow[t]{2}{*}{$\Delta R^{2}$} \\
\hline & $\boldsymbol{B}$ & S.E. & & & & & \\
\hline 1 & -- & -- & -- & -- & 2.892 & .015 & -- \\
\hline (Constant) & 2.326 & .489 & -- & .00 & -- & -- & -- \\
\hline Passion & -.020 & .065 & -.015 & .77 & -- & -- & -- \\
\hline Win Satisfaction & .225 & .089 & .122 & .02 & -- & -- & -- \\
\hline 2 & -- & -- & - & -- & $12.071 * *$ & .164 & $.148 * *$ \\
\hline (Constant) & 1.625 & .587 & -- & .06 & -- & -- & -- \\
\hline Passion & -.026 & .064 & -.020 & .68 & -- & -- & -- \\
\hline Win Satisfaction* & .205 & .088 & .112 & .02 & -- & -- & -- \\
\hline Interact. Intensity* & -.180 & .077 & -.119 & .02 & -- & -- & -- \\
\hline Agent Disclosure & -.133 & .069 & -.099 & .06 & -- & -- & -- \\
\hline Cust. Disclosure** & .486 & .078 & .370 & .00 & -- & -- & -- \\
\hline Cooperative Int. & .038 & .078 & .031 & .62 & -- & -- & -- \\
\hline
\end{tabular}

** Indicates significance at the $p<.01$ level

$*$ Indicates significance at the $p<.05$ level 
RQ2d. Which aspects of relationship selling (interaction intensity, agent

disclosure, customer disclosure, and cooperative intentions) predict season ticket cross-sell intentions for the following season?

To address research question 2(d) a fourth hierarchical linear regression was performed using two blocks. First, the control variables of performance satisfaction and passion were entered into the regression equation to determine the predictive nature of performance satisfaction and passion by itself. Next, the independent variables of interaction intensity, agent disclosure, customer disclosure, and cooperative intentions were entered into the equation (block 2). The control variables (win satisfaction and passion) entered into the equation with the dependent variable (cross-sell) did not result in a statistically significant amount of variance explained $\left[R^{2}=.007, F(2,374)=1.295, p\right.$ $=.275]$. However, block 2 of the linear equation resulted in a statistically significant amount of variance explained $\left[\Delta R^{2}=.072, F(4,370)=7.182, \mathrm{p}<.001\right]$ suggesting the combination of independent variables uniquely accounted for $7.2 \%$ of the variance in cross-sell intentions. Among the combination of independent variables, statistically significant relationships were found for agent disclosure $(B=.177, t=2.715, p=.007)$ as well as cooperative intentions $(B=-.223, t=-3.028, p=.003)$.

Results of the data suggest the combination of win satisfaction and passion may not be a significant predictor of cross-sell intentions. Additionally, when controlling for win satisfaction and passion, the strongest predictor of renewal intentions was cooperative intentions (a negative correlation). Furthermore, agent disclosure was found as weaker, yet still significant predictor of upsell intentions. The remaining independent 
variables were not found to significantly predict the dependent variable. Table 23 shows the results of the hierarchical linear regression for RQ2d.

Table 23

Results of Hierarchical Linear Regression Analysis for RQ2d

\begin{tabular}{|c|c|c|c|c|c|c|c|c|}
\hline & Measurement & $\begin{array}{r}\text { Unsta } \\
\text { coe }\end{array}$ & $\begin{array}{l}\text { rdized } \\
\text { ent }\end{array}$ & $\begin{array}{c}\text { Standardized } \\
\text { coefficient }\end{array}$ & $p$ & $F$ & $R^{2}$ & $\Delta R^{2}$ \\
\hline & & $\boldsymbol{B}$ & S.E. & $\beta$ & & & & \\
\hline 1 & -- & -- & -- & -- & -- & 1.295 & .007 & -- \\
\hline & (Constant) & 3.281 & .470 & -- & .00 & -- & -- & -- \\
\hline & Passion & -.050 & .062 & -.041 & .43 & -- & -- & -- \\
\hline & Win Satisfaction & -.119 & .085 & -.072 & .16 & -- & -- & -- \\
\hline 2 & -- & -- & -- & -- & -- & $5.248 * *$ & .078 & $.072 * *$ \\
\hline & (Constant) & 3.984 & .555 & -- & .00 & -- & -- & -- \\
\hline & Passion & -.045 & .060 & -.037 & .46 & -- & -- & -- \\
\hline & Win Satisfaction & -.095 & .083 & -.057 & .25 & -- & -- & -- \\
\hline & Int. Intensity & -.066 & .073 & -.048 & .37 & -- & -- & -- \\
\hline & Agent Disc.* & .177 & .065 & .147 & .00 & -- & -- & -- \\
\hline & Customer Disc. & -.100 & .074 & -.084 & .18 & -- & -- & -- \\
\hline & Cooperate. Int.** & -.223 & .074 & -.200 & .00 & -- & -- & -- \\
\hline
\end{tabular}

** Indicates significance at the $p<.01$ level

* Indicates significance at the $p<.05$ level 


\section{Summary of Results}

The purpose of this study was to measure the impact of relationship quality and relationship selling techniques on consumer behavior in Division I college football. The instrument underwent a three-step pretesting procedure which included a panel of experts, field test, and pilot study. Changes from pretesting procedures developed a survey which was appropriate to address the problem and research questions of the study. The survey was distributed using Amazon MTurk and resulted in a dataset of 520 responses for RQ1 and 377 responses for RQ2. The instruments used in this study were then tested using a confirmatory factor analysis to confirm the theoretical factor structure of the instruments were appropriate and model fit to the data. In order to address the research questions, eight hierarchical linear regression models were performed and analyzed. The data met the assumptions of multiple regression and deemed appropriate for analysis of specific research questions and sub-questions.

The independent variables uniquely predicted renewal intentions in the linear equations for RQ1 and RQ2, with $10.1 \%$ and $7.8 \%$ of the variance explained, respectively. Positive predictors of renewal intentions included customer disclosure $(B=$ $.470)$, commitment $(B=.410)$, and trust $(B=.103)$. Negative predictors of renewal intentions included cooperative intentions $(B=-.210)$, interaction intensity $(B=-.188)$, and reciprocity $(B=-.147)$. Add-on intentions were uniquely predicted by the independent variable in the linear equation for RQ1 and RQ2 as well, with $6.3 \%$ and $16.1 \%$ of the variance explained, respectively. Positive predictors of add-on intentions included customer disclosure $(B=.306)$, cooperative intentions $(B=.261)$ and commitment $(B=.260)$. There were no negative predictors of add-on intentions. Upsell 
intentions were uniquely predicted by the independent variables in the linear equation for RQ1 and RQ2 as well, with $2.9 \%$ and $14.8 \%$ of the variance explained, respectively. Positive predictors of upsell intentions included customer disclosure $(B=.486)$, and commitment $(B=.167)$. Negative predictors of upsell intentions included interaction intensity $(B=-.180)$. Finally, cross-sell intentions were uniquely predicted by the independent variable in the linear equation for RQ1 and RQ2 as well, with 5.2\% and $7.2 \%$ of the variance explained, respectively. Positive predictors of cross-sell intentions included trust $(\mathrm{B}=.205)$, agent disclosure $(B=.177)$, and reciprocity $(B=.114)$. Negative predictors of cross-sell intentions included cooperative intentions $(B=-.233)$.

Taken together, the data shows relationship quality was more effective at predicting variance in renewal intentions, while relationship selling was considerably more effective at predicting "new" sales (add-on, upsell, and cross-sell). Among relationship quality, commitment was the only factor appearing significantly in three of the predictive models and tended to have a stronger relationship than other factors. For relationship selling, customer disclosure was the only factor significantly predicting in three of the four predictive models, and also tended to have a stronger relationship than the other factors. Interestingly, interaction intensity and cooperative intentions both appeared to be significantly correlated negatively with two purchase behaviors, conflicting with existing literature. Table 24 lists each purchase behavior as well as the independent variables which predicted each outcome.

Table 24

Summary of Significant Predictors

\begin{tabular}{ccc} 
Outcome Variable & $\begin{array}{c}\text { Relationship } \\
\text { Quality }\end{array}$ & $\begin{array}{c}\text { Relationship } \\
\text { Selling }\end{array}$ \\
\hline
\end{tabular}




\begin{tabular}{|c|c|c|c|}
\hline Positive Predictors & Renewal Intentions & Commitment & Cust. Disclosure \\
\hline & Add-On Intentions & Commitment & Cust. Disclosure, \\
\hline & & & Coop. Intentions \\
\hline & Upsell Intentions & Commitment & Cust. Disclosure \\
\hline & Cross-Sell Intentions & Trust & Agent Disclosure \\
\hline & & Reciprocity & \\
\hline Negative Predictors & Renewal Intentions & Reciprocity & Interaction Intensity, \\
\hline & & & Coop. Intentions \\
\hline & Add-On Intentions & -- & -- \\
\hline & Upsell Intentions & -- & Interaction Intensity \\
\hline & Cross-Sell Intentions & -- & Coop. Intentions \\
\hline
\end{tabular}




\section{CHAPTER V \\ DISCUSSION}

The purpose of this study was to measure the impact of relationship quality and relationship selling techniques on consumer behavior in Division I college football. By better understanding the effects box office operations have on consumer purchase intentions, college athletics departments may be better able to leverage one of their few controllable revenue streams and decrease financial dependence on their host institutions. Additionally, this study contributes to the theoretical frameworks of social exchange theory, as well as the literature surrounding service quality, relationship quality, relationship selling, and sport ticket sales.

The following section contains five sections: First, an interpretation of the results will discuss the results of the sample characteristics, as well as the four common outcomes variables of interest in this study. This section will be organized by outcome variable rather than research question since the outcome variables were the same for both research questions. Next, theoretical implications of the study will be reviewed, including the implications from the theoretical frameworks used in the study as well as the contributions to the literature resulting from the study. Third, the practical implications of the study will be reviewed as they relate to actual practitioners in college athletics departments and how the results of this study may be used to benefit revenue generation. Fourth, the limitations of the study will be highlighted and explained, allowing future 
researchers to place the findings in context. Lastly, the direction of possible future research will be outlined and discussed.

\section{Interpretation of the Results}

\section{Sample Characteristics}

The characteristics of this study contribute to the literature by offering a comprehensive sample of Division I programs combined with primary data collected from the consumer. This provides a unique benchmark which may be used to compare results of previous and future studies for differences and implications. Comprehensive samples have been gathered using secondary data provided by the NCAA, however few studies have examined this population using both primary data and more than a handful of participating schools. The current study represented all 10 of the major Division I conferences, as well as 94 of the 129 FBS teams. Thus, the current study may be used to compare against literature which consisted of one or few schools to implicate differences between such programs and the general population of college football season ticketholders..

The study consisted of 377 individuals who spoke with the box office over the phone, as well as an additional 143 who reported no phone contact with the box office, suggesting most college sports fans still engage in some form of communication with ticket sales professionals, despite trends leaning towards digital and mobile contact in the professional counterpart (Jhabvala, 2018). This finding supports a medium of contact between the box office and the customer which may be leveraged to improve service quality. Interestingly, there were very few demographic differences between those who contact the box office and those who do not. Specifically, it is worth noting participant 
age, longevity as a season ticketholder, and dollars spent were similar between the groups. Furthermore, despite actual method of contact, demographic data showed the preferred method of contact for most fans was via telephone (60.4\%), suggesting phone sales as an appropriate contact method for box office staff aiming to improve relationship-building practices.

The study utilized MTurk to solicit participation. Respondents were generally representative of college football fans according to SBRNet (2014) data. However, minor differences existed in marital status and racial makeup. Those in the current study were $10.4 \%$ less likely to be married. Furthermore, the sample contained $6.6 \%$ fewer white participants than the 2014 SBRNet data. Comparable demographics between MTurk users and general sports fans suggest MTurk can be a useful data collection platform for researchers investigating college football populations. The study consisted of only 22 student season ticketholders (4.2\%) and only 77 employee season ticketholders (14.4\%), suggesting MTurk may not be appropriate for studying student populations or employeeconsumers in Division I athletics.

\section{Relationship Quality}

Research question 1 examined the impact of variables of relationship quality on consumer purchase intentions. Commitment was the strongest predictor among the relationship quality variables, as it uniquely predicted renewals, upselling, and crossselling. Specifically, the unstandardized beta for renewal intentions (.410) suggests fans who demonstrate high levels of commitment to the team are much more likely to renew their tickets each year. This is consistent with previous literature which examined existing ticketholders (Kim et al., 2011; Wang et al., 2012). While positive predictive 
variables are helpful to the current problem of revenue generation in college athletics, implications may also be drawn from both negative predictors as well as non-predictors. While commitment was the strongest predictor of renewal intentions, it was also a significant predictor of both add-on and cross-sell intentions. Taken together, the implications of these results suggest commitment is a strong predictor of all-around football consumer behavior, and valuable to college sport organizations.

Aside from commitment, few independent variables significantly predicted variance in the purchase intentions studied. Interestingly, reciprocity negatively predicted renewal intentions, conflicting with existing literature (Kim et al., 20111; Wang et al., 2012). Additionally, trust and reciprocity significantly predicted cross-sell intentions. Given the nature of cross-selling involving an entirely different sport, the results may be interpreted by suggesting customers who trust in their sales representative are more likely to purchase because of their reliance on the sales representative's information and assistance. Likewise, since purchasing a different sport places a degree of separation between the customer and their football-fandom, consumers who have high levels of reciprocity may be more likely to purchase a different sport due to their faith in the program's likelihood to reward their patronage.

Lastly, while few variables significantly predicted positive purchase intentions, intimacy and self-connection reported no significant predictive ability with any purchase intentions. Additionally, trust resulted in no significant findings for any behaviors other than cross-selling. Such findings are noteworthy, since an emphasis on such variables from a practical standpoint may represent a waste of time, effort or money. For instance, since the only positive predictor of all football-related purchase behaviors was fan 
commitment, and resources invested in improving self-connection or intimacy with the fans are more likely to provide little financial return from the customer. Likewise, athletics departments who wish to leverage a strong football fanbase to increase revenues to different sports would be best served allocating time, money, or effort towards building trust between the department and the fans or showing fans reciprocal behaviors. Thus, both the findings, and non-findings of RQ1 offer implications for their impact on consumer behavior.

\section{Relationship Selling}

Research question 2 examined the predictive ability of relationship selling behaviors on consumer purchase behavior. Customer disclosure was the strongest positive predictor of purchase intentions across all football-related purchase behaviors. Customer disclosure represented the only positive predictor of renewal intentions and upsell intentions. Additionally, customer disclosure positively predicted add-on intentions along with cooperative intentions. This finding suggests customer disclosure is a "catchall" positive predictor of consumer behavior in college football and would likely warrant the most attention from practitioners. However, the addition of cooperative intentions as a predictor to add-on intentions suggests that cooperative intentions may also yield a benefit as a "specialized" predictor to athletics departments who want to specifically emphasize add-on ticket sales for their football team.

Significant negative predictors also existed in the relationship selling results, specifically regarding renewal intentions and upsell intentions. Renewal intentions were negatively predicted by interaction intensity and cooperative intentions. Additionally, interaction intensity had a significantly negative linear relationship with add-on purchase 
intentions, while the negative relationship between add-on purchase intentions and agent disclosure approached significance. Generally, negative correlations with relationship selling techniques would conflict with existing literature which finds relational selling as a largely positive attribute (Crosby et al., 1990; Wotruba, 1991; Boles et al., 2000; Eveleth \& Morris, 2002; Lai, Chou, \& Cheung, 2015). However, negative relationships specifically tied to information frequency from the agent (such as interaction intensity or agent disclosure) would parallel findings from Han et al., (2014) related to informational overload. Such findings may suggest that sales representatives who contact the customer too frequently or provide too much personal information create an information overload for the consumer, leading to possible negative purchase behavior.

Interpreting the positive predictors of football-related purchase behavior would suggest that the more a sales representative can extract information regarding the customer, the more likely the customer would be to purchase football-related tickets. It is likely such results may be attributed to the sales representative's ability to build rapport and better address the customers' needs, given more information about the customer's individual situation (Campbell, Davis, \& Skinner, 2013). The ability of cooperative intentions to uniquely predict add-on intentions would suggest a "specialized" attribute of relationship selling, useful to sales representatives who want to maximize the financial investment of a customer. This may suggest customers are more likely to invest in additional tickets when they believe the sales representative has the customer's best interest in mind, rather than their own.

Negative predictors present in the study suggest sport may be unique in its application of relationship selling practices. Interaction intensity negatively predicted 
both renewal intentions as well as add-on intentions. Likewise, cooperative intentions negatively predicted renewal intentions as well as cross-sell intentions. This finding suggests sport consumers may be unique from traditional business int their desire for only a limited amount of contact with the sales representative. Negative findings regarding cooperative intentions are difficult to interpret; made even more difficult by the positive prediction of add-on intentions. However, this may be explained by suggesting customers prefer to maintain control in the areas of renewal and cross-selling while they are more likely to seek help for add-on intentions due to possible scarcity of available tickets. That is to say, sport is unique in that there may be a scarcity of inventory, requiring help from the sales representative for add-on sales that is not needed for other purchase intentions. If not soliciting an add-on purchases, findings suggest there may be an interesting phenomenon involving the sales representative being "too helpful". Ultimately, negative findings suggest sales representatives should be cautious in how many times they engage a customer within a certain timeframe, as well as how the project their willingness to help. Additionally, sales representatives may want to avoid sharing large amounts of information about themselves to the customer.

Lastly, the study highlights a considerable number of non-findings in the results. Interaction intensity did not positively predict any of the outcome variables, suggesting sport consumers place less emphasis on the frequency of contact than traditional business consumers. Furthermore, agent disclosure only positively predicted cross-selling intentions, suggesting football-related purchase behavior is not affected by the amount of personal information offered from the sales representative. Likewise, while cooperative intentions did not positively predict any variable other than add-on intentions while 
negatively predicting renewals and cross-selling, suggesting this variable as a risky attribute to highlight. Taken together, non-findings from this study suggest while relationship selling activities positively predicted a considerable amount of variance, the more specific functions of relationship selling were not consistent, emphasizing the unique nature of sport business.

\section{Practical Implications}

The problem the current study attempts to address involves the financial deficit between the generated revenues and expenses of college athletics departments, and the reliance on institutional funds to close such a deficit. Practical implications from this study may be used to promote college athletics revenue generation from one of the few controllable, institution-specific revenues remaining in each school's financial portfolio. The current study demonstrates improving relationship quality and relationship selling techniques from the box office of the institution may increase the likelihood of not only season ticket renewal intentions, but also provide additional revenue from existing customers. Similar to the sport management education implications, these findings are most appropriately implemented in marketing efforts and sales training.

Football-Specific Sales. Both commitment and customer disclosure predicted all football-related sales (renewal, add-on, and upsell). Broadly speaking, the results suggest sales teams and box office personnel should emphasize commitment to the team in all sales pitches. Likewise, marketers (especially those with limited resources) looking to increase football revenue from existing customers may find it useful to segment customers with high levels of commitment for "new revenue" sales campaigns. These customers are more likely to increase their investment and would be most pragmatic 
customers to target. Additionally, further training in the area of customer disclosure is warranted, as this variable maintained the highest predictive ability among the variables studied. Specifically, sales training should emphasize strategies to efficiently gather as much information from the customer as possible. Lastly, cooperative intentions uniquely predicted add-on intentions, suggesting sales representatives who are trying to solicit an existing customer to purchase more tickets should emphasize having the customers' best interest in mind.

Cross-Selling (to a non-football sport). The current study introduced one of the only investigations into sport cross-sell behavior. Within ticket sales operations, this may be somewhat specific to college athletics; however professional sport practitioners may find use of the results as well. The current study shows the predictive factors of footballspecific purchase behaviors (renewal, upsell, add-on) are not the same as those which predict cross-sell behavior. This finding is important for sport management practitioners as it suggests a different marketing strategy and different sales training method may be required to emphasize cross-selling.

Cross-sell purchase intentions were uniquely predicted by trust and reciprocity, suggesting there is a distinctly different strategy when trying to solicit football season ticketholders into purchasing other sports. During cross-sell sales pitches, sales representatives may be benefitted by emphasizing a trustworthy department, and trying to highlight the reciprocal relationship between the fan and the athletics department. Similar to football purchase intentions, these variables may also be used to segment fanbases based on high levels of trust and reciprocity, as those customers would be more likely to cross-purchase. Interestingly, while agent disclosure showed no relationship or a negative 
relationship with some purchase behaviors, it was found to significantly predict cross-sell intentions. This may imply sales representatives should exercise caution when offering too much personal information and limit such behavior to the interaction with a customer during a cross-sell solicitation.

\section{Theoretical Implications}

Social Exchange Theory. SET behaviors are governed by the balance of rewards and costs between two people (Emerson, 1976). Research in sales has suggested sales representatives enter a social exchange which may add value to the relationship during the exchange, improving perceived worth of the service or item being sold (Lee, Capella, Taylor, \& Gabler, 2014; Johnson, 2015). The current study shows sales representatives' actions predict significant amounts of variance in the customers' purchase behavior by engaging in relationship selling activities. These findings support the use of SET in sport sales, despite the dearth of SET in the sport management literature. More broadly speaking, Exchange Theory (ET), a more robust application of SET, may be useful in grounding studies which approach the relationship from an organizational level, rather than an individual one.

Service Quality. Service quality refers to the bundle of benefits provided by the organization to the customer, which includes the facility, appearance, and personnel, among other aspects (Bateson, 1992). By improving service quality, an organization is able to add value to the customer and increase the likelihood of future purchase behavior (PZB, 1992, 1994). Since the current study aims to investigate the effects of box office personnel on college athletics consumer purchase behavior, service quality is highlighted as the conceptual framework to guide the study. 
Sport service quality literature has typically measured the continuum of the customer from arrival at the venue to departure (Howat \& Murray, 1999; Theodorakis et al., 2001; Murray \& Howat, 2002; Shonk \& Chelladurai, 2008; Theodorakis et al., 2009; Yoshida \& James, 2010; Ko et al., 2011; Biscaia et al., 2013). However, the current study investigates the impact of box office sales representatives who contact customers yearround, and often provide the first point of contact between fans and the event. Since relationship selling techniques predicted significant portions of the purchase intentions of the customer, the current study supports the extension of the timeline which service quality is commonly framed within and encourages future research to consider sport service quality as a year-round interaction with the customer, rather than a short-lived engagement between the customer and gameday personnel.

Relationship Quality. Relationship quality measures the strength of the relationship between the customer and an organization and has been described as both a moderator to purchase intentions (Crosby et al., 1990) as well as a competitive advantage in business (Hughes et al., 2013). Relationship quality in sport stems primarily from the work of Kim and Trail $(2009 ; 2011)$ as well as Kim et al., (2011). Relationship quality has been studied for predictive abilities with purchase intentions in the literature previously (Kim et al., 2011; Wang et al., 2012); however it has only been studied using single institutions or teams. The current study bolsters the literature surrounding relationship quality in sport as well as the SCTRQS (Kim et al., 2011), as a representative sample of over 90 institutions resulted in significant predictive variance of purchase intentions. 
However, the current study also highlights challenges of the SCTRQS measurement. The results of the sport-specific SCTRQS scale resulted in less explained variance than the modified relational selling scale. Additionally, only one of the five variables positively predicted purchase intentions, which conflicts with existing literature. Lastly, the scale showed poor convergent validity, suggesting the conceptual framework which grouped the five (theoretically similar) variables of the SCTRQS together may need to be revisited. These results conflict with the findings of the article regarding the instrument's original development (Kim et al., 2011), and therefore further investigation into the convergent validity and effectiveness of the SCTRQS is warranted.

Relationship Selling. Relationship selling refers to the practice of engaging in exchanges with the customer which promote long-term relationship building (Jolston, 1997). Relationship selling typically measures interactions at an individual level between a sales agent and a customer, allowing researchers to investigate the more specific interaction between the parties. This study investigated relationship selling between box office sales representatives and season ticketholders. There is currently a gap in the literature surrounding relationship selling practices in sport and given the importance of revenue generation in college athletics, this study aimed to fill such a gap.

The findings of this study suggest relationship selling is appropriate to examine with respect to consumer behavior, as the linear equation of variables predicted fairly large amounts of variance (as much as 16.1\%) in the purchase behaviors studied. This suggests relationship selling is an effective tool in promoting sales effectiveness and may be highlighted as a possible remedy to the dire financial dilemma which many college athletics departments face. Such findings are substantial, especially considering the 
instrument used to measure relationship selling was not originally intended to do so. The effectiveness of the modified relationship selling instrument used in this study would suggest more robust research involving a sport-specific relationship selling scale is warranted.

Lastly, the current study contributes to relationship selling by highlighting the unique addition of the sport industry to the literature, which includes differences from the general business literature. Relationship selling literature in general business services often concludes with linear, positive relationships with purchase behaviors (Crosby et al., 1990; Wotruba, 1991; Boles et al., 2000; Eveleth \& Morris, 2002; Lai, Chou, \& Cheung, 2015). However, the current study represents the unique nature of the sport industry and sport product, as some of the variables (interaction intensity, agent disclosure, cooperative intentions) showed significantly negative correlations with purchase behavior. This suggests some factors of relationship selling may, in fact, be a detriment to sales effectiveness toward some purchase behaviors. Such findings may be explained by Han et al.'s (2014) study involving information overload from sales representatives.

Spectator Sport Ticket Sales. The current study agrees with much of the existing literature surrounding box office operations and their effect on sport ticket sales. Previous studies have shown box office operations as impactful on customer satisfaction (Smith \& Roy, 2011) as well as pricing (Warren, 2016) and word-of-mouth behavior (Theodorakis \& Alexandris, 2008). Where the current study contributes to the box office operations literature lies in the specific measurement of individual aspects of the sales process, and how each specifically predicts purchase behavior, giving a more detailed view of the sales process and sales effectiveness surrounding box office operations. Additionally, the 
current study adds robustness to the ticket sales literature by including an entire league of member institutions (Division I) rather than a select few, which allows for greater generalizability of the results and implications.

While the predictor variables of interest contribute to the literature by adding specificity, the outcome variables of the current study may maintain the largest contribution to sport ticket sales literature. Traditionally, studies involving consumer purchase intentions in ticket sales are designed to measure ticket sales as a whole, and few studies distinguish different types of sales from one another. This study poses contributions to the literature in its division of different purchase behaviors by including not only season ticket renewals, but also upselling, add-on purchases, and cross-selling. As college athletics departments look to maintain the existing fanbase, they will also be looking for growth and acquisition of new revenues. Literature has shown one of the most promising "new" revenue streams lies in the existing fanbase (Spoelstra, 2009). By adding upsell, add-on, and cross-sell implications to the literature, the study highlights customers who may opt to increase their financial commitment to the athletics department, helping practitioners maximize the revenue acquired from each customer.

The last contribution of this study to the spectator sport literature includes the justification of relationship selling practices in sport management education. Previous studies have emphasized the importance of teaching relationship-based selling to sport management students (Smith \& Roy, 2011), however without empirical evidence of relationship selling effectiveness, sport management educators may be left in questions as to whether they are teaching the most appropriate material. The current study confirms the importance of relationship selling in box office operations and justifies its including 
in sport sales education. Specifically, sport management educators may want to allocate time and effort towards prompting customer disclosure in the sales process, given this variable's considerable predictive nature with purchase intentions. Additionally, sport management educators may want to temper their emphasis on agent disclosure and cooperative intentions in the sales process for football-related sales, yet highlight trust, reciprocity, and cooperative intentions when engaging in a cross-sell solicitation to another sport.

\section{Limitations}

Given ticket sales represents a larger percentage of revenue in Division I and is most likely to address the problem of budget deficits, the current study only examined Division I athletics departments. Implications from this study may be used to guide practitioners and researchers examining other divisions, however more specific research related to the financial situation and sales effectiveness in other divisions would be needed. Additionally, this study asked participants to indicate their likelihood of future purchase behavior and does not measure actual purchase behavior. A longitudinal study which collects data at the conclusion of the football season and re-connects with the same customers to collect actual purchase behavior prior to the following season would have been preferable. However, the MTurk platform combined with the need for a large, generalizable sample including dozens of schools made such a data collection unlikely. Furthermore, the timing of the data collection was not ideal. Data were collected months into the sales process, and while only $12 \%$ of consumers had indicated purchase commitments at the time of the study, future studies should aim to collect data at the conclusion of football season, rather than during the sales cycle. 
Lastly, the current study utilized a modified relationship selling scale which was initially used to measure relationship selling in whole-term life insurance. This is a limitation of the study since it is possible there are additional factors of relationship selling specific to sport which would not be represented in the current study. However, it is worth noting the modified instrument was thoroughly tested for its applicability in the current study and found acceptable. Furthermore, the modified instrument predicted considerable amounts of variance in purchase behaviors, suggesting its use as a valuable tool in the literature. Regardless, a sport-specific relationship selling scale may provide an even more predictive tool and would certainly have benefitted the current study.

\section{Future Research}

Given the predicted variance of the linear equation related to relationship selling, a sport-specific relationship selling scale would certainly be highlighted as a promising future contribution to the sales literature. Such a study may highlight additional relationship selling activities not accounted for in the current study and would yield more practical applicability to address the problem of this study. Additionally, studies utilizing data from a longitudinal standpoint would provide a more robust understanding of the changes in consumer purchase intentions in sport ticket sales. Future research would also be warranted to examine relationship quality and relationship selling on the professional level to determine differences between college and professional sport consumers.

Future research specific to the problem of college athletics revenue deficits may wish to investigate the sales representative-ticketholder relationship more specifically. Qualitative data collected during the sales process, combined with interviews from season ticketholders along with the sales representative themselves would allow researchers to 
triangulate specifically why the findings of the current study were present. For instance, a mixed-methods examination of customer disclosure, measuring the perceived disclosure from the standpoint of the customer combined with a qualitative interview of the customer's experience may lead researchers to a better understanding of the nature of customer disclosure, including how and why it predicted purchase intentions more so than other variables in this study. Ultimately, there is a dearth of sport management literature targeting one-on-one engagements of sales representatives and customers and given the findings of the current study regarding relationship selling and social exchange, future research in the area is certainly warranted.

\section{Summary of Study}

College athletics departments are spending money faster than they make it, and in an effort to make ends meet, athletics departments are becoming more heavily dependent on institutional and allocated funds (Fulks, 2016). Many of the largest revenue streams available to an athletics problem to alleviate the financial strain are fixed, as they are guaranteed within decade-long agreements which offer little flexibility for future growth during the term of the contract. Ticket sales remains a large revenue generator which is specific to each institution and variable enough to be influenced by the department, potentially increasing revenue and profitability for the department. However, ticket sales have remained flat, and box office operations have been highlighted as inefficient, limiting the profitability of this revenue stream. Thus, the purpose of this study was to examine relationship quality and relationship selling from the perspective of the box office to determine its impact on several college athletics ticket purchase behaviors. 
The study found both relationship selling and relationship quality to be significant predictors of purchase intentions, suggesting possible benefit in increasing revenues. Specifically, fan commitment and customer disclosure were found to be the most considerable influencers of purchase behavior, significantly predicting all footballrelation purchase intentions. Cross-selling was introduced as a new focus for revenue generation and found to be significantly predicted by different variables than the football related outcomes. Specifically, agent disclosure, trust, and reciprocity predicted such behaviors, suggesting consumers likely to cross-purchase act different from football-only consumers.

Implications from the current study offer both practical and theoretical implications. The study broadens the spectrum of service quality literature by expanding the timeframe in which researchers may view the collective actions of service quality. Additionally, the study highlights the need for additional confirmation of the effectiveness of current relationship quality instruments, while highlighting the need for a sport specific relationship selling instrument of its own. Practical implications from the current study suggest sport consumers behave differently from traditional business consumers and provide a better understanding of marketing efforts and sales training efforts which may be effective in increasing revenues streams to benefit the bottom line. 


\section{REFERENCES}

Anderson, E., \& Weitz, B. (1989). Determinants of continuity in conventional industrial channel dyads. Marketing Science, 8(4), 310-323.

Arli, D., Bauer, C., \& Palmatier, R. W. (2017). Relational selling: Past, present and future. Industrial Marketing Management, 69(1), 169-184.

Avila, R. A., \& Inks, S. A. (2017). The evolution of the sales process: Relationship selling versus the challenger sales. Retrieved from: https://digitalcommons. kennesaw.edu/cgi/viewcontent.cgi?referer=https://scholar.google.com/\&httpsredir $=1 \&$ article $=1218 \&$ context $=$ ama_proceedings

Awang, Z., Afthanorhan, A., Mohamad, M., \& Asri, M. A. M. (2015). An evaluation of measurement model for medical tourism research: The confirmatory factor analysis approach. International Journal of Tourism Policy, 6(1), 29-45.

Baker, D. A., \& Crompton, J. L. (2000). Quality, satisfaction and behavioral intentions. Annals of Tourism Research, 27(3), 785-804.

Bateson, J. E. (1992). Managing services marketing: Text and readings. London, England: Dryden Press.

Baysinger, T. (2016). The ACC finally lands its own tv network through a partnership with ESPN. Adweek. Retrieved from: http://www.adweek.com/tv-video/acc-dodd finally-lands-its-own-tv-network-through-partnership-espn-172619/

Bee, C., \& Kahle, L. (2006). Relationship marketing in sports: A functional approach, Sport Marketing Quarterly, 15(2), 102-110. 
Bentler, P. M. (1992). On the fit of models to covariances and methodology to the Bulletin. Psychological Bulletin, 112(3), 400.

Bergkvist, L., \& Rossiter, J. R. (2007). The predictive validity of multiple-item versus single-item measures of the same constructs. Journal of Marketing Research, 44(2), 175- 184.

Berkowitz, S., Upton, J., \& Brady, E. (2013). Most NCAA Division I athletics departments take subsidies. USAToday.com. Retrieved from: https://www.usatoday.com/story/sports/college/2013/05/07/ncaa-financessubsidies/2142443/

Berinsky, A. J., Huber, G. A., \& Lenz, G. S. (2012). Evaluating online labor markets for experimental research: Amazon.com's Mechanical Turk. Political Analysis, 20(3), 351-368.

Berry, L. L. (1983). Relationship marketing. Emerging Perspectives on Services Marketing, 25-28

Berry, L. L., Parasuraman, A., \& Zeithaml, V. A. (1994). Improving service quality in America: lessons learned. The Academy of Management Executive, 8(2), 32-45.

Berry, L. L. (1995). Relationship marketing of services- growing interest, emerging perspectives. Journal of the Academy of Marketing Science, 23(4), 236-245.

Biscaia, R., Correia, A., Rosado, A. F., Ross, S. D., \& Maroco, J. (2013). Sport sponsorship: The relationship between team loyalty, sponsorship awareness, attitude toward the sponsor, and purchase intentions. Journal of Sport Management, 27(4), 288-302. 
Bishop Gagliano, K., \& Hathcote, J. (1994). Customer expectations and perceptions of service quality in retail apparel specialty stores. Journal of Services Marketing, 8(1), 60-69.

Blake, R. R., \& Mouton, J. S. (1970). The grid for sales excellence: Benchmarks for effective salesmanship. New York, NY: McGraw-Hill Companies.

Boles, J. S., Johnson, J. T., \& Barksdale Jr, H. C. (2000). How salespeople build quality relationships: A replication and extension. Journal of Business Research, 48(1), $75-81$

Bouchet, A., Ballouli, K., \& Bennett, G. (2011). Implementing a ticket sales force in college athletics: A decade of challenges. Sport Marketing Quarterly, 20(2), 8492.

Boulding, W., Kalra, A., Staelin, R., \& Zeithaml, V. A. (1993). A dynamic process model of service quality: From expectations to behavioral intentions. Journal of Marketing Research, 30(1), 7-27.

Browne, M. W., \& Cudeck, R. (1993). Alternative ways of assessing model fit. Sage Focus Editions, 154, 136-137

Bollen, K. A., \& J. S. Long (1992). Tests for structural equation models: Introduction. Sociological Methods and Research, 21(2), 123-131

Burnsed, B. (2015). Athletics departments that make more than they spend still a minority. Ncaa.org. Retrieved from: http://www.ncaa.org/about/resources/mediacenter/news/athletics-departments-make-more-they-spend-still-minority.

Byon, K. K., Zhang, J. J., \& Baker, T. A. (2013). Impact of core and peripheral service quality on consumption behavior of professional team sport spectators as 
mediated by perceived value. European Sport Management Quarterly, 13(2), 232263.

Chelladurai, P., \& Chang, K. (2000). Targets and standards of quality in sport services. Sport Management Review, 3(1), 1-22.

Chen, C. (2006). Identifying significant factors influencing consumer trust in an online travel site. Information Technology \& Tourism, 8(3-4), 197-214.

Cousens, L., Babiak, K., \& Bradish, C. L. (2006). Beyond sponsorship: Re-framing corporate-sport relationships. Sport Management Review, 9(1), 1-23.

Creswell, J. W. (2008). Educational research: Planning, conducting, and evaluating quantitative and qualitative research, New York, NY: Pearson.

Cronin Jr., J.J., Brady, M.K., \& Hult, G.T.M. (2000). Assessing the effects of quality, value, and customer satisfaction on consumer behavioral intentions in service environments. Journal of Retailing, 76(2), 193-216.

Cronin Jr, J. J., \& Taylor, S. A. (1992). Measuring service quality: A re-examination and extension. The Journal of Marketing, 56(3), 55-68.

Crosby, L. A., Evans, K. R., \& Cowles, D. (1990). Relationship quality in services selling: An interpersonal influence perspective. The Journal of Marketing, 54(3), $68-81$.

Davis, J. C. (1995). Dependency, self-interest, and relationship marketing: A view of the nature of exchange. Journal of Marketing Theory and Practice, 3(4), 17-23.

Derlega, V. J., \& Berg, J. H. (1987). Self-disclosure: Theory, research, and therapy. New York, NY: Plenum Press. 
De Cannière, M. H., De Pelsmacker, P., \& Geuens, M. (2010). Relationship quality and purchase intention and behavior: The moderating impact of relationship strength. Journal of Business and Psychology, 25(1), 87-98.

De Wulf, K. D., Odekerken-Schröder, G., \& Iacobucci, D. (2001). Investments in consumer relationships: A cross-country and cross-industry exploration. Journal of Marketing, 65(4), 33-50.

Denhart, M., \& Ridpath, D. (2011). Funding the arms race: A case study of student athletic fees. Center for College Affordability and Productivity. Retrieved from: https://files.eric.ed.gov/fulltext/ED536146.pdf

Derlega, V. J., Winstead, B. A., Wong, P. T. P., \& Greenspan, M. (1987). Self-disclosure and relationship development: An attributional analysis. Sage Annual Reviews of Communication Research, 14, 172-187.

DeVellis, R. F. (2016). Scale development: Theory and applications, Thousand Oaks, CA: Sage publications.

Dillman, D. A., Smyth, J. D., \& Christian, L. M. (2014). Internet, phone, mail, and mixed-mode surveys: The tailored design method. Hoboken, NJ: John Wiley \& Sons.

“Division I Revenue Distributions", (2017). NCAAorg.com. Retrieved from: http://www.ncaa.org/about/resources/finances/distributions

Drayer, J., \& Shapiro, S. (2009). Value determination in the secondary ticket market: A quantitative analysis of the NFL playoffs. Sport Marketing Quarterly, 18(1), 5-13.

Drigotas, S. M., \& Rusbult, C. E. (1992). Should I stay or should I go? A dependence model of breakups. Journal of Personality and Social Psychology, 62(1), 62-87. 
Drollinger, T., \& Comer, L. B. (2012). Salesperson's listening ability as an antecedent to relationship selling. Journal of Business \& Industrial Marketing, 28(1), 50-59.

Dwyer, B., Drayer, J., \& Shapiro, S. (2013). Proceed to checkout? The impact of time in advanced ticket purchase decisions. Sport Marketing Quarterly, 22(3), 166-180.

Dwyer, F. R., Schurr, P. H., \& Oh, S. (1987). Developing buyer-seller relationships. The Journal of Marketing, 11-27.

Emerson, R. M. (1976). Social exchange theory. Annual Review of Sociology, 2(1), 335362.

Eveleth, D. M., \& Morris, L. (2002). Adaptive selling in a call center environment: A qualitative investigation. Journal of Interactive Marketing, 16(1), 25-39.

Field, A. (2009). Discovering statistics using SPSS. Thousand Oaks, CA: Sage publications.

Fink, J. S., Trail, G. T., \& Anderson, D. F. (2002). Environmental factors associated with spectator attendance and sport consumption behavior: Gender and team differences. Sport Marketing Quarterly, 11(1).

Fornell, C., Johnson, M. D., Anderson, E. W., Cha, J., \& Bryant, B. E. (1996). The American customer satisfaction index: Nature, purpose, and findings. The Journal of Marketing 60(4), 7-18.

Foster, B. D., \& Cadogan, J. W. (2000). Relationship selling and customer loyalty: An empirical investigation. Marketing Intelligence \& Planning, 18(4), 185-199.

Fowler, J. (2013). The Southeastern Conference altered its media rights deal with CBS, but no new money is involved. CBSSports.com. Retrieved from: 
https://www.cbssports.com/college-football/news/sec-cbs-rework-long-termcontract/

Fournier, S. (1998). Consumers and their brands: Developing relationship theory in consumer research. Journal of Consumer Research, 24(4), 343-373.

Fulks, D. L. (2016). NCAA Division I Intercollegiate Athletics Programs Report, 20042015: Revenues and Expenses. Retrieved from: http://www.ncaapublications .com/p-4443-division-i-revenues-and-expenses-2004-2015.aspx

Funk, D. C., Mahony, D. F., \& Ridinger, L. L. (2002). Characterizing consumer motivation as individual difference factors: Augmenting the sports interest inventory (SII) to explain level of spectator support. Sport Marketing Quarterly, 11(1), 33-43.

Funk, D. C., Ridinger, L. L., \& Moorman, A. M. (2004). Exploring origins of involvement: Understanding the relationship between consumer motives and involvement with professional sport teams. Leisure Sciences, 26(1), 35-61.

Gladden, J. M., Milne, G. R., \& Sutton, W. A. (1998). A conceptual framework for assessing brand equity in Division I college athletics. Journal of Sport Management, 12(1), 1-19.

Goolsby, J. R., Lagace, R. R., \& Boorom, M. L. (1992). Psychological adaptiveness and sales performance. Journal of Personal Selling \& Sales Management, 12(2), 5166.

Gouldner, A. W. (1960). The norm of reciprocity: A preliminary statement. American Sociological Review, 25, 161-178. 
Green, S. B. (1991). How many subjects does it take to do a regression analysis? Multivariate Behavioral Research, 26(3), 499-510.

Greenwell, T. C., Fink, J. S., \& Pastore, D. L. (2002). Assessing the influence of the physical sports facility on customer satisfaction within the context of the service experience. Sport Management Review, 5(2), 129-148.

Greenwell, T. C., Brownlee, E., Jordan, J. S., \& Popp, N. (2008). Service fairness in spectator sport: The importance of voice and choice on customer satisfaction. Sport Marketing Quarterly, 17(2), 71-78.

Grönroos, C. (1984). A service quality model and its marketing implications. European Journal of Marketing, 18(4), 36-44.

Grönroos, C. (1990). Relationship approach to marketing in service contexts: The marketing and organizational behavior interface. Journal of Business Research, 20(1), 3-11.

Hallowell, R. (1996). The relationships of customer satisfaction, customer loyalty, and profitability: An empirical study. International Journal of Service Industry Management, 7(4), 27-42.

Han, D., Herjanto, H., \& Gaur, S. (2014). Impact of salesperson information overload on relationship selling behaviors and sales performance: A conceptual framework. Retrieved from: http://aut.researchgateway.ac.nz/bitstream/handle/10292/8272/ Managing\%20Information\%20in\%20the\%20Selling\%20Process8Jan14 $\% 20(1) \cdot$ pdf; sequence $=9$ 
Han, D., Mahony, D. F., \& Greenwell, T. C. (2016). A comparative analysis of cultural value orientations for understanding sport fan motivations. International Journal of Sports Marketing and Sponsorship, 17(3), 260-276.

Hennig-Thurau, T., \& Klee, A. (1997). The impact of customer satisfaction and relationship quality on customer retention: A critical reassessment and model development. Psychology \& Marketing, 14(8), 737-764.

Homburg, C., Müller, M., \& Klarmann, M. (2011). When does salespeople's customer orientation lead to customer loyalty? The differential effects of relational and functional customer orientation. Journal of the Academy of Marketing Science, 39(6), 795-812.

Houston, F. S., \& Gassenheimer, J. B. (1987). Marketing and exchange. The Journal of Marketing, 51(4), 3-18.

Honson, W., \& Steven, R. (2015). Why students foot the bill for college sports, and how some are fighting back. Washingtonpost.com. Retrieved from: https://www.washingtonpost .com/sports/why-students-foot-the-bill-for-collegesports-and-how-some-are-fighting-back/2015/11/30/7ca47476-8d3e-11e5-ae1f af46b7df8483story.html?utm_term=.6fa828ef2003.

Hooper, D., Coughlan, J., \& Mullen, M. (2008). Structural equation modelling: Guidelines for determining model fit. Electronic Journal of Business Research Methods, 6(1), 53-60.

Howard, D. R., \& Crompton, J. L. (2004). Tactics used by sports organizations in the United States to increase ticket sales. Managing Leisure, 9(2), 87-95. 
Hu, L. T., \& Bentler, P. M. (1998). Fit indices in covariance structure modeling: Sensitivity to underparameterized model misspecification. Psychological methods, 3(4), 424-453.

Hughes, D. E., Le Bon, J., \& Rapp, A. (2013). Gaining and leveraging customer-based competitive intelligence: The pivotal role of social capital and salesperson adaptive selling skills. Journal of the Academy of Marketing Science, 41(1), 91110.

Irwin, R. L., \& Sutton, W. A. (2011). Ticket sales coaching innovation: A few pages from Paul Brown's playbook. Sport Marketing Quarterly, 20(2), 103-111.

Irwin, R. L., Sutton, W. A., \& McCarthy, L. M. (2008). Sport promotion and sales management. Champaign, IL: Human Kinetics.

Jae Ko, Y., Zhang, J., Cattani, K., \& Pastore, D. (2011). Assessment of event quality in major spectator sports. Managing Service Quality: An International Journal, 21(3), 304-322.

Jiang, Y., \& Lu Wang, C. (2006). The impact of affect on service quality and satisfaction: The moderation of service contexts. Journal of Services Marketing, 20(4), 211218.

Jolson, M. A. (1997). Broadening the scope of relationship selling. Journal of Personal Selling \& Sales Management, 17(4), 75-88.

Kahn Jr., S. (2018). College football attendance dropped for the fourth consecutive season. Espn.com. Retrieved from: http://www.espn.com/collegefootball/story/_ /id/22422239/ college-football-attendance-declines-2017 
Kempf, D. S. (1999). Attitude formation from product trial: Distinct roles of cognition and affect for hedonic and functional products. Psychology \& Marketing, 16(1), $35-50$.

Keillor, B. D., Parker, R. S., \& Pettijohn, C. E. (1999). Sales force performance satisfaction and aspects of relational selling: Implications for sales managers. Journal of Marketing Theory and Practice, 7(1), 101-115.

Kim, W. G., \& Cha, Y. (2002). Antecedents and consequences of relationship quality in hotel industry. International Journal of Hospitality Management, 21(4), 321-338.

Kim, W. G., Han, J. S., \& Lee, E. (2001). Effects of relationship marketing on repeat purchase and word of mouth. Journal of Hospitality \& Tourism Research, 25(3), $272-288$.

Kim, Y. K., \& Trail, G. (2011). A conceptual framework for understanding relationships between sport consumers and sport organizations: A relationship quality approach. Journal of Sport Management, 25(1), 57-69.

Kim, Y. K., Trail, G., \& Ko, Y. J. (2011). The influence of relationship quality on sport consumption behaviors: An empirical examination of the relationship quality framework. Journal of Sport Management, 25(6), 576-592.

Kim, Y. K., Trail, G. T., Woo, B., \& Zhang, J. (2011). Sports consumer-team relationship quality: development and psychometric evaluation of a scale. International Journal of Sports Marketing and Sponsorship, 12(3), 57-74.

Ko, Y. J., \& Pastore, D. L. (2005). A hierarchical model of service quality for the recreational sport industry. Sport Marketing Quarterly, 14(2), 84-97. 
Kuo, Y. F., Wu, C. M., \& Deng, W. J. (2009). The relationships among service quality, perceived value, customer satisfaction, and post-purchase intention in mobile value-added services. Computers in Human Behavior, 25(4), 887-896.

Koo, G., Hardin, R., \& Dittmore, S. W. (2015). Effects of service dimensions on service assessment in consumer response: A study of college football season ticket holders. International Journal of Sport Management, 16(3), p. 371-392

Kotler, P., Saliba, S., \& Wrenn, B. (1991). Marketing management: Analysis, planning, and control: Instructor's Manual. Upper Saddle River, NJ: Prentice-hall.

Kwon, H. H., Trail, G., \& James, J. D. (2007). The mediating role of perceived value: Team identification and purchase intention of team-licensed apparel. Journal of Sport Management, 21(4), 540-554.

Lai, M. C., Chou, F. S., \& Cheung, Y. J. (2013). Investigating Relational Selling Behaviors, Relationship Quality, and Customer Loyalty in the Medical Device Industry in Taiwan. International Journal of Business and Information, 8(1).

Lance, C. E., Butts, M. M., \& Michels, L. C. (2006). The sources of four commonly reported cutoff criteria: What did they really say? Organizational Research Methods, 9(2), 202-220.

Langeard, E., Bateson, J.E.G., Lovelock, C.H., \& Eiglier, E. (1981). Marketing of services: New insights from consumers and management (Report No.81-104). Cambridge, MA: Marketing Sciences Institute.

Larson, A. (1992). Network dyads in entrepreneurial settings: A study of the governance of exchange relationships. Administrative Science Quarterly 37(1), 76-104. 
Levy, M., \& Weitz, B. A. (2004). Retailing management. New York, NY: McGrawHill/Irwin.

Macintosh, G., \& Lockshin, L. S. (1997). Retail relationships and store loyalty: A multilevel perspective. International Journal of Research in Marketing, 14(5), 487497.

Mael, F., \& Ashforth, B. E. (1992). Alumni and their alma mater: A partial test of the reformulated model of organizational identification. Journal of Organizational Behavior, 13(2), 103-123.

Mahony, D. F., Nakazawa, M., Funk, D. C., James, J. D., \& Gladden, J. M. (2002). Motivational factors influencing the behaviour of J. League spectators. Sport Management Review, 5(1), 1-24.

Marquaridt, D. W. (1970). Generalized inverses, ridge regression, biased linear estimation, and nonlinear estimation. Technometrics, 12(3), 591-612.

McDonald, H., \& Stavros, C. (2007). A defection analysis of lapsed season ticket holders: A consumer and organizational study. Sport Marketing Quarterly, 16(4), 218-229.

McEvoy, C., \& Popp, N. (2012). Measuring the scope and effectiveness of outbound ticket sales teams in NCAA Division I athletic departments. The Winthrop Note. Retrieved from: http://winthropintelligence.com/2012/06/18/measuringscopeeffectiveness-outbound-ticket-sales-teams-ncaa-division-i-athletic departments/

McQuiston, D. H. (1989). Novelty, complexity, and importance as causal determinants of industrial buyer behavior. The Journal of Marketing 53(2), 66-79. 
Miller, N. J., \& Kean, R. C. (1997). Reciprocal exchange in rural communities:

Consumers' inducements to inshop. Psychology \& Marketing, 14(7), 637-661.

Moore, D. S. (1997). New pedagogy and new content: The case of statistics.

International Statistical Review, 65(2), 123-137.

Moore, D. S., \& Kirkland, S. (2007). The basic practice of statistics (Vol. 2). New York, NY: WH Freeman.

Moorman, C., Zaltman, G., \& Deshpande, R. (1992). Relationships between providers and users of market research: The dynamics of trust within and between organizations. Journal of Marketing Research, 29(3), 314-328.

Morgan, R. M., \& Hunt, S. D. (1994). The commitment-trust theory of relationship marketing. The Journal of Marketing, 58(2), 20-38.

Mullin, B. J., Hardy, S., \& Sutton, W. (2014). Sport marketing: 4th edition. Champaign, IL: Human Kinetics.

Neter, J., Kutner, M. H., Nachtsheim, C. J., \& Wasserman, W. (1996). Applied linear statistical models (Vol. 4, p. 318). Chicago: Irwin.

"New Big East, Fox Sports Formally Ink”. (2013). New Big East, Fox Sports formally ink 12-year, \$500M deal; ESPN signs Mountain West. Sportsbusinessdaily.com. Retrieved from:http://www.sportsbusinessdaily.com/Daily/Issues/2013/03/21/ Media/Big-East-MWC.aspx.

Mukherjee, A., \& Nath, P. (2003). A model of trust in online relationship banking. International Journal of Bank Marketing, 21(1), 5-15. 
Murray, D., \& Howat, G. (2002). The relationships among service quality, value, satisfaction, and future intentions of customers at an Australian sports and leisure centre. Sport Management Review, 5(1), 25-43.

Norman, G. (2010). Likert scales, levels of measurement and the "laws" of statistics. Advances in Health Sciences Education, 15(5), 625-632.

Novoy-Williams, E. (2017). College football's top teams are built on crippling debt. Bloomberg.com. Retrieved from: https://www.bloomberg.com/news/features/ 2017-01-04/college-football-s-top-teams-are-built-on-crippling-debt.

Novoy-Williams, E., (2018). College football teams mount blitz to lock in donors' tax breaks. Bloomberg.com. Retrieved from: https://www.bloomberg.com/news /articles/2017-12-22/college-football-teams-mount-blitz-to-lock-in-donors-taxbreaks

Nufer, G. (2011). Relevant factors for successful relationships between professional sporting organisations and their sponsors. Journal of Physical Education and Sport Management, 2(3), 26-31.

Nufer, G., \& Bühler, A. (2010). Establishing and maintaining win-win relationships in the sports sponsorship business. Journal of Sponsorship, 3(2), 157-168.

Nunnally, J. C., \& Bernstein, I. H. (1994). Psychometric theory, New York, NY: McGraw-Hill

Okada, E. M. (2005). Justification effects on consumer choice of hedonic and utilitarian goods. Journal of Marketing Research, 42(1), 43-53.

Oliver, R. L. (1999). Whence consumer loyalty?. the Journal of Marketing, 63(Special Issue 1999), 33-44. 
Palmatier, R. W., Dant, R. P., Grewal, D., \& Evans, K. R. (2006). Factors influencing the effectiveness of relationship marketing: A meta-analysis. Journal of Marketing, 70(4), 136-153.

Pan, D. W., \& Baker, J. A. (2005). Factors, differential market effects, and marketing strategies in the renewal of season tickets for intercollegiate football games. Journal of Sport Behavior, 28(4), 351-377.

Parasuraman, A., Zeithaml, V. A., \& Berry, L. L. (1985). A conceptual model of service quality and its implications for future research. The Journal of Marketing 49(2), 41-50.

Parasuraman, A., Zeithaml, V. A., \& Berry, L. L. (1988). SERVQUAL: A multiple-item scale for measuring consumer perceptions of service quality. Journal of Retailing, 64(1), 12-40.

Parasuraman, A., Zeithaml, V. A., \& Berry, L. L. (1994). Reassessment of expectations as a comparison standard in measuring service quality: implications for further research. Journal of Marketing, 58(1), 111-124.

Perrien, J., Filiatrault, P., \& Ricard, L. (1992). Relationship marketing and commercial banking: A critical analysis. International Journal of Bank Marketing, 10(7), 2529.

Philip, G., \& Hazlett, S. A. (1997). The measurement of service quality: A new PCP attributes model. International Journal of Quality \& Reliability Management, 14(3), 260-286.

Pituch, K. A., Whittaker, T. A., \& Stevens, J. P. (2015). Intermediate statistics: A modern approach, New York, NY: Taylor \& Francis. 
Popp, N. (2014). Ticket sales in college athletics. Athletics Administration, 49(8), 26-31.

Popp, N., Simmons, J., \& McEvoy, C. D. (2017). Sport ticket sales training: Perceived effectiveness and impact on ticket sales results. Sport Marketing Quarterly, 26(2), 99-109.

Porter, S. S., Wiener, J. L., \& Frankwick, G. L. (2003). The moderating effect of selling situation on the adaptive selling strategy-selling effectiveness relationship. Journal of Business Research, 56(4), 275-281.

Pruitt, D. G. (1981). Negotiation Behavior. New York: Academic Press, Inc.

Reese, J. D., \& Bennett, G. (2013). Satisfaction with the Season Ticket Sales Process. Journal of Contemporary Athletics, 7(2), 1-15

Ridpath, D. (2014). Why actually funds intercollegiate athletics? Forbes.com. Retrieved from: https://www.forbes.com/sites/ccap/2014/12/12/who-actually-fundsintercollegiate-athletic-programs/\#1af9a33417af.

Rittenberg, A. (2017). Save the date: All eyes on 2023 for conference realignment. Espn.com. Retrieved from: http://www.espn.com/collegefootball /story/_id/19743196 /why-2023-next-big-date-conference-shuffling.

Roberts, K., Varki, S., \& Brodie, R. (2003). Measuring the quality of relationships in consumer services: An empirical study. European Journal of Marketing, 37(1), 169-196.

Robinson, M. J., Trail, G. T., \& Kwon, H. (2004). Motives and points of attachment of professional golf spectators. Sport Management Review, 7(2), 167-192. 
Robinson, M. J., Trail, G. T., Dick, R. J., \& Gillentine, A. J. (2005). Fans vs. spectators: An analysis of those who attend intercollegiate football games. Sport Marketing Quarterly, 14(1), 43-53.

Rogerson, P. (2001). Statistical methods for geography. Thousand Oaks, CA: Sage Publishing.

Román, S., \& Iacobucci, D. (2010). Antecedents and consequences of adaptive selling confidence and behavior: A dyadic analysis of salespeople and their customers. Journal of the Academy of Marketing Science, 38(3), 363-382.

Rossiter, J. R. (2002). The C-OAR-SE procedure for scale development in marketing. International Journal of Research in Marketing, 19(4), 305-335.

Rousseeuw, P. J., \& Leroy, A. M. (2005). Robust regression and outlier detection (Vol. 589). Oklahoma City, OK:John Wiley \& Sons.

Ryu, G., \& Feick, L. (2007). A penny for your thoughts: Referral reward programs and referral likelihood. Journal of Marketing, 71(1), 84-94.

Saxe, R., \& Weitz, B. A. (1982). The SOCO scale: A measure of the customer orientation of salespeople. Journal of Marketing Research, 19(3), 343-351.

Schmidt, A. F., \& Finan, C. (2018). Linear regression and the normality assumption. Journal of clinical epidemiology, 98, 146-151.

Shani, D. (1997). A framework for implementing relationship marketing in the sport industry. Sport Marketing Quarterly, 6(2), 9-16.

Shapiro, S. L. (2010). Does service matter? An examination of donor perceptions of service quality in college athletics. Sport Marketing Quarterly, 19(3), 154-165. 
Shapiro, S. L., \& Drayer, J. (2012). A new age of demand-based pricing: An examination of dynamic ticket pricing and secondary market prices in Major League Baseball. Journal of Sport Management, 26(6), 532-546.

Shavelson, R. J. (1996). Statistical reasoning for the behavioral sciences. New York, NY: Pearson.

Sheth, J. N., \& Parvatiyar, A. (1995). Relationship marketing in consumer markets: antecedents and consequences. Journal of the Academy of Marketing Science, 23(4), 255-271.

Sheth, J. N., \& Parvatiyar, A. (2000). Relationship marketing in consumer markets. Handbook of Relationship Marketing, 171-208, London: Sage Publications,

Sherman, R. (2016). The NCAA's new March Madness, TV deal will make them a billion dollars a year. SBNation.com, Retrieved from: https://www.sbnation.com /college-basketball/2016/4/12/11415764/ncaa-tournament-tv-broadcast-rightsmoney-payout-cbs-turner

Shonk, D. J., \& Chelladurai, P. (2008). Service quality, satisfaction, and intent to return in event sport tourism. Journal of Sport Management, 22(5), 587-602.

Shreffler, M. B., Schmidt, S. H., \& Weiner, J. (2018). Sales training in career preparation: An examination of sales curricula in sport. Sport Management Education Journal, 12(1). 15-25

Smith, E., Bronner, F., Tolboom, M. (2007). Brand relationship quality and its value for personal contact. Journal of Business Research, 60, 627-633 
Smith, J. G., \& Roy, D. P. (2011). A framework for developing customer orientation in ticket sales organizations. Sport Marketing Quarterly, 20(2), 93-102.

Spoelstra, J. (2009). Ice to the Eskimos: How to market a product nobody wants. New York, NY: Harper Collins.

Staples, A. (2016) The future of college sports media rights: How will deals evolve with the landscape? Si.com. Retrieved from: https://www.si.com/college-football /2016/03/28/how-are-college-sports-media-rights-deal-evolving

Stavros, C., Pope, N. K. L., \& Winzar, H. (2008). Relationship marketing in Australian professional sport: An extension of the Shani framework. Sport Marketing Quarterly, 17(3), 135-145.

Stevens, J. R., \& Taylor, A. M. (2009). Hierarchical dependence in metaanalysis. Journal of Educational and Behavioral Statistics, 34(1), 46-73.

Stock, R. M., \& Hoyer, W. D. (2005). An attitude-behavior model of salespeople's customer orientation. Journal of the Academy of Marketing Science, 33(4), 536552.

Stryker, S. (1968). Identity salience and role performance: The relevance of symbolic interaction theory for family research. Journal of Marriage and the Family 30(4), $558-564$.

Spiro, R. L., \& Weitz, B. A. (1990). Adaptive selling: Conceptualization, measurement, and nomological validity. Journal of Marketing Research, 27(1), 61-69.

Tapp, A. (2004). The loyalty of football fans: We'll support you evermore?. Journal of Database Marketing \& Customer Strategy Management, 11(3), 203-215. 
Taylor, S. A., \& Baker, T. L. (1994). An assessment of the relationship between service quality and customer satisfaction in the formation of consumers' purchase intentions. Journal of Retailing, 70(2), 163-178.

Trail, G. T., Fink, J. S., \& Anderson, D. F. (2003). Sport spectator consumption behavior. Sport Marketing Quarterly, 12(1), 8-17.

Theodorakis, N. D., \& Alexandris, K. (2008). Can service quality predict spectators' behavioral intentions in professional soccer?. Managing Leisure, 13(3-4), 162178.

Theodorakis, N., Kambitsis, C., \& Laios, A. (2001). Relationship between measures of service quality and satisfaction of spectators in professional sports. Managing Service Quality: An International Journal, 11(6), 431-438.

Thompson, J. A. (2005). Proactive personality and job performance: A social capital perspective. Journal of Applied psychology, 90(5), 1011-1017.

Tower, J., Jago, L., \& Deery, M. (2006). Relationship marketing and partnerships in notfor-profit sport in Australia. Sport Marketing Quarterly, 15(3), 167-180.

Trail, G. T., \& James, J. D. (2001). The motivation scale for sport consumption: Assessment of the scale's psychometric properties. Journal of Sport Behavior, 24(1), 108-127.

Vallerand, R. J. (2008). On the psychology of passion: In search of what makes people's lives most worth living. Canadian Psychology/Psychologie Canadienne, 49(1), 113.

Wakefield, K. (2016). Using fan passion to predict attendance, media consumption, and social media behaviors. Journal of Sport Management, 30(3), 229-247. 
Wang, R. T., Ho, C. M., \& Zhang, J. J. (2012). Examining the effects of relationship quality and calculative commitment on sport consumer behaviors for intercollegiate athletics. Journal of Issues in Intercollegiate Athletics 5(7), 301328.

Wanless, E., \& Judge, L. W. (2014). Improving collegiate ticket sales: The importance of a trained sales staff. Journal of Facility Planning, Design, and Management, 2(2), 137-142.

Wann, D. L. (2006). The causes and consequences of sport team identification. In A. Raney \& J. Bryant (Eds.), Handbook of sports and media, (331-352).Mahwah, NJ: Lawrence-Erlbaum.

Wann, D. L., \& Branscombe, N. R. (1993). Sports fans: Measuring degree of identification with their team. International Journal of Sport Psychology, 15, 700725.

Wann, D. L., Haynes, G., McLean, B., \& Pullen, P. (2003). Sport team identification and willingness to consider anonymous acts of hostile aggression. Aggressive Behavior, 29(5), 406-413.

Warren, C. (2016). Social media and outbound ticket sales: Examining social media strategies among top-performing salespeople. Journal of Applied Sport Management, 8(4), 49-62.

Weilbaker, D. C. (1990). The identification of selling abilities needed for missionary type sales. Journal of Personal Selling \& Sales Management, 10(3), 45-58.

Weitz, B. A. (1981). Effectiveness in sales interactions: a contingency framework. The Journal of Marketing, 45(1), 85-103. 
Weitz, B. A., Sujan, H., \& Sujan, M. (1986). Knowledge, motivation, and adaptive behavior: A framework for improving selling effectiveness. The Journal of Marketing 50(4), 174-191.

Wieseke, J., Alavi, S., \& Habel, J. (2014). Willing to pay more, eager to pay less: The role of customer loyalty in price negotiations. Journal of Marketing, 78(6), 17-37.

Wiesel, T., Skiera, B., \& Villanueva, J. (2008). Customer equity: An integral part of financial reporting. Journal of Marketing, 72(2), 1-14.

Williams, J., \& Chinn, S. J. (2010). Meeting relationship-marketing goals through social media: A conceptual model for sport marketers. International Journal of Sport Communication, 3(4), 422-437.

Williams, M. N., Grajales, C. A. G., \& Kurkiewicz, D. (2013). Assumptions of multiple regression; Correcting two misconceptions. Practical Assessment, 18(11), 1-14.

Williamson, N. C. (1983). A method for determining the causes of salesperson turnover. Journal of Personal Selling \& Sales Management, 3(1), 26-35.

Wilson, P. H., Journell, W., Wilson, P. H., \& Journell, W. (2011). Lies, damn lies, and statistics: Uncovering the truth behind polling data. Social Studies Research and Practice, 6(1), 169-180.

Yoshida, M., \& James, J. D. (2010). Customer satisfaction with game and service experiences: Antecedents and consequences. Journal of Sport Management, 24(3), 338-361.

Zeithaml, V. A., Parasuraman, A., \& Berry, L. L. (1990). Delivering quality service: Balancing customer perceptions and expectations. New York, NY: The Free Pres. 


\section{APPENDIX A}

Sport Consumer Team Relationship Quality Scale (Kim et al., 2011)

Trust (3 items) "strongly disagree (1) to strongly agree (7)"

- I trust [university] athletics

- [University] athletics is reliable

- I can count on [university] athletics

Commitment (3 items) - "strongly disagree (1) to strongly agree (7)"

- I am committed to [university] athletics

- I am devoted to [university] athletics

- I am dedicated to [university] athletics

Intimacy (3 items) - "strongly disagree (1) to strongly agree (7)"

- I am very familiar with [university] athletics

- I know a lot about [university] athletics

- I feel as though I really understand [university] athletics

Self-Connection (3 items) "strongly disagree (1) to strongly agree (7)"

- [University] athletics reminds me of who I am

- [University] athletics' image and my self-image are similar in a lot of ways

- [University] athletics and I have a lot in common

Reciprocity (3 items) - "strongly disagree (1) to strongly agree (7)"

- [University] athletics unfailingly pays me back when I do something extra for them

- [University] athletics gives back equivalently what I have given them

- [University] athletics constantly returns the favor when I do something good for them

Modified Relational Selling Instrument for Division I College Football Ticket Sales

Interaction Intensity (4 items) "not very often (1) to very often (7)"

- The [university] box office stays in touch to make sure I am satisfied during the season

- The [university] box office contacts me to offer different options that better suit my needs

- The [university] box office contacts me to thank me for being a season ticketholder

- The [university] box office contacts me to keep abreast of my ticketing needs

Mutual Disclosure (Agent Disclosure) - "not very accurate (1) to very accurate (7)"

- The [university] box office representative offered personal information about his/her background, personal life, or family

- The [university] box office representative told me about his/her job responsibilities

- The [university] box office representative confided a lot of information about his/her personal goals and objectives

- The [university] box office representative confided in me a lot of information about his/her values and beliefs

Mutual Disclosure (Customer Disclosure) - "not very accurate (1) to very accurate (7)"

- I have confided in the [university] box office a lot of information about my current financial situation 
- I have confided in the [university] box office a lot of information about my background, personal life, and family situation

- I have confided in the [university] box office a lot of information about concerns I have had with past ticket purchases

- I have confided in the [university] box office a lot of information about my ticketing wants and needs

Cooperative Intentions - "not very accurate (1) to very accurate (7)"

- The [university] box office has expressed a willingness to help me make my financial decisions even if there's nothing in it for him/her

- The [university] box office takes the time to prepare ticket information for me to evaluate

- The [university] box office treats me the same whether we're talking about a $\$ 500$ season ticket or a $\$ 5,000$ season ticket

- The [university] box office has expressed a desire to develop a long-term relationship

Sport Passion Scale (Wakefield, 2016)

- How passionate are you about [university] athletics - "no passion (1) to ultimate passion (7)"

- To what degree does [university] athletics occupy your mind? - "Never on my mind (1) to always on my mind (7)

- How much do you prioritize your time so you can follow [university] athletics "Not at all (1) to Completely (7)"

- I can't live without [university] athletics - "strongly disagree (1) to strongly agree (7) 
CURRICULUM VITA

\section{James F. Weiner}

\section{EDUCATION}

Ph.D. Educational Leadership \& Organizational Development

July 2018

Concentration in Sport Administration

(expected)

University of Louisville, Louisville KY

M.Ed. Sport Leadership

May 2015

Virginia Commonwealth University, Richmond VA

B.S. Kinesiology - Sport and Recreation Management

December 2011

Minor: Business

James Madison University, Harrisonburg VA

\section{CURRENT ACADEMIC APPOINTMENT}

\section{Old Dominion University, Norfolk VA}

Sport Management Program

August 1st - Present

Lecturer

- Full-time lecturer for the Sport Management program

- Assisting with a comprehensive marketing plan for the growth and development of graduate programs throughout the HMS department.

- Assisting with website improvement and digital materials for all programs

\section{TEACHING EXPERIENCE}

\section{Old Dominion University, Norfolk VA}

August $1^{\text {st }}-$ Present

Sport Management Program

\section{Lecturer}

- Teaching a $3 / 3$ course load with a release for a special project assigned by the department chair.

- Informal advisor for sport career development with a focus (though not a requirement) towards students who have inquired about careers in sales or collegiate administration

\section{Courses Taught}


- $\quad$ SMGT 414- Sport Marketing

- SMGT 331- Fiscal Planning and Management in Sport and Rec

- SMGT 368- Internship

- No formal course evaluations have been conducted yet

University of Louisville, Louisville KY

August 2015 - August 2017

Sport Administration Program

Adjunct Faculty and University Fellow

- Adjunct lecturer for undergraduate-level Financial Principles of Sport (three consecutive sections taught; 40 students per section)

- Oversaw and assisted doctoral student teaching additional sections of Financial Principles of Sport

- One of 20 recipients university-wide for the SIGS Research Fellowship: an award which provides funding for full tuition costs and monthly stipends.

Courses Taught:

- SPAD 404 Financial Principles of Sport (Spring 17, Fall 16, Spring 16)

- Approximately 40 students per class

- Developed SPAD 404 resource guide intended to be used as a foundational teaching tool for future instructors

○ Student evaluation showed overall score of 4.2 out of 5 , with "Instructor teaching" scoring 4.31, "Instructor's Presentations" scoring 4.33, and "How much did you learn" scoring 4.25

- Average Department Score $=4.02$

- Last evaluation included 33 out of 34 students rating "Instructor teaching was..." as either "above average" or "excellent"

\section{Invited Lectures:}

\section{University of Louisville, Louisville KY}

- SPAD 530 Sport Promotion and Sales- Graduate and Undergraduate (Spring 2017)

Lecture Topic: Relationship and benefit selling in sport

- SPAD 530 Sport Promotion and Sales (Fall 2016)

Lecture Topic: Sponsorship and business-to-business sales

- $\quad$ SPAD 383 Sport Marketing (Spring 2016)

Lecture Topic: Marketing different ticketing campaigns

- SPAD 382 Organizational Behavior in Sport (Spring 2016)

Lecture Topic: Managing Change-Private sport firms within a nonprofit university setting 
- $\quad$ SPAD 390 Sport Governance (Spring 2016)

Lecture Topic: Leadership hierarchies in sport

- SPAD 383 Sport Marketing (Fall 2015)

Lecture Topic: Consumer behavior in sport

- SPAD 530 Sport Promotion and Sales (Fall 2015)

Lecture Topic: Ticket sales in the intercollegiate athletics landscape

Texas A\&M, Corpus Christi, Corpus Christi, TX

- KINE 2413 Sport Marketing and Promotions (Spring, 2017)

Lecture Topic: Ticket sales, fundraising, and sponsorship sales

Duke University, Durham NC

- MMS 490 Business of Sports (Fall 2014, Fall 2013)

Lecture Topic: Intercollegiate athletics revenues: Ticket sales, sponsorship, development and fundraising

James Madison University

- SRM 241 Introduction to Sport and Recreation Management (Spring 2014)

Lecture Topic: Different career options in sport with interview and resume tips

\section{Elon University}

- SEM 212 Contemporary Sport Management (Fall 2014, Fall 2013)

Lecture Topic: Different career options in sport and best practices for graduating seniors to acquire entry-level jobs in the sport industry

\section{PROFESSIONAL WORK EXPERIENCE}

IMG Learfield Ticket Solutions, Durham NC

July 2013 - July 2015

General Manager - Duke University Athletics

- Advised Duke Administration on sales, marketing, and fundraising strategies aimed at increasing revenue and attendance

- Hired, trained and managed a team of four full-time Account Executives responsible for Duke Football, Men's Lacrosse, Baseball, Women's Basketball, and Women's Lacrosse season, group and partial plan sales

- Compiled financial planning, projections, reporting, and analytics for multiple Duke Athletics sports

- Managed Duke's inside sales efforts for the 2013 Chick Fil A Bowl as well as the 2013 ACC Football Championship 
- Achieved a $210 \%$ increase in gross new season ticket revenue and $63 \%$ increase in total average attendance for Duke Football from 2013 to 2015

- Totaled a $23 \%$ increase in average women's basketball attendance

IMG Learfield Ticket Solutions, Durham NC Senior Account Executive - Duke University Athletics

May 2013 - July 2013

- Sold season and group tickets with a strong focus on corporate ticket packages and event-based group sales

- Assisted in training of new Account Executives

IMG Learfield Ticket Solutions, Durham NC

February 2012 - May 2013

Account Executive - Duke University Athletics

- Sold season tickets, partial plans and group/corporate packages for Duke Football and Women's Basketball

- Set Duke IMGL records in both annual corporate /group sales, and total new revenue for 2012

Blue Devil IMG Sport Marketing, Durham NC

August 2011 - February 2012

Staff Assistant

- Fulfilled and activated partner contracts, promotions, and compiled proofof-performance

- Assisted with prospecting and sales of potential partners

Mac McDonald Media, Charlottesville VA

September 2010 - August 2011

Sales Representative

- Involved in prospecting, sales, and sponsor relations for "Inbounds with Mac McDonald", a sports-talk radio show broadcast throughout Virginia

\section{SCHOLARLY RESEARCH}

\section{Peer-Reviewed Publications:}

Shreffler, M., Schmidt, S., \& Weiner, J. F., (2018). The importance of sales training in career preparation: An examination of sales curricula in sport management education. Sport Management Education Journal, 12(1), 15-25

Weiner, J. F., \& Dwyer, B. (2017). Motivational and behavioral differences in traditional and daily fantasy sport participants. Sport Marketing Quarterly, 26(3), p. $140-152$. 
Dwyer, B., \& Weiner, J. F., (2017). Daily grind: A comparison of causality orientations, emotions, and fantasy sport participation. Journal of Gambling Studies, https://link.springer.com/article/10.1007/s10899-017-96844?wt_mc=Internal.Event.1.SEM.ArticleAuthorOnlineFirst. (Five-year impact factor $=2.442$ )

\section{Works in Progress:}

Weiner, J. F., Williams, S., \& Shreffler, M., (2 ${ }^{\text {nd }}$ Review) Show me the money! Financial implications of ticket revenue generation options. Submitted to Case Studies in Sport Management

Popp, N., Jensen, J., Weiner, J. F. \& McEvoy, C. Comparing the outsourcing of ticket sales functions and its effect on revenue generation. To be submitted to Journal of Sport Management in the spring of 2018

Weiner, J. F., Dwyer, B., LeCrom, C., \& Greenwell, T. C., Examining differences between early and late buyers in division I college football. To be submitted to Journal of Applied Sport Management in the summer of 2018

Weiner, J. F., Greenwell, T. C., \& Shreffler, M. Secret agents in college athletics: An agency theory examination of third-party ticketing partnerships. To be submitted to Journal of Issues in Intercollegiate Athletics in the summer of 2018

\section{Book Chapter Contributions:}

Weiner. J. F., Popp, N. (2017). Big Citi business: Sales management options for The Citi Open. In Advanced Theory and Practice in Sport Marketing. London, England: Routledge

\section{Scholarly Presentations:}

Weiner, J. F., Dwyer, B., LeCrom, C., \& Greenwell, T. C., Examining differences between early and late buyers in division I college football. Presented at the annual Sport Marketing Association conference in Boston, MA.

Weiner, J. F., Greenwell, T. C., \& Shreffler, M., (2017, June). Secret agents in college athletics: An agency theory examination of third-party-ticketing partnerships. Presented at the annual North American Society for Sport Management conference in Denver, CO. 
Weiner, J.F., Williams, S., (2016, October). Show me the money! Financial implications of ticket revenue generation options. Presented in the Sport Marketing Association Teaching Symposium in Indianapolis, IN.

Weiner, J.F., Dwyer, B., (2016, October). Motivational and behavioral differences in daily and traditional fantasy sport participation. Presented at the annual Sport Marketing Association conference in Indianapolis, IN.

Weiner, J. F. (2016, April). Examining differences between early and late buyers in division I college football. Presented at the annual Spring Research Conference in Lexington, KY.

Weiner, J. F. (2015, October). It's not gambling, I swear! Daily fantasy doubles down marketing efforts: An Ignite presentation. Presented at the annual Sport Marketing Association Conference. Atlanta, GA.

\section{FUNDING AND GRANT ACTIVITY}

Weiner, J. F. University Fellowship awarded by the Louisville School of Interdisciplinary and Graduate Studies in the amount of \$61,132.00 covering full tuition and monthly stipend

Weiner, J. F. Travel to Atlanta, GA for the 2015 Sport Marketing Association (SMA) Conference. Funded by the Graduate Student Council, University of Louisville in the amount of $\mathbf{\$ 3 5 0 . 0 0}$

\section{SERVICE}

Volunteer Attendee / Representative

Provided feedback for hire of Director of Innovative Technology

September 2017

ODU - Human Movement Sciences

NASSM Conference Committee

May 2017

Student Representative

North American Society for Sport Management

Peer Reviewer

March 2016

Peer reviewer for textbook titled "SELLING IN THE SPORT INDUSTRY"

Kendall Hunt Publishing Company

Graduate Student Application and Interview Committee

February 2016

Doctoral Student Member

University of Louisville

Grawemeyer Awards Program

December 2015 
Event Volunteer

University of Louisville

Sport Administration Association

2015 -Present

Committee Member

University of Louisville

Student-Athlete Advisory Committee

2009-2011

Committee Member

James Madison University

MEMBERSHIPS AND ASSOCIATIONS

North American Society for Sport Management (NASSM): Member since 2014

Sport Marketing Association (SMA): Member since 2015 